This PDF is a selection from a published volume from the National Bureau of Economic Research

Volume Title: Social Security Programs and Retirement around the World: Micro-Estimation

Volume Author/Editor: Jonathan Gruber and David A. Wise, editors

Volume Publisher: University of Chicago Press

Volume ISBN: 0-226-31018-3

Volume URL: http://www.nber.org/books/grub04-1

Publication Date: January 2004

Title: The Impact of Incentives on Retirement in Denmark Author: Paul Bingley, Nabanita Datta Gupta, Peder J. Pedersen URL: http://www.nber.org/chapters/c10701 


\title{
The Impact of Incentives on Retirement in Denmark
}

\author{
Paul Bingley, Nabanita Datta Gupta, \\ and Peder J. Pedersen
}

\subsection{Introduction}

In Denmark, the official retirement age of sixty-seven years - from 2004, sixty-five years - is high in an international context. A main point in the Danish policy reform discussions is, however, the widening gap there has been between the official retirement age and actual behavior concerning exit from the labor force. The average actual retirement age has been declining to around sixty-one years old, a decline that gained momentum especially after the introduction of a labor market policy program for early retirement in $1979 .{ }^{1}$ Before that time, early retirement with a publictransfer income was only possible for health reasons.

Both the official and the actual average retirement ages in Denmark are still high compared with most other Organization for Economic Cooperation and Development (OECD) member countries. Nevertheless, policy options and analyses in the pension area are central to current debates of economic policy in Denmark (e.g., see Socialkommissionen 1993; Finansministeriet 1996; Finansrådet 1998; and Economic Council 1998). Two

Paul Bingley is associate professor at the National Center for Register-Based Research (NCRR) at the University of Aarhus. Nabanita Datta Gupta is associate professor of economics at the Aarhus School of Business. Peder J. Pedersen is professor of economics at the University of Aarhus.

All three authors are affiliated with the Center for Integration and Marginalisation (CIM), Aarhus, and the Center for Labour Market and Social Research (CLS), Aarhus. The authors gratefully acknowledge financial support from the Danish Social Science Research Council, the Danish National Research Foundation and the University of Aarhus Research Fund.

1. Average retirement differs depending on individual background characteristics. In 1997, it was sixty-three years for employed men, fifty-nine years for men who entered retirement from unemployment, sixty-one years for employed women, and fifty-eight years for women who left the labor force from unemployment (Statistics Denmark 1999). 
main factors behind the high priority of this area are the projected change in demography and the public finance prospects from this change regarding publicly funded social security programs for retirement. The current level of public-sector-financed income transfers to social security retirement programs is around 8-9 percent of the gross national product (GNP). Public expenditures on health and other services to elderly people should be added to this amount. Projected changes in the age composition of the population along with changes in retirement behavior have potentially large consequences for public-sector finances. In the Danish context, the full impact on the tax-GNP ratio has been estimated to be an incremental increase of around 4-5 percent in a number of recent studies (cf. the references at the beginning of this paragraph).

The structure of the remainder of this chapter is as follows. Section 3.2 gives an introduction to the policy environment, both the current as well as the recent, ongoing state policy reforms. Furthermore, section 3.2 introduces some quantitative aspects of the retirement landscape in Denmark. Section 3.3 describes the contents and structure of the micro-data we analyze. Section 3.4 contains the earnings histories and projections needed as inputs in the micro-analyses. In section 3.5, we describe the construction of the social security incentive measures and some of the complications met in this area. Section 3.6 contains the results from a great number of estimations of the impact from the incentive measures described in section 3.5 on retirement behavior. In Section 3.7, the estimation results are used to simulate the expected outcome in the Danish context from a common set of strategic reforms of retirement policy. Finally, section 3.8 concludes the chapter.

\subsection{The Policy Environment}

Until recently, the foundation of Danish policy in the field of pensions has been the so-called universal or Beveridge-type system of eligibility to a pay-as-you-go (PAYG) system for old age pension (OAP) that has age and residence in the country for a sufficient number of years as the only criteria. The expenditures are financed from general tax revenues. Until a few years ago, a base amount was paid to everybody sixty-seven years or older, while a supplementary amount was means tested against other income in the household. From 1993, the base amount has been means tested against earnings from work, but not against capital income.

The other main social security program is the route to early retirement through social disability pension (SDP). Initially, eligibility to this program for people younger than sixty-seven years was dependent on health criteria. More recently, there has been a gradual widening of the scope to include also social criteria for eligibility. The program is quite complex, including a number of different benefit levels and with an intricate combina- 
tion of various tax treatment and different rules regarding means testing for the many components making up this program. When people covered under this program reach the age of sixty-seven years, they enter OAP. ${ }^{2}$ Participation in the SDP program has been fairly stable, reflecting among other things the opening up of other routes-non-health related, however - to early retirement. Like OAP, the SDP is financed from general tax revenues.

A dominant part of Danish social security is defined benefits, fully financed from general tax revenues. There is however a small area- of growing importance in the future-of defined-contribution programs (following the so-called Bismarck model). The oldest, mandatory public pension program is the Additional Labour Market Pension (ATP) program, which has been operative since $1963 .{ }^{3}$ The flat-rate contributions depend on the number of hours of work. Until now, this program has been of minor importance compared with OAP. Beginning in 1999, the program has expanded, as 1 percent of all wages are contributed to a so-called Special Pension program (SP). Future individual benefits from this program are, however, dependent on the accumulated amount of work and not on the individual earnings history throughout the working life. ${ }^{4}$ The accumulated benefits are paid out as a ten-year annuity from the age of sixty-seven or sixty-five.

The historical development in the important area outside social security per se is made up by a multitude of labor market pensions and individual tax-subsidized arrangements and began in 1849 with the introduction of a defined-benefit system of pensions, the tjenestemandspension (public employee pension; PEP) for some public-sector employees. About one hundred years later in the 1950s and 1960s, the build up of funded pension programs (Labour Market Pension programs; LMP) began for other groups of public-sector employees and for academics, both in public and private employment. Until the late 1980s, this resulted in a coverage of about onethird of the labor force with supplementary labor market pension programs (PEP and the funded LMPs). From the beginning of the 1990s, funded LMPs have been extended to cover an increasing part of the public sector and blue-collar workers in manufacturing, trade, services, construction, and transport in the private sector. The typical structure is defined contributions with 3 percent of earnings from the worker and 6 percent from the employer. Certainly the majority and presumably all of the programs have an early retirement option before the OAP age, typically from

2. Here and at later occasions, sixty-seven is changed to sixty-five from 2004 for everybody younger than sixty in 1999, according to a policy reform enacted in 1999.

3 . The program shares the name with a corresponding program in Sweden, but the scope in Denmark has been much more limited so far.

4. This new instrument seems to have an impact on both the lifetime allocation of income and on the distribution of income between individuals. 
the age of sixty and depends on the specific age in most of the programs with an actuarially fair reduction.

Since 1979, the dominant path to early retirement in Denmark has been through the efterlon (post-employment wage program; PEW). Officially, this is a labor market policy program intended to redistribute a (presumed) restricted number of jobs from older workers with physically demanding jobs to unemployed young workers. In practice, the program has functioned as a reduction in the pension age for broad groups in the labor market. Entry can occur either from a job or from unemployment. Eligibility starts at age sixty and extends to sixty-six, depending on long-term labor market attachment and is documented by membership in an unemployment-insurance fund. A further requirement is that labor supply while in receipt of pension must not exceed 200 hours per year. The rules regarding eligibility have been tightened on a number of occasions. Benefits in PEW are related to unemployment-insurance benefits, either to maximum benefits or 82 percent of the maximum. The main source of funding for the programs is from general tax revenues. A reform was enacted in 1998-1999 to be phased in during the coming years. The contents and the purpose of the reform are taken up below.

In 1992, a transitional benefits program (TBP) was introduced. Eligibility to this new early retirement program was conditional on being fifty-five to fifty-nine years old, a member of an unemployment-insurance fund, and to have been unemployed for at least twelve out of the last fifteen months. From the beginning of 1994, the program was extended to cover fifty to fifty-four year olds with the same labor market criteria as for the fifty-five to fifty-nine year olds. Benefits in the program are 82 percent of maximum unemployment-insurance benefits and the duration is until the person enters PEW at the age of sixty years. Participation in the program greatly exceeded government expectations, and entry was terminated in the beginning of 1996 with a strong cyclical upturn underway.

\subsubsection{Work and Retirement}

In this section, we illustrate first the current state of labor market attachment among the fifty and older age group in Denmark. Table 3.1 summarizes the participation rate by age intervals, while figure 3.1 shows the profile for single-year age groups separately for men and women in 1998.

It is evident that the largest decline occurs at age sixty, where many become eligible for PEW. Figure 3.1 illustrates the almost-linear declines during the fifties, with the steepest slope for women. In spite of the declining participation rates from the age of fifty, the level, especially from sixty to sixty-seven, is high in international comparison. The Economic Council (1998) replicates the approach taken in Gruber and Wise (1999; available as a working paper in 1997) and calculates a measure of unused capacity for Denmark. Based on the share of men aged fifty-five to sixty-five outside 


\begin{tabular}{lc}
\hline Age & Participation Rate \\
\hline $50-54$ & 82.3 \\
$55-59$ & 72.1 \\
$60-62$ & 38.9 \\
$63-66$ & 20.0 \\
$67-70$ & 14.7 \\
$70+$ & 5.4 \\
\hline
\end{tabular}

Source: Statistics Denmark (1999).

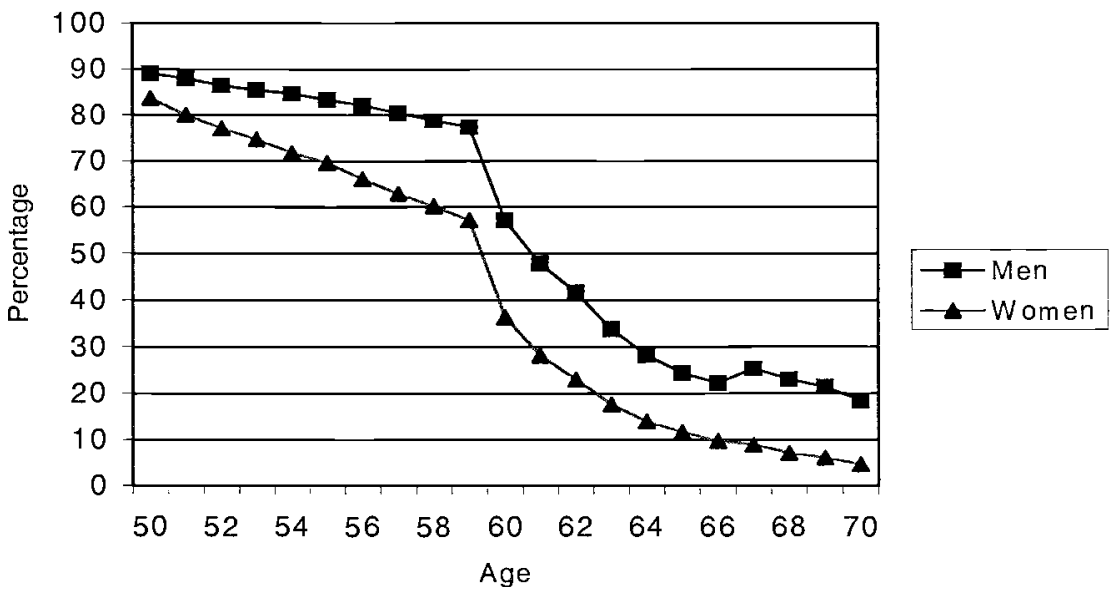

Fig. 3.1 Participation rates, 1998

the labor force, they found that only Sweden, the United States, and Japan have lower levels of unused capacity than Denmark.

Consequently, one interesting question is why the participation rate is so high in Denmark for the sixty to sixty-six age group, considering the availability of a multitude of exit routes from the labor force. A possible explanation is that financial incentives to retire early are strong for people with fairly low wages. Regarding the extent to which early retirement creates financial incentives to continue working during ones' sixties, ${ }^{5}$ out-of-work compensation is typically fairly low relative to earnings for people with higher wages. In Denmark, net compensation is between 70 percent for the low-wage group and 40 percent for the high-wage group. In Germany, the reverse is true - that is, the differences are much smaller between compen-

5. This is illustrated in Ministry of Economics $(2000,46)$, which shows for a number of countries the net compensation from public pensions relative to earnings for people with low, average, and high wages - more precisely, for people with 75, 100, and 150 percent of the earnings of an average production worker. 


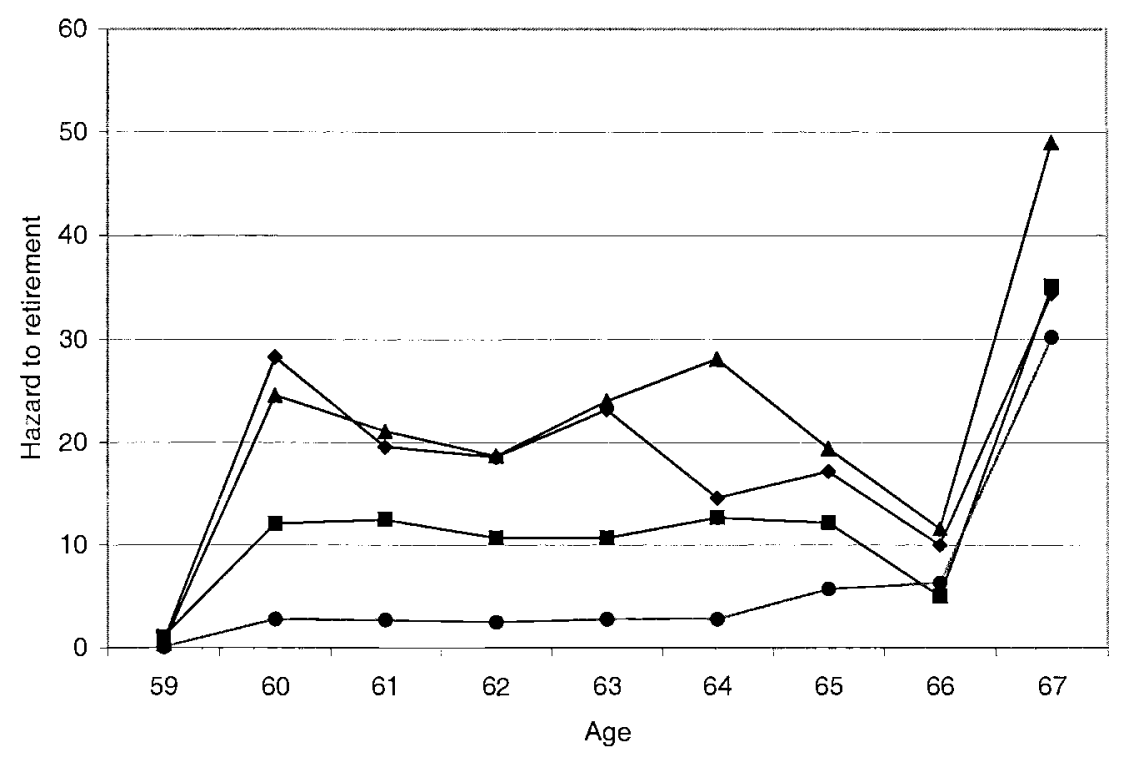

-Women, 5th dec $\rightarrow-$ Women, 10th dec. $\rightarrow-$ Men, 5th dec. Men, 10th dec.

Fig. 3.2 Average retirement hazards for women and men, fifth and tenth decile in the income distribution

sation in the three wage-earner groups, but net compensation is highest for the high-wage group. So, given the structure of public pensions in Denmark, an obvious interpretation is the high-wage earners work to a greater degree later in life simply to accumulate supplementary pension income in order to raise net compensation in retirement above the 40 percent level reached through the public system.

Other indicators in the same direction can be found in Economic Council $(1998,93)$ and in Pedersen $(1998,175)$. The Economic Council relates the actual shares in early retirement to age and to the degree of financial compensation in different educational groups. Using 1996 data, the degree of compensation, as well as the share in early retirement, are consistently lower for groups with higher education. Pedersen analyzes the expected retirement age in a panel survey, supplemented with register data on incomes, and finds a significant positive impact (i.e., higher expected age of retirement) from gross earnings for those with supplementary pension schemes, while no effect is found for those without any supplementary arrangements.

The dichotomy regarding early retirement with one group generally retiring as soon as possible, and another with fairly high labor force participation beyond the age of sixty, can be studied further using panel data. An illustrative example is shown in figure 3.2. This is drawn from a 2 percent 
Structure of the Working and the Nonworking Parts of the Population, 50+ Group (1998)

\begin{tabular}{lcccccccc}
\hline & \multicolumn{9}{c}{ Working Population (\%) } & & \multicolumn{2}{c}{ Nonworking Population (\%) } \\
\cline { 2 - 3 } Age & $\begin{array}{c}\text { Self- } \\
\text { Employed }\end{array}$ & $\begin{array}{c}\text { Wage Earner, } \\
\text { Full time }\end{array}$ & $\begin{array}{c}\text { Wage Earner, } \\
\text { Part time }\end{array}$ & Total & & Unemployed & Other & Total \\
\hline $50-54$ & 11.7 & 81.2 & 7.1 & 100 & & 20.7 & 79.3 & 100 \\
$55-59$ & 14.1 & 78.0 & 7.9 & 100 & & 17.9 & 82.1 & 100 \\
$60-66$ & 26.0 & 58.5 & 15.5 & 100 & & 3.0 & 97.0 & 100 \\
$67-74$ & 47.2 & 7.9 & 44.9 & 100 & & - & 100.0 & 100 \\
$75+$ & 65.2 & 2.5 & 32.3 & 100 & & - & 100.0 & 100 \\
\hline
\end{tabular}

Source: Calculations based on Statistics Denmark (1999)

Note: Dashes indicate that data is not applicable.

representative sample of the population followed since 1980. We suppress the fact that retirement behavior may vary over time in our present illustration in order to get enough observations to relate retirement behavior to individual income distribution at the age intervals that are most relevant regarding retirement. Each person in the sample contributes one income observation for each age at which they are still a labor market participant. Take, for example, observations relating to age sixty, where we compute decile points in the (real) income distribution for the subsample observed since 1980 that is sixty years old and still in the labor force at some point in time. We then calculate the share retiring for each decile of income distribution for labor market participants at each age between fifty-nine and sixty-nine. (Calculations are made separately for women and men.) A small selection of the great number of age- and income-related retirement frequencies are shown in figure 3.2. Tentatively, they seem to support the hypothesis that the relatively high participation rate in Denmark of the sixty and older age group is concentrated mainly among males at the top of the income distribution.

Next, the structure in 1998 of the working and nonworking population fifty years and older is shown in table 3.2. For the working group, the structural composition divides - not surprisingly — at the age of sixty. The share of wage earners working full time goes down 20 percentage points, and from age sixty-seven, more than 90 percent of those still working are either self-employed or part-time workers. The cross-sectional nature of the table does not allow any conclusions regarding part-time work as a stepping stone from full-time employment to retirement. ${ }^{6}$ The right-hand panel in table 3.2 shows that the expansion of routes to early retirement has meant practically an end to unemployment in the sixty and older group. A major analyses drawing on panel data will enable conclusions to be drawn on this point. 
Table 3.3 Proportions of the Nonworking Population 50-69 Years, by Dominant PublicSector Benefit Program Category (1998)

\begin{tabular}{lccccccccc}
\hline Age & UIB & LMP & TBP & PEW & SWB & SDP & OPA & None & Total \\
\hline $50-54$ & 20.7 & 3.8 & 16.5 & - & 3.5 & 42.1 & - & 13.5 & 100 \\
$55-59$ & 17.9 & 1.9 & 24.0 & - & 1.4 & 43.6 & - & 11.1 & 100 \\
$60-66$ & 3.0 & 0.1 & - & 52.6 & 0.4 & 35.6 & - & 8.2 & 100 \\
$67-69$ & - & - & - & - & 0.3 & - & 97.8 & 1.9 & 100 \\
\hline
\end{tabular}

Source: Calculations based on Statistics Denmark (1999).

Notes: UIB = unemployment-insurance benefits; LMP = different labor market programs; TBP $=$ Transitional Benefit Program; PEW = post-employment wages; $\mathrm{SWB}=$ social welfare benefits; $\mathrm{SDP}=$ social disability pension; $\mathrm{OAP}=$ national old age pension. A case where a labor market pension is the income source will, in principle, fall in the category "None." The coverage of labor market pensions and private schemes is, however, imperfect in the table. Dashes indicate that data is not applicable.

part of the income for people fifty years and older, outside of labor force participation or unemployment, comes from the broad range of mainly publicly financed programs. The distribution in 1998 by different sources of income ranked according to the dominant program in each individual case is shown in table 3.3.

The dominant source of income for nonworkers is SDP until the eligibility age of sixty for PEW. The lower share receiving TBP in the fifty to fiftyfour group simply reflects that entry to this program was terminated in early 1996, so the youngest recipients in table 3.3 are fifty-two years old. The residual group is fairly small. Because the options cover both the (shrinking) group of housewives without an independent income and people with an early receipt of labor market pension or private means as their dominating source of income, it is obvious that early retirements options outside the (mainly) social security programs are still a long way from maturity.

Next, we consider some aspects of the transitions to a condition outside the labor force. Presenting a comprehensive empirical picture of all the possible routes would be a major undertaking, so the present intention is to concentrate on some of the major transitions. A sketch of these is presented in table 3.4.

Before age sixty, SDP is the only exit route with an income compensation, apart from the temporary TBP for long-term unemployed, open for two and four years, respectively, in the mid-1990s. In the age interval of sixty to sixty-six, transitions can be to SDP (although not to the highest level) from the same states of origin as for younger people. Next, the very important PEW program is available - conditional on eligibility-for entry from either a job or from unemployment. The stock of people covered

7. Note that the unemployed in table 3.2 are implicitly defined as those who receive unemployment benefits. However, some unemployed receive social welfare benefits (SWB), and some do not receive any benefits. 
Table 3.4

Typical Exit Routes from the Labor Force by Age Intervals

\begin{tabular}{|c|c|c|c|}
\hline$<50$ years & $50-59$ years & $60-66$ years & $67+$ \\
\hline \multirow[t]{3}{*}{$\begin{array}{l}\text { To: SDP } \\
\text { From: Employment; } \\
\text { unemployment; sick- } \\
\text { ness benefits; welfare } \\
\text { benefits }\end{array}$} & $\begin{array}{l}\text { Same option and same } \\
\text { rules regarding SDP as } \\
49 \text { years and younger } \\
\text { group }\end{array}$ & $\begin{array}{l}\text { To: SDP } \\
\text { Same as younger but } \\
\text { excluded from highest } \\
\text { level SDP }\end{array}$ & $\begin{array}{l}\text { To: OAP } \\
\text { From: All states }\end{array}$ \\
\hline & $\begin{array}{l}\text { To: } \mathrm{TBP}^{\mathrm{a}} \\
\text { From: Long term un- } \\
\text { employment }\end{array}$ & $\begin{array}{l}\text { To: PEW } \\
\text { From: Employment; } \\
\text { unemployment; TBP } \\
(100 \%)\end{array}$ & \\
\hline & & $\begin{array}{l}\text { To: Early option, labor } \\
\text { market pension } \\
\text { From: Employment }\end{array}$ & $\begin{array}{l}\text { To: LMP, PEP } \\
\text { From: All states }\end{array}$ \\
\hline
\end{tabular}

Note: See table 3.3 for explanation of abbreviations.

aProgram for long-term unemployed, open 1992-96, transition from age 60 to PEW.

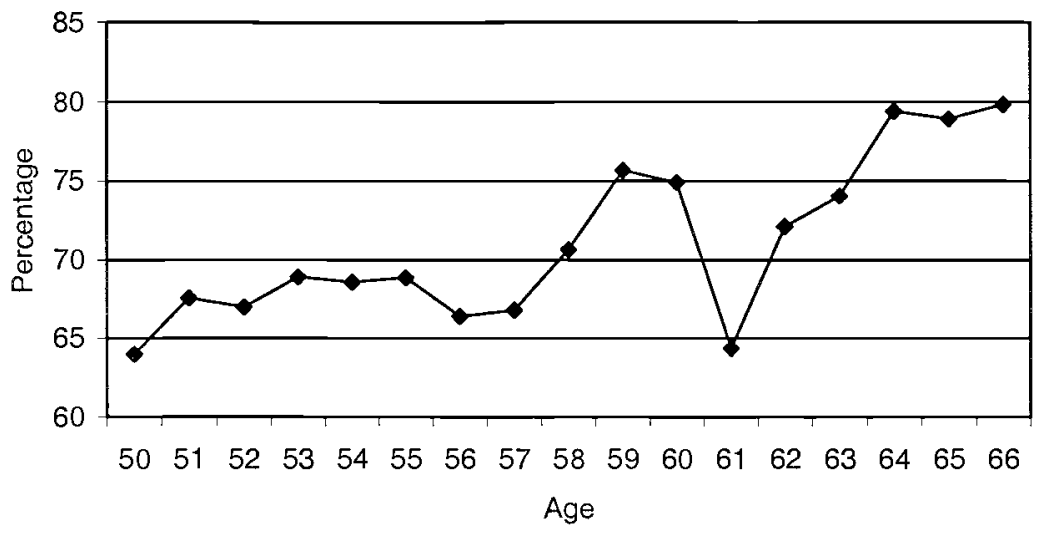

Fig. 3.3 Percent of labor force exits from employment

by TBP transit automatically to PEW at age sixty. Finally, most — or alllabor market pension schemes have, as mentioned, an early retirement option. People with this option who are at the same time eligible for the PEW will most likely have an incentive to enter the PEW and postpone use of labor market pension schemes due to means-testing rules in the PEW program. People who are not eligible for the PEW and who retire early on a labor market pension scheme will normally transit directly from a job. From age sixty-seven, people still in a job (or the very few in unemployment), as well as people in all kinds of early retirement programs, transit to the OAP.

For people initially in the labor force and fifty to sixty-six years old in 1997, figure 3.3 shows the share of the work-originating exits to retirement 


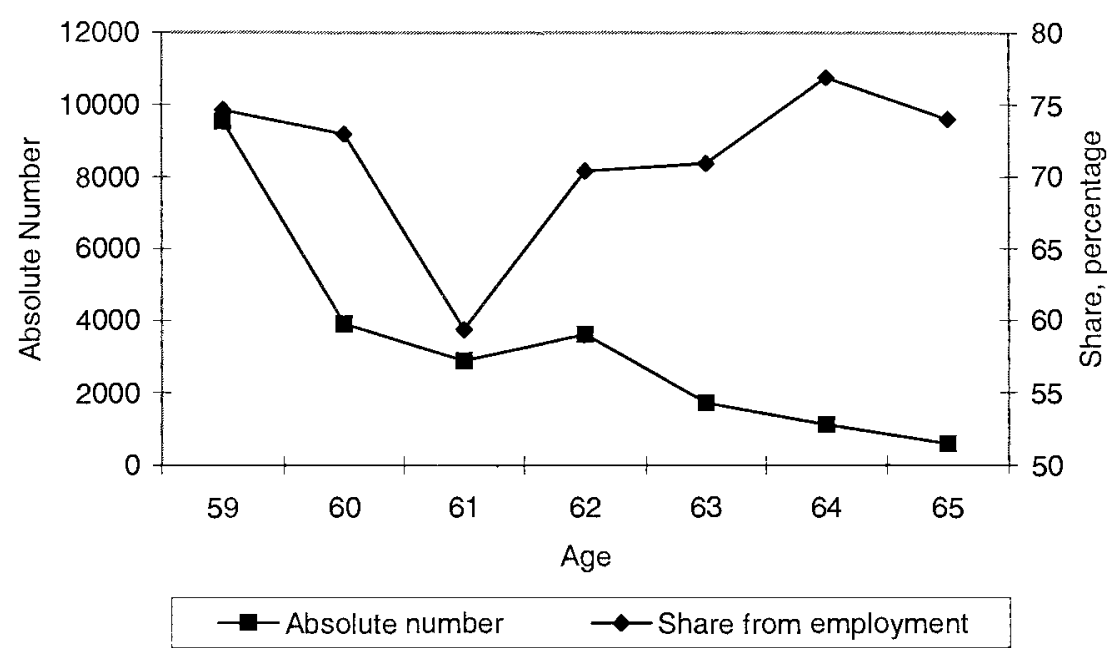

Fig. 3.4 The absolute number of transactions to PEW and the share from employment

to be around two-thirds until the PEW option at age fifty-nine, at which point the share from employment jumps to three-fourths.

The share at age sixty-one is a low point and is related to the specific transition patterns to PEW (cf. figure 3.4 below). For those sixty-two years and older who still are in the labor force, the share coming from employment is somewhat higher, which is not surprising given the strong selection mechanisms into programs for the unemployed.

Figure 3.4 concentrates on exits to PEW. The absolute number of exits to PEW, independent of state of origin, peaks when the minimum possible age of eligibility is reached. The only exception to the much lower number at higher ages is the local peak at sixty-two years. This presumably reflects the option of being eligible for maximum unemployment benefits for the whole period remaining until OAP if entry to PEW is postponed until sixty-two. Figure 3.4 also shows the share by age of exits to PEW coming from a job. This is seen to be fairly stable between 70 and 80 percent, except for the dip at age sixty-one that could reflect the incentive for people in long-term unemployment, when turning sixty, to delay entry to PEW, which might imply a reduction of their income up to 82 percent of maximum unemployment benefits. Instead, in some cases, an option is to remain unemployed and collect maximum unemployment insurance benefits until the end of benefit eligibility and then exit to PEW.

Looking at transitions to PEW from employment by industry, we see the profile for 1997-1998 shown in figure 3.5. The transition rates shown are calculated as the flow to PEW relative to the stock of employed people sixty to sixty-six years old in each of the industries. The highest values are found 


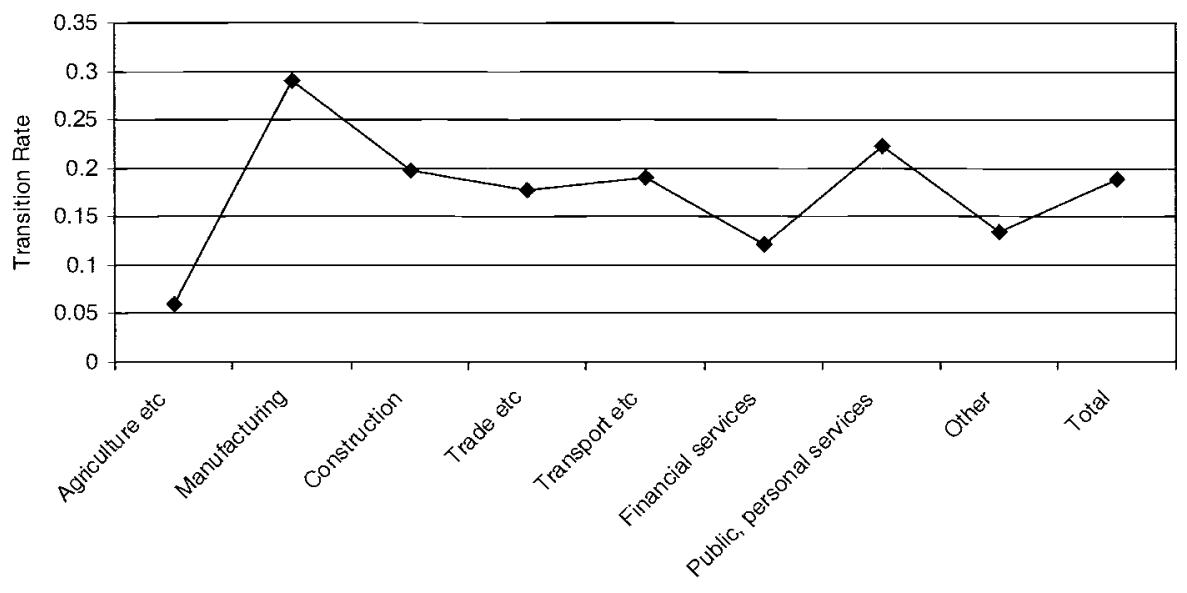

Fig. 3.5 Transition rate to PEW by industry, 1997-98

Table 3.5 Status Prior to Entry to SDP

\begin{tabular}{lcccccr}
\hline & \multicolumn{5}{c}{ Status Immediately Before Entry (\%) } \\
\cline { 2 - 7 } Earlier Status & Employed & Unemployed & $\begin{array}{c}\text { Welfare } \\
\text { Benefits }\end{array}$ & $\begin{array}{l}\text { Sickness } \\
\text { Benefits }\end{array}$ & Other & Total \\
\hline Employed & 8 & 0 & 0 & 22 & 1 & 31 \\
Unemployed & 0 & 0 & 10 & 21 & 0 & 32 \\
Welfare benefits & 0 & 0 & 7 & 3 & 2 & 12 \\
Sickness benefits & 0 & 1 & 3 & 1 & 0 & 5 \\
Other & 0 & 1 & 8 & 2 & 8 & 20 \\
$\quad$ Total & 9 & 2 & 28 & 50 & 11 & 100 \\
\hline
\end{tabular}

Source: Calculations based on Statistics Denmark (1999).

for manufacturing and for public and private services (i.e., industries with a high share of unskilled workers). Many of them will have a fairly high potential rates of compensation upon entering the PEW. ${ }^{8}$ The low share from agriculture reflects both the dominance of self-employment in this age group and the condition that a farmer must sell the farm to be eligible for the PEW. Another low share is found for financial services, probably because this is a group in which most employees have access to labor market pensions. The industry group "other" includes workers with a more marginal attachment to the labor force. A higher-than-average share of these probably do not fulfill the requirements for eligibility to PEW.

Regarding the transition to SDP, table 3.5 shows the status immediately

8. Many in these groups will also have had physically demanding, repetitive jobs, or both (i.e., belong to the groups for whom the PEW was originally designed). 
before the transition (i.e., as a minimum, the latest month) and shows also the earlier status, or the one preceding the state immediately before entry to SDP.

Looking at the immediately preceding status, we find - not surprisingly, as an SDP application takes time to process - that only 11 percent are in the labor force. But by extending the perspective to include people coming from unemployment, we find that nearly two-thirds come from the labor force. For people coming from employment, both immediately before and as the earlier status, it seems fairly obvious that the route to SDP is health related.

\subsubsection{Policy Reforms - Pressure and (Beginning) Action}

The background to policy reforms is similar in Denmark to most other OECD countries, even though the pressure for reforms may be less. The setting is the well-known combined effects from the projected aging of the population, the declining average retirement age, and the transition from a predominantly PAYG system to predominantly funded systems.

During the next forty years, the number of people within the potential labor force age range relative to people sixty-five years and older is projected to decline from a 4-1 ratio to a 2-1 ratio. At the same time, a significant decline has occurred in the actual average retirement age during the last quarter of a century, widening the gap between actual average retirement ages and the hitherto very high official pension age of sixty-seven years.

The core of the problem is, like in other OECD countries, an expected increase in public expenditures for pensions and for health-related care for elderly people, and at the same time, the decline in average retirement ages means an erosion of real production and the tax base in the economy.

Denmark shares the problems in this area along with other OECD countries, but the specific problems related to demography are expected to be relatively smaller. Roseveare et al. (1996) project an increase in taxes relative to GNP conditional on demographic factors until the year 2030. Italy, Germany, Japan, and the Netherlands are on top in this ranking with projected increases in the range of 9-11 percentage points. Sweden, Denmark, Norway, the United Kingdom, and Ireland are at the opposite end with projected increases in the range of 2-4 percentage points.

Nevertheless, when the problems are considered very important by Danish policy makers, it reflects among other things that the fairly small impact on taxes as a share of GNP (tax/GNP) must be seen in relation to a level of the tax/GNP that - along with the level in Sweden — is the highest among the OECD countries.

It will be ten years before the demographic change affects Denmark. Nevertheless, reform discussions and initiatives have been on the policy agenda already for some time. The current reform plans are summarized in 
the present section. The general strategy seems to consist of three main areas.

- A gradual shifting of the weight from PAYG to funded programs

- Policy changes to reverse the decline in actual average retirement ages

- More broad policy changes to mobilize an increase in labor supply from nonparticipants in different public-sector income-transfer programs

Obviously, the last part of the strategy has the double benefits of reducing public expenditures at the same time as expanding the tax base.

Regarding the OAP, the general trend - in accordance with the strategy outlined previously - has been a reduction of the universal base amount and an increase in the means-tested supplementary pension. As the labor market pension schemes reach maturity, an increasing number of pensioners will be entitled only to the base amount. The universal base amount was independent of other income until changes in 1982 and 1993 introduced means testing against earnings, but not against capital income. This seems to reflect the philosophy of those years of trying to combat unemployment by reducing labor supply.

The major current change regarding OAP is the reduction of the eligibility age from sixty-seven to sixty-five. Superficially, this seems surprising considering the nature of the problems regarding the pension burden. It must however be interpreted in the light of, first, the widening gap between the high official retirement age and the declining actual average age. Then, a major share of people sixty-five and sixty-six years old receive the PEW, which is higher than OAP, so public expenditures may decline. ${ }^{9}$ Finally, means testing of the base amount against earnings is changed in a way to make gradual retirement more attractive. Reduction of the base amount begins at a higher level of earnings than previously and the rate of reduction of the base amount is reduced from 60 to 30 percent, implying that the base amount will only be fully phased out at an earnings level well above the average earnings of skilled workers.

The number of people entering the SDP annually has gone down since 1988. Especially in the most recent years, the number of new entrants has been at a very low level. The background is the spending of more resources on rehabilitation to reverse the expansion of SDP, and in 1998-1999, an increasing number of "flex-jobs" on special conditions have been supplied as an alternative to SDP. Critics of the recent reforms have claimed that the strong decline in admission to SDP mostly reflects a tightening by the administration of requirements for eligibility. The policy changes have been in effect for too short a period to reach any conclusion as to their effect yet.

9. A counter effect might come from people who have not received any income transfers, but who now become eligible for OAP two years earlier. 
The PEW, introduced in 1979, has become the dominant route to early retirement after the age of sixty. Until now, the only financial incentive to delay entry has been eligibility to maximum unemployment-insurance (UI) benefits until the age of sixty-seven if entry was postponed until the age of sixty-three. A reform of the PEW was enacted to gradually have effects onward from July 1999. The main point in the reform is to create incentives to postpone entry to the program until the age of sixty-three. Combined with the reduction of the OAP age to sixty-five, the long-run effect is intended to be a significant decline in the stock of people in the PEW program.

As mentioned in the introduction, the reform tightens the entry requirement for PEW regarding the years of membership of an UI fund. Benefits are changed from a system in which they were reduced as a function of time spent in the PEW to a system in which benefits depend on age at entry being sixty to sixty-one or sixty-two or older. In the first case, benefits are 91 percent of the maximum UI benefits until OAP eligibility, while in the second case they are 100 percent of maximum UI benefits. Furthermore, benefits are means tested against income from all other pension schemes for people aged sixty to sixty-one years. After age sixty-two, means testing is only against the income from pension schemes with monthly payments originating in earlier employment. Until the reform, this was the rule for everybody aged sixty to sixty-six.

Hitherto, participants in the program were not allowed to work more than 200 hours annually. The reform replaces this with a flexible scheme, always resulting in a financial incentive to work to some extent. Eligibility to PEW in the new system will be terminated if the person works thirty hours or more per week. This compares with the earlier system in which no reduction occurred as long as annual labor supply was below 200 hours and entitlement was permanently and completely lost if a recipient worked more than 200 hours.

Furthermore, the reform introduces a tax premium for people who are entitled to PEW, but who go on working after age sixty-two. Working until the new OAP eligibility age of sixty-five would entitle the person to a tax premium at a level of 50 percent of the annual income of an unskilled worker.

In summary, the main objective of the PEW reform is to reverse the decline in the average actual retirement age and increase labor supply, especially among people in their early sixties. The reform has only been in effect for a short period of time, so evidence concerning the impacts on behavior is not yet available. Danø, Ejrnæs, and Husted (2000) have entered the main elements of the PEW reform into a quantitative study of retirement in Denmark in order to simulate the effects. The major impact from the reform is a big reduction in the implicit tax on continued work, especially for sixty-one year olds and for people sixty-three to sixty-four. Based on the model, the prediction is that the reform will result in increases in the aver- 
age retirement age for eligible individuals in the 1-1.5 year range for men and 1-2 years for women. Christensen and Datta Gupta $(1999,2000)$ have compared the labor supply and government budgetary effects of a delay in PEW eligibility age versus a reduction in PEW benefits and have found that delaying PEW eligibility from sixty to sixty-two will lead to a greater increase in the average retirement age ( 0.6 years for men and 0.75 years for women) and greater per capita savings than a reduction in benefits.

The main points in current policy reforms are thus to delay early retirement and to increase labor supply. This combines with the ongoing longrun shift of emphasis from PAYG to funded pension systems.

\subsection{Data Overview}

The data for this study are drawn from the Integrated Database for Labour Market Research (IDA; Statistics Denmark 2003), which is combined longitudinal data for persons and establishments in the period 19801995 and is compiled by Statistics Denmark. The IDA links information on employees and establishments drawn from central administrative registers that contain labor market information on the entire Danish population. Thus, there is no sample survey component to this data. As far as persons can be followed over time, IDA contains annual labor market information on all individuals in Denmark.

We use a 2 percent extract of IDA (the population is all public- and private-sector workers) and restrict our retirement estimations to all older workers aged fifty to seventy in the period 1980-1995 who have been observed in the labor force at any time. Although early retirement eligibility begins at age sixty, we start our analysis at fifty, as this is the age at which public or private retirement income for disability or illness can first be expected for those in the labor market. We condition on labor force attachment before fifty. The sample sizes for the estimations are 210,073 female person-years ${ }^{10}$ and 224,621 male person-years.

The definition of retirement is based on the receipt of benefits such that a person is considered retired if the main source of income during the year comes from a pension. In addition, we also condition on the absence of labor earnings and employer pension contributions during the year. Several key public pension benefit programs are considered in addition to the pure-social security program or OAP. These are, respectively, the PEW, SDP, and PEP. We also include the TBP, which was a special earlyretirement pension option available to the long-term unemployed (aged fifty-five to fifty-nine initially, and later also including fifty to fifty-four years) that was in effect between 1992 and 1996.

10. "Person-years" represents the volume of observations. For instance, 5 women observed for 5 years will constitute 25 female person-years. 
The IDA sample contains information on an individual's demographics, years of education, earnings, and other income and assets. The main limitations from the point of view of a retirement study are lack of information on private pensions and health. Mortality information is available, and survivor probabilities are assigned on the basis of gender- and age-specific national average life tables for ages fifty to ninety-nine (death is assumed at age one hundred). In the Danish case, there is only a limited use for spousal information, as calculation of benefits is almost entirely on an individual basis and does not depend on the spouse's entitlement, although adjustments are made to the benefit level for marital status in some of the programs. Neither dependent benefits nor survivor benefits are relevant in the Danish social security context.

We determine eligibility for OAP on the basis of age, and eligibility to PEW on the basis of age and retrospective information on membership in an unemployment insurance fund. Potential entry in to the special TBP can also be determined on the basis of age, UI fund membership, and information on individual unemployment degree in the two years before potential eligibility. Eligibility to disability pension is determined probabilistically, based on population averaged by year, age, and gender participation rates in each of the three levels of the disability program. Without access to health information, it is difficult to make a more precise assignment to disability program eligibility. Finally, eligibility to PEP is observed directly in the data. But while we can effectively analyze retirement decisions of those who would be eligible for the major social security benefits programs, it is not possible on the basis of these data to determine eligibility to employer-provided private pension plans.

\subsection{Sample Descriptives and Earnings Projections}

Sample descriptives are reported in tables 3A.11 and 3A.12 in appendix A. The gender-specific means are shown both for the full sample (table 3A.11) and by PEW eligibility (table 3A.12). Means are taken across all person-year observations within each gender group. On average, males are around 56.6 years of age and females a few months younger. Around 17 percent of the males in the sample are eligible for PEW, although only 9 percent of females have accumulated the necessary years of membership in an UI fund. In terms of incentive measures, the average accrual for males is around $\$ 1,745$, while for females it is $\$ 1,161$. Both peak and option value figures are about 1.4 times higher for males than females on average. About 9 percent of the males and 10 percent of the females are retired. Average annual earnings for males are $\$ 35,970$ while the corresponding figure for females is only a little more than half, $\$ 19,368$. In terms of occupational ranking, males are more likely to be in skilled blue-collar managerial positions (especially top- and middle-management positions), and females are 
more likely to be in white-collar and the unclassified occupational category.

When disaggregating by PEW status in table 3A.12, it can seen that males who are eligible for PEW are on average two years older, have slightly higher annual earnings $(\$ 36,406$ versus $\$ 35,625)$, and are much more likely to be in skilled and unskilled blue-collar jobs and less likely to be in top- and middle-management jobs, compared to males not eligible for PEW. In table 3A.12, females eligible for PEW are not that different compared to uneligible females, except in terms of higher earnings $(\$ 23,138$ versus \$17,692), higher representation in white-collar and unskilled bluecollar, and lower representation in the unclassified occupational category.

Annual earnings are top coded at the real 99.9 percent level. The (log real) annual earnings regressions are based on a sample of workers aged forty-nine to seventy in all the available years (1980-1995). A simple, agequadratic, individual fixed-effects specification is chosen for the log earnings regressions, with separate regressions run by gender. In the Danish case, as retirement benefits are largely independent of past earnings, the benefit calculations in most cases depend only on most recent earnings and not on earnings histories or projections. The only program that ties benefits to past record is the PEP. For the purposes of earnings projections of an individual's expected earnings stream from work, a flat real ageearnings profile is applied when going forward from the predicted earnings in the last observed year of work. ${ }^{11}$

\subsection{Construction of Incentive Measures}

Central to the analysis are the construction of social security wealth (SSW) and the calculation of the various incentive measures, which are based on SSW and other data components. The construction of SSW is complicated by the fact that there has been extensive reform of pension programs in Denmark over the 1980-1995 period. Also, in the Danish context, there are multiple policies, such as SDP and TBP, for older workers, that need to be integrated (see the discussion in section 3.2).

We make the assumption that all expected future changes in eligibility, generosity of programs, or both are unknown at each age. In other words, the agent assumes in each calendar year, that the future social security system will remain as it is in that calendar year. Table 3.6 summarizes the main elements of the programs and their respective eligibility criteria.

We adopt a weighted-average income flow measure, in which the weights are determined by empirical take-up rates of disability pension. These

11. The within estimator $R^{2}$ is equal to 0.1733 for males, and $R^{2}$ is equal to 0.1395 for females. All estimated coefficients have the expected signs and are highly significant. The ageearnings profiles are concave and reach maximums at age 52.5 for males and at age 53.1 for females. 
Table 3.6

Criteria for Program Eligibility

\begin{tabular}{lll}
\hline Program & \multicolumn{1}{c}{ Eligibility Age } & Determines Eligibility Based On \\
\hline PEW (post-employment wage) & $60-66$ & $\begin{array}{l}\text { Age and insurance fund } \\
\text { information }\end{array}$ \\
$\begin{array}{l}\text { TBP (Transitional Benefits } \\
\text { Program) }\end{array}$ & $\begin{array}{l}55-59 \text { long-term unemployed } \\
\text { from 1992 to 1996; 50-59 from } \\
1994 \text { to } 1996\end{array}$ & $\begin{array}{l}\text { Age and insurance fund and } \\
\text { unemployment info in two } \\
\text { years prior to age }\end{array}$ \\
PEP (public employees pension) & $60-69$ & $\begin{array}{l}\text { Employer pension contribu- } \\
\text { tions over required period }\end{array}$ \\
$\begin{array}{l}\text { SDP (social and disability } \\
\text { pensions) }\end{array}$ & $18-66$ & $\begin{array}{l}\text { Probability: Based on observed } \\
\text { participation rates by age, year, } \\
\text { and gender in each of the three } \\
\text { levels of the disability program } \\
\text { Age } \geq 67\end{array}$ \\
OAP (old age pension) & 67 & \\
\hline
\end{tabular}

weights are calculated from the age, year, and gender disability rates within the IDA sample. Thus, at each potential retirement age, the individual is assumed to be eligible for disability pension with probability $p$ and for one of the other nondisability social security retirement programs with probability $1-p$. Within disability, the level of disability (highest incapacity, middle incapacity, and lowest incapacity) is also determined on the basis of population age- and gender-specific participation rates. Within the nondisability social security programs, we allow one income flow for each potential retirement age from fifty to sixty-nine depending on eligibility. This is consistent with the Danish system in which individuals cannot draw multiple pensions. The possible programs are PEW, the TBP, PEP, or no pension. From the official retirement age of sixty-seven and onward, all individuals (independent of potential disability status) are entitled to OAP and possibly PEP in addition, if eligible. ${ }^{12}$

Thus, suppose that with probability $p$, a person goes on disability pension at age $a$, then the individual's income flow at age $a$, IFLOWR, is given by

$$
\begin{aligned}
\operatorname{IFLOWR}_{a}= & (1-p)\left(\operatorname{IFLOWR}_{a}^{\mathrm{PEW}} \text { or } \operatorname{IFLOWR}_{a}^{\mathrm{TBP}} \text { or } \operatorname{IFLOWR}_{a}^{\mathrm{PEP}}\right. \\
& +p \mathrm{IFLOWR}_{a}^{\mathrm{SDP}}, \quad 49 \leq a \leq 66
\end{aligned}
$$

and

$$
\operatorname{IFLOWR}_{a}=\operatorname{IFLOWR}_{a}^{\mathrm{OAP}}, \quad a \geq 67,
$$

12. Part of them will have supplementary income from labor market pensions or from private arrangements that are not included in the present data and therefore are not covered in the study. 
where SSW is the present discounted value of future income flow. Our SSW measure incorporates both broad changes in pension policy that took place in the 1980-1995 period, as well as the detailed year-to-year reforms in the generosity, taxation, and eligibility rules. The major reforms in this period include the sweeping SDP reform of 1984 in which the so-called widow's pension and special pension rules for single women was cancelled. In its place, the disability pension was broadened to include pensions based on social criteria. A special retirement window, the TBP, was available starting in 1992 (and ending in 1996) for the long-term unemployed between the ages of fifty-five and fifty-nine-later also between fifty and fifty-four - who would fulfill the eligibility criteria for the PEW program by age sixty. Finally, in 1993, there were benefit increases dependent on delayed retirement and other changes in compensation in the PEW program.

Tables 3A.1-3A.10 summarize the incentive calculations based on our construction of SSW on the micro-data. Tables 3A.1-3A.5 present results for the males, and tables 3A.6-3A.10 are the corresponding calculations for the females. For each of the preceding samples, we present calculations made for the overall sample, as well as specifically by the type of pension program (PEW or not). Three incentive measures are considered: accrual, peak value, and option value. The accrual is the accumulation in SSW if the worker postpones retirement by a year. The option value is the difference between the maximum of the expected present values of retiring at each future age minus the present value of immediate retirement. Thus, if the option value is positive, the individual continues to work, otherwise he retires. We assume a discount factor $\beta$ is 0.97 , the risk aversion parameter $\gamma$ is 0.75 , and the utility of a dollar of income while retired relative to a dollar of income while working equal to 1.5 , using values previously estimated for the United States by Stock and Wise (1990). The peak value is simply the option value under the assumptions of no risk aversion, and the same utility from a dollar while working and a dollar while retired-i.e., $(\gamma, k)$ is equal to $(1,1)$ - or what has been labeled the "financial option value" by Coile and Gruber (2000).

We consider the worker at the median, tenth percentile, and ninetieth percentile who retires between the ages of forty-nine and seventy. In general, working another year can affect SSW in the following ways.

- By working another year, the worker who is less than sixty-seven may forgo a year of benefits through either SDP or early retirement (TBP plus PEW, or early PEP) if he meets eligibility criteria. This will lower net SSW.

- The worker who considers retiring at fifty-nine (instead of sixty) would be entitled to receive early retirement benefits starting the next year only, which would lead to a big increase in SSW at retirement age sixty.

- Between the retirement ages of sixty and sixty-seven, working another 
year can lead to accumulating an additional year of "pension rights" in the PEP program (if the worker is eligible) that increase the pension that can be drawn after sixty-seven and therefore SSW.

- At retirement age sixty-seven, we would expect another spike in SSW, reflecting the availability of OAP.

- Finally, if a worker chooses to work after sixty-seven, this would mean forgoing a year of social security benefits available to all, which would mean a shorter interval over which social security can be collected and therefore lower net SSW.

Table 3A.1 reports median SSW and median, tenth percentile, and ninetieth percentile accrual figures for the males, together with the standard deviation of accrual and the rates of taxes and subsidies, which is the change in SSW relative to what the worker could have earned over the coming year. Median SSW increases slowly up to retirement age sixty (last work age fifty-nine) and declines thereafter. This is also seen in the median accrual, which is positive up to age sixty (the first age of eligibility of early retirement through PEW) and then turns negative. The negative accrual clearly reflects the actuarial unfairness of the benefits system such that the gain in wage earnings from postponing retirement are more than offset by the loss in future social security benefits.

The corresponding subsidies are in the range of $10-15$ percent before retirement age sixty and taxes of 15-35 percent after sixty. Thus, this would indicate that there are strong incentives to retire through PEW in the Danish system. However, at retirement age sixty-seven, accrual turns positive again and the tax becomes a subsidy of 40 percent. This sudden reversal in sign at retirement age sixty-seven is possibly a result of pooling together workers of different eligibilities (namely those eligible for PEW and those not eligible for PEW and only eligible for either OAP or PEP) who respond differently to program incentives. Thus, a sizable fraction of our sample (mostly low-wage earners) retire through PEW, while the remainder (highwage earners) have incentives to remain in the labor force until age sixtyseven (see the discussion in section 3.2).

This is also confirmed in part by considering separately the tenth and ninetieth percentile in the SSW distribution. At the tenth percentile in table 3A.1, accruals follow the expected pattern, positive up to retirement age sixty and negative thereafter. At the ninetieth percentile, accrual is always positive, but a has a double-peaked profile at last work ages fifty-nine and sixty-six (the relatively larger of the two), reflecting the large gain in SSW by continuing to work until program eligibility. Variability in SSW (standard deviation) increases with age, reaching a maximum at retirement age sixty-seven, as some are eligible for PEP in addition to OAP and others not.

In table 3A.2, we present peak value and option value calculations at the median, tenth percentile, and ninetieth percentile for the males. Peak and 
option value are measured in utility terms and are therefore not comparable to accrual figures. Both are positive but declining throughout the age interval, indicating a propensity to continue working even at older ages. Thus, retirement incentives, as measured by option and peak value, seem to be weak in the Danish system. Although, it should be pointed out that these figures are typically higher at the ninetieth and lower at the tenth percentile relative to the median.

Program-induced incentives are difficult to detect when the sample is pooled irrespective of program eligibility. This is because, as described in section 3.2, a significant fraction retires through the PEW program at age sixty or shortly thereafter, while the remainder retires at age intervals up to sixty-seven. The two groups are heterogeneous in terms of their work history and expected replacement rate of income through social security, and therefore large selection effects may be present when pooling the data.

In tables 3A.3-3A.5, we regenerate the incentive calculations for the subsamples eligible for PEW and those uneligible. The latter is relatively more heterogeneous, consisting of individuals retiring through disability, PEP, or, in most cases, only through OAP (compare standard deviations of the incentive measures and SSW across the two groups). We report only results at the median here. Looking at the age distribution of accrual by PEW eligibility in table $3 \mathrm{~A} .3$, it is clear that strong early retirement incentives are present for those who are eligible for PEW. In this case, accrual is positive until retirement at age sixty and turns sharply negative thereafter. Work is encouraged (subsidies of 9-17 percent) in the forty-nine to sixty retirement age group, and work is heavily taxed after that with taxes ranging from about $10-40$ percent. For those not eligible for PEW, the story is not as clear due to the mixing of different groups (see previous discussion), but the tax on work at older ages is clearly lower than for the PEW-eligible persons ranging from about $1-6$ percent.

Tables 3A.4 and 3A.5 report the distribution of the forward-looking measures separately by PEW eligibility. Both peak value and option value measures are positive and declining throughout for both samples and are roughly comparable in magnitudes.

Tables 3A.6-3A.10 present similar calculations for the female sample. Several features are worth noting in comparison to the male sample. Median SSW is higher for women at retirement ages forty-nine to fifty-five and sixty-seven to seventy. In the earlier age groups, women have higher rates of participation in disability and therefore higher SSW (as well as pre-1984 access to widow's pension). In the highest age group, the working women present in the sample may not be representative in terms of their access to different pension schemes. In the normal retirement age interval, men have higher SSW.

At the median, one-year accruals are smaller for women than men at all ages, indicating a smaller incentive to keep working before sixty and a 
smaller incentive to retire after sixty. This is also seen in the relatively smaller tax and subsidy rates for women. The female sample is also more homogeneous in terms of the variability of SSW, accrual, peak value, and option value (compare standard deviations in tables 3A.6 and 3A.7 to those in 3A.1 and 3A.2).

Peak and option value are smaller for women, although the same order of magnitude (compare tables 3A.2 and 3A.7). The 10-90 split is not as clear-cut in the case of the female sample. While at the tenth percentile, accruals turn negative from retirement age fifty-eight and onward at the ninetieth percentile, accruals turn negative at retirement age sixty-one but positive again at age sixty-seven. This indicates that some selection effects may be present due to pooling together of heterogeneous groups who may be retiring at different times due to program-induced incentives (see table 3A.6). Females eligible for PEW (like males) also exhibit a clear preference for early retirement, although in this case, retirement begins for the median worker at age sixty-one, perhaps due to the delayed retirement incentive present in PEW. (PEW benefits are 90 percent of previous wage up to a maximum UI-benefit ceiling for the first two and a half years on PEW starting at age sixty, and 80 percent thereafter until age sixty-six. If retirement is first taken at age sixty-three, benefits can be collected at the higher 90 percent rate for the rest of the remaining period under PEW.) Median SSW for females on PEW is higher than that for males at all retirement ages, perhaps indicating that the average female on PEW also has access to other types of social insurance. Retirement income for this sample is also more variable (see table 3A.8). Women eligible for PEW also exhibit slightly smaller (but still positive and declining with retirement age) peak value and option value than men, indicating a lower tendency towards postponing current retirement (see tables 3A.9 and 3A.10).

In the Danish case, therefore, the driving force behind the age-incentive structure seems to be program rules and eligibility. As social security is funded through general taxes, no payroll tax-induced work disincentives can be expected. Except for the delayed retirement incentive in the PEW described above, no actuarial adjustments are made to benefit levels for later retirement through OAP (a "waiting supplement" was phased out in 1983). The PEP program is actuarially adjusted, as a reduction in benefit amount is present for retirement before age sixty-seven, with the reduction depending on age at retirement and number of pension years that have been accumulated up to the point of retirement. However, as only a fraction of the labor force is eligible for this program in our sample period, this effect is unlikely to be reflected in the data. The old-age social security system in Denmark works mainly as a safety net, providing a basic guaranteed income at older ages. This redistributive function explains why low-wage workers face a fairly high replacement rate while higher-wage workers resort to labor market pensions and private pensions to make up for the 
rather low compensation through the social security system (cf. the discussion in section 3.2).

\subsection{Estimation}

We estimate an option value-based model of retirement (see Stock and Wise 1990) in which an individual compares the expected value of retiring today to the expected value of continuing to work today and postponing retirement until the best possible future age of retirement. Thus, for the individual, the value of working from age $t$ to age $r-1$, and then retiring at age $r$ is given by

$$
V_{t}(r)=\sum_{S=t}^{r-1} \beta^{S-t} U_{W}\left(Y_{S}\right)+\sum_{S=r}^{S} \beta^{S-t} U_{R}\left[B_{S}(r)\right],
$$

where $U_{W}$ is the instantaneous utility of work that takes as its argument a worker's income, and $U_{R}$ is the instantaneous utility of retirement and is a function of retirement benefits that depend on the worker's retirement age, and $\beta$ is the discount factor.

Let $E_{t} V_{t}(r)$ be the expected value at age $t$ of working through $r-1$ and retiring at $r$, and let $E_{t} V_{t}(t)$ be the expected value of current retirement, and let $r^{*}$ be the value of $r$ that maximizes $E_{t} V_{t}(r)$. Then, the individual will postpone retirement if the option value $G_{t}\left(r^{*}\right)$ is positive.

$$
G_{t}\left(r^{*}\right)=E_{t} V_{t}\left(r^{*}\right)-E_{t} V_{t}(t)>0
$$

Otherwise, the person retires at age $t$. Utility specifications allow for risk aversion through the parameter $\gamma$. The parameter $k$ measures the utility of a dollar of income obtained while retired relative to the utility of a dollar of income obtained while working. Thus, if $k>1$, then a dollar of income while retired gives greater utility than a dollar of income accompanied by work. The utility functions are

$$
\begin{aligned}
U_{W}\left(Y_{S}\right) & =Y_{S}^{\gamma}+\omega_{S}, \\
U_{R}\left(B_{S}(r)\right) & =\left[k B_{S}(r)\right]^{\gamma}+\xi_{S} .
\end{aligned}
$$

A simple alternative to a full-blown maximum likelihood estimation of the option value model is to specify retirement in terms of the gain from continuing to work, computed on the basis of some assumed values for $\gamma$, $k$, and $\beta$, which can then be used to calculate income. ${ }^{13}$ Assuming that retirement depends on this calculated option value as well as other determinants (observed and unobserved), a probability model of retirement (for example, probit) can be specified as 
$\operatorname{Pr}($ retire in year $t)=\operatorname{Pr}\left[\alpha+\beta G_{t}\left(r^{*}\right)+\delta \mathbf{X}+\varepsilon_{t}>0\right]$,

where the dependent variable is binary and takes the value 1 if retired, 0 if not, and where $G(\cdot)$ is the option value of postponing retirement (in other cases the peak value or the accrual measure) calculated under the assumed parameter values, and $\mathbf{X}$ is a vector of additional variables.

Thus, any changes in social security plan provisions that would affect income and benefits and hence the retirement decision are reflected in changes in $G(\cdot)$ and captured by the parameter $\beta$. The larger the option value, the greater is the gain from postponing retirement - that is, $\beta$ should be negative in the probit regression.

The sample for the probit regression is all individuals aged forty-nine to seventy in our data, which is 2 percent of the population of workers. Everyone is assumed to have retired before age seventy-one. Observations on individuals are pooled in the analysis, and individuals are retained up to and including the year of retirement. The results of this probit regression analysis can be found in table 3A.13, where the first panel presents the results for the male sample for each incentive measure (accrual, peak value, and option value), and the second panel shows the corresponding results for females. These regressions use as controls a full set of demographics: sector, earnings, and higher powers in earnings. For each incentive measure, we report two alternative specifications with a linear age term or with agespecific dummies. The social security measure is also included in addition to the incentive measure in all the specifications in order to capture the wealth effects of the system. The incentive measures can then be thought of as capturing the substitution effects.

In terms of goodness of fit as measured by the pseudo- $R^{2}$, all three models yield comparable fits in the range of $0.24-0.37$. The option value gives the best fit when age enters linearly, while the accrual model explains the data the best when age dummies are used in place of a linear age term. This is true for both males and females. For all incentive measures, the specification with age dummies yields a better fit, for both males and females. In all cases, fit is marginally better for males than females.

All coefficients are highly significant, except the coefficient on SSW in two out of the twelve cases. For the males, the coefficient on the incentive measure is estimated negative (as it should be) in all cases except in the accrual model with linear age. The coefficient on the SSW variable is positive in all cases. Thus for males, the greater the incentive measure (particularly the forward-looking ones), the greater is the incentive to continue working, and the higher the accumulated SSW, the higher is the probability of retirement. For females, the coefficient on SSW is in all cases positive, and the coefficient on incentive is negative, except in the accrual model with linear age. Again, for the most part, retirement wealth and incentive measures have the expected effects. 
Besides improving fit, for both males and females, adding age dummies seems to yield signs and significance that conform to prior expectations. In terms of the estimated coefficients on the incentive measures, the peak and option value give the conventional signs in all cases, while the accrual model does so only in the case with age dummies.

The retirement hazard and the profile of the age dummies from the estimations for women and men are shown in figure 3B.1 in appendix B. The age dummies reflect very clearly the main rules in the major retirement programs, that is, the spikes at sixty and at sixty-seven reflecting the PEW entitlement and the universal entitlement to OAP, respectively. In the next section, we carry out some simulations of the impacts of policy changes on retirement probabilities.

\subsection{Policy Simulations}

In this section, we describe the results arising from two kinds of policy simulations. ${ }^{14}$ First, in what we label the three-year reform, we raise the age of first eligibility of all early retirement programs and normal retirement by three years. Thus, the age of first eligibility to PEW and early retirement through PEP is increased by three years (from sixty to sixty-three), and the age of first eligibility of TBP-UI is also delayed by three years, from fiftyfive to fifty-eight. The normal OAP retirement age is increased by three years. The age- and gender-specific probability of disability for those aged sixty to sixty-two is assumed to be that probability observed in the data at age fifty-nine, and for those aged sixty-three to seventy the age- and gender-specific probabilities are those observed in the data for individuals three years younger. ${ }^{15}$

In the second policy simulation, which we call the common reform, we simulate the response to imposing a single unified plan with the following features

- An early entitlement age of sixty

- A normal retirement age of sixty-five

- A replacement rate of 60 percent of projected age-sixty earnings if claimed at sixty-five

- A 6 percent per year actuarial reduction for claiming before sixty-five

- A 6 percent per year actuarial increase for claiming after sixty-five

- No other pathways to retirement (i.e., SDP or UI)

For each type of policy reform, we model the effect of age on retirement in three different ways. The first approach is to implement the reforms on

14. Benchmark program rules relate to the most recent year-1995.

15. At the same time, we adjust the age at which the supplement for delayed retirement to PEW is effective from sixty-three to sixty-six. 
the model with a linear age specification by recomputing SSW and applying the new SSW and accrual values to the estimated coefficients from that model and thereby deriving new retirement rates. This is referred to as simulation type S1. Note that the linear age specification will imply that people will have a greater preference for retirement as they age, as preferences for leisure rise smoothly with age. As a variant, we try using age dummies in place of the linear age in the estimation in order to capture any nonlinearities in the effect of age, thus allowing for spikes at the early and normal retirement ages (or at other program-induced variations) and nonmonotonicities in the demand for leisure at various ages. However, the estimated age dummies are not applied in the simulation. This is done in simulation type S2. As S2 most likely attributes too much of an effect to the age dummies (by including all program-induced spikes) and too little to the SSW measure, we try a variant to S2, which we label S3, that compensates for this. Under this approach, we use the estimated age indicators in a way to simulate the change in retirement due to the program. For example, in the case of the three-year reform, $\mathrm{S} 3$ shifts the profile for share in retirement at different ages (age-retirement) forward by three years by assigning the age-sixty-three dummy to age sixty and the age-sixty-four dummy to age sixty-one, and so forth. In the case of the common reform, age dummies are adjusted in a way as to retain the effect on retirement age of early and normal retirement and the expected increased desire for leisure at older ages but also to take out the effect of other retirement programs. ${ }^{16}$ Thus, by shifting the age dummies, S3 loads all of the estimated effect to the program changes, while $\mathrm{S} 2$ likely minimizes the effect of program changes. Therefore, S2 and S3 can be thought of as bounding the prediction, while $\mathrm{S} 1$ falls in the middle. We expect that in the Danish case, like most other countries, S3 will give the largest estimated effect because the age of eligibility is key to the retirement decision, as evidenced in section 3.5, and S2 will give the smallest effect.

Results of the simulation exercise appear in table 3A.14 and in figures 3B.2-3B.10 for males and figures 3B.11-3B.19 for females (see appendixes $A$ and $B$ ). There are nine figures in all for each gender (three simulation types for each of the three incentive measures). Each figure has two portions, the first showing the predicted hazards for the baseline, the threeyear reform, and the common reform and the latter showing the cumulative probabilities, or the proportion of the sample that retires at each age.

Table 3A.14 compares baseline average retirement age to average predicted retirement age under each of the two reforms, applying each type of simulation to each of the three incentive measures. Looking at the results

16. The actual adjustment involves identifying the spike at the first eligibility age (not due to early retirement) and linearizing the age-retirement profile up to the early retirement age on the basis of the implied annual growth rate in retirement attributed to this program. Also, the retirement profile is made linear between normal and early retirement ages. 
for males, we see that while the baseline retirement age ranges from between 60.27 to 60.77 years, the three-year reform leads to predicted retirement ages between 60.28 and 62.59 years, while the common reform results in average retirement ages ranging from about 60.38 to 61.23 years. In fact, under the three-year reform, all specifications predict higher retirement ages compared to the baseline, the only exception being the accrual case with the S1 assumption. Under the common reform, five of nine cases predict a higher average retirement age than baseline. Simulated average retirement ages are close for the peak value and option value estimates and predict a $0.9-3.1$ percent rise in the average retirement age under the threeyear reform, and a modest fall in the average retirement age of about 1 percent in some cases (S3), while a slight rise in the average retirement age of about $0.6-1$ percent in some cases (S2 and sometimes S1) under the common reform. All specifications show, however, that there is a definite difference in the Danish case as to whether or not age is entered linearly or captured through dummies and whether or not variation induced by other program eligibility is smoothed out in the age-dummy specification (i.e., between S2 and S3). The effects also vary depending on whether the incentive measure adopted is forward-looking or myopic. However, there is not a lot of difference between the two forward-looking measures. Very similar patterns are evidenced for the women in table 3A.14.

While table 3A.14 shows the effects of each reform on the average retirement ages in our sample, to get an idea of how the changes resulting from each of the reforms are distributed across the age profile, we compare baseline retirement age hazards to simulated hazards for each specification, for each reform type, for each gender.

Looking at figures 3B.2-3B.10 for males, we see that regardless of the incentive measure being considered, the baseline hazard lies between the common reform (higher hazard) and the three-year reform (lower hazard). This is true irrespective of whether age is entered linearly or captured through dummies. That is, retirement is predicted to increase with the common reform but decrease under the three-year reform. This is due to the generosity of the proposed common reform compared to the existing system, in terms of a higher average replacement rates and the earlier availability of normal social security benefits.

Note that the S2 and S3 hazards in general show much more variability because of the use of age indicators, while the $\mathrm{S} 1$ hazard by definition rises smoothly with age.

Interestingly, the baseline hazard reproduces the early and normal peaks at first availability ages (sixty and sixty-seven) in the accrual case only, while in the peak and option value cases, the early peak occurs first at age sixty-one, probably reflecting actuarial adjustment of PEW in a setting with forward-looking behavior.

Comparing the relative effects of the different assumptions to our pri- 
ors - the expectation that S3 should give the biggest effect and S2 the smallest effect, while S1 should lie in the middle-we see that at least for the peak and option value incentive measures, $\mathrm{S} 3$ predicts the greatest decrease in retirement, S2 the smallest, and S1 an intermediate decrease.

For example, looking at the cumulative retirement probabilities for the male sample, the decline in the proportion of fifty to sixty-five year olds who would retire following the three-year reform compared to the baseline is approximately 13 percentage points under $\mathrm{S} 1,6-7$ percentage points under S2 and 17-18 percentage points under S3 in peak and option value cases. Only in the accrual case does S1 give a smaller impact (in fact, a 1 percentage point increase in the proportion of fifty to sixty-five year olds who retire) than S2 (7 percentage point decrease) and S3 (15 percentage point decrease), but recall that the accrual model with the $\mathrm{S} 1$ assumption gave the worst fit and a positive sign on the incentive measure.

Looking at the effects of the common reform on the cumulative distribution functions, again we see that $\mathrm{S} 3$ gives the greatest impact (in this case, increasing retirement), while $\mathrm{S} 2$ and $\mathrm{S} 1$ predict much smaller effects but still imply increased retirement, and $\mathrm{S} 1$ is bounded by $\mathrm{S} 2$ and $\mathrm{S} 3$ for all three incentive measures. For example, in the case of the forward-looking incentive measures, $\mathrm{S} 1$ predicts a 6 percentage point increase in retirement in the fifty to sixty-five age range, $\mathrm{S} 2$ predicts a 5 percentage point increase, and $\mathrm{S} 3$ predicts a full 27 percentage point increase. In the case of the accrual measure, $\mathrm{S} 1$ predicts an 8 percentage point increase in retirement, S2 actually predicts a 2 percentage point decrease in retirement, while $\mathrm{S} 3$ predicts a 23 percentage point increase in the proportion of fifty to sixty-five year olds who retire.

In general, comparing across both types of reforms, all three incentive measures exhibit similar age-retirement hazards, although peak and option value estimates, both being forward-looking, are closer. In fact, the treatment of age and type of reform seems to make a bigger difference to the predicted retirement patterns than the type of incentive measure being considered. This derives from the fact that, in the Danish case, very similar coefficients were estimated on SSW and the incentive measure (except for accrual and linear age) in the probit regressions.

Comparing the relative impacts of the reforms across the age profile (hazards), we again see that quite substantial effects are associated with both the reforms under S3 assumptions and more modest impacts with S1 and S2 assumptions. For example, using option value estimates, the S2 specification produces hazards that are bunched fairly tightly around the underlying baseline hazard (less than 0.05 difference in hazards), with the common hazard lying slightly above and the three-year hazard slightly below the baseline. Moving to S3, we see that by making the profile linear between the early (sixty-one) and normal (sixty-seven) peaks, the common reform distributes the mass of retirement between these two ages so that 
there is dramatic upward shift of the hazard between sixty-two and sixtysix. In the three-year case, the simulated hazard is shifted to the right so that the early and normal peaks now appear at ages sixty-four and seventy. Similar results are obtained in the peak value case.

Figures 3B.11-3B.19 show the comparable predictions for the females. For the females, we focus only on the figures pertaining to the option value incentive measure (3B.17-3B.19), as this model gives both precise estimates and an equally good fit for males and females. The results here are fairly similar to those for the males. The baseline retirement rate of the fifty to sixty-five year-old group is much higher than in the male sample, confirming the greater incidence of early retirement among women in Denmark. In fact, almost 92 percent are retired under S1 and 78 percent under $\mathrm{S} 2$ and $\mathrm{S} 3$. The comparable figures for the males (option value) are 79 percent (S1) and 72 percent (S2 and S3). The relative effects of the two reforms are the same for men and women, although the predicted effects of the reforms on the female sample are slightly smaller. Under the three-year reform, $\mathrm{S} 1$ predicts a 7 percentage point decrease, S2 predicts a 4.5 percentage point decrease, and $\mathrm{S} 3$ predicts a 13.5 percentage point decrease in the proportion of fifty to sixty-five year-olds who retire. Under the common reform, retirement is predicted to increase, just as for the males. Looking at the cumulative retirement probabilities in the fifty to sixty-five age group, $\mathrm{S} 1$ predicts a 2 percentage point increase, $\mathrm{S} 2$ predicts a 1.3 percentage point increase, and $\mathrm{S} 3$ predicts a 21 percentage point increase.

To summarize, the three-year reform would delay retirement while the common reform would bring it forward, and the actual extent of these changes is quite sensitive to the treatment of the age effect. That is, the specification with age dummies (in which the program effect is maximized) shows large effects using both types of reforms, whereas the linear age specification and the simple age-dummy specification produce more modest effects. As pointed out earlier, the age-dummy specification in general produces a better fit of the data and produces signs and significance that conform more closely with prior expectations than the linear age model, so that simulated effects arising from this model can be considered particularly relevant.

\subsection{Conclusions}

We model the impacts of incentives on retirements on micro-data using a 2 percent sample of the Danish population. An interesting aspect of retirement in Denmark is that, compared to most other OECD countries, participation is high in the sixty to sixty-six age group, despite the availability of a multitude of exit routes from the labor market. A possible explanation is that the financial incentives to retire early are strong among low-wage earners. Whereas for high-wage earners, the replacement rate is 
typically low, creating financial incentives to continue working in the sixties. We construct a measure of SSW that integrates multiple policies, such as OAP, early retirement, disability, and retirement options for the longterm unemployed. The implicit tax rates derived from this measure confirm our expectations that there are tax rates on continued work for the lowest decile after the start of early retirement eligibility, while work is encouraged at older ages for the highest decile. Estimations of a probability model of retirement show that the provisions of the social security system play an important role in determining retirement behavior in Denmark. In particular, forward-looking incentive measures, such as peak and option value, have the expected significantly negative effect on the probability of retirement, both with a specification in which age is entered linearly as well as with a full set of age dummies. In the Danish data, for both males and females, the option value gives the best fit when age enters linearly, while the accrual model fits the data the best when age dummies are used instead. Furthermore, the specification with age dummies generally fits the data better than the specification with the linear age term. A simulation of changes in the social security system reveals that while a policy reform designed to raise the first eligibility age of early and normal retirement will increase the average retirement age, a common policy reform that replaces all programs by a single, unified plan with a 6 percent actuarial adjustment will reduce it. However, the simulated impacts vary according to the treatment of age and, to a lesser extent, to the incentive definition that is used. Assuming forward-looking behavior and allowing for variation in program availability and in age-specific demands for leisure that affect the ageretirement profile, we find quite a large delaying impact of the three-year reform on the retirement of men and women in Denmark. 


\section{Appendix A}

Table 3A.1

Distribution of One-Year Accrual (males)

\begin{tabular}{|c|c|c|c|c|c|c|}
\hline Age & $\begin{array}{c}\text { Median } \\
\text { SSW } \\
(\$)\end{array}$ & $\begin{array}{l}\text { Median } \\
(\$)\end{array}$ & $\begin{array}{c}10 \text { th } \\
\text { Percentile } \\
(\$)\end{array}$ & $\begin{array}{c}90 \text { th } \\
\text { Percentile } \\
(\$)\end{array}$ & SD & $\begin{array}{c}\text { Median } \\
\text { Tax } \\
\text { Rate }\end{array}$ \\
\hline 49 & 143211.98 & - & - & - & 0.00 & - \\
\hline 50 & 147333.55 & 3953.19 & 3025.39 & 4380.95 & 1124.24 & -0.103 \\
\hline 51 & 151533.75 & 4077.58 & 3002.89 & 4606.97 & 1209.03 & -0.108 \\
\hline 52 & 155283.28 & 4092.34 & 2988.55 & 4636.06 & 1314.57 & -0.108 \\
\hline 53 & 159540.84 & 4257.56 & 2784.72 & 5058.67 & 1438.41 & -0.115 \\
\hline 54 & 164108.61 & 4375.28 & 2218.49 & 5153.81 & 1538.61 & -0.119 \\
\hline 55 & 168756.02 & 4352.42 & 2118.35 & 5261.59 & 1647.33 & -0.121 \\
\hline 56 & 173405.06 & 4533.42 & 1571.86 & 5248.23 & 2440.39 & -0.124 \\
\hline 57 & 178059.63 & 4712.42 & 1357.88 & 5576.45 & 2648.25 & -0.129 \\
\hline 58 & 182432.17 & 4670.63 & 1074.46 & 5560.48 & 2813.21 & -0.131 \\
\hline 59 & 185462.44 & 4875.97 & 971.26 & 5627.75 & 3030.70 & -0.138 \\
\hline 60 & 188715.20 & 4899.05 & 818.62 & 5962.23 & 3210.62 & -0.151 \\
\hline 61 & 172423.08 & -11974.49 & -14443.27 & 594.59 & 6131.92 & 0.298 \\
\hline 62 & 154982.63 & -11541.14 & -15033.03 & 497.30 & 6237.18 & 0.257 \\
\hline 63 & 138475.11 & -7624.74 & -15450.25 & 334.98 & 6295.76 & 0.239 \\
\hline 64 & 125049.11 & -4436.73 & -12360.71 & 774.72 & 4954.03 & 0.149 \\
\hline 65 & 108636.64 & -4943.47 & -12102.69 & 463.85 & 5032.07 & 0.144 \\
\hline 66 & 91859.85 & -3456.88 & -11265.78 & 413.28 & 4795.36 & 0.135 \\
\hline 67 & 90699.14 & 16647.82 & -11969.81 & 25003.32 & 15860.04 & -0.401 \\
\hline 68 & 81051.21 & -2563.63 & -3751.34 & 723.87 & 3238.97 & 0.063 \\
\hline 69 & 75878.41 & -2678.45 & -3525.67 & 535.21 & 3044.00 & 0.054 \\
\hline 70 & 73303.66 & -2607.57 & -3226.49 & 663.25 & 2807.40 & 0.053 \\
\hline
\end{tabular}

Note: $\mathrm{SD}=$ standard deviation. Dashes indicate that the data is not applicable. 


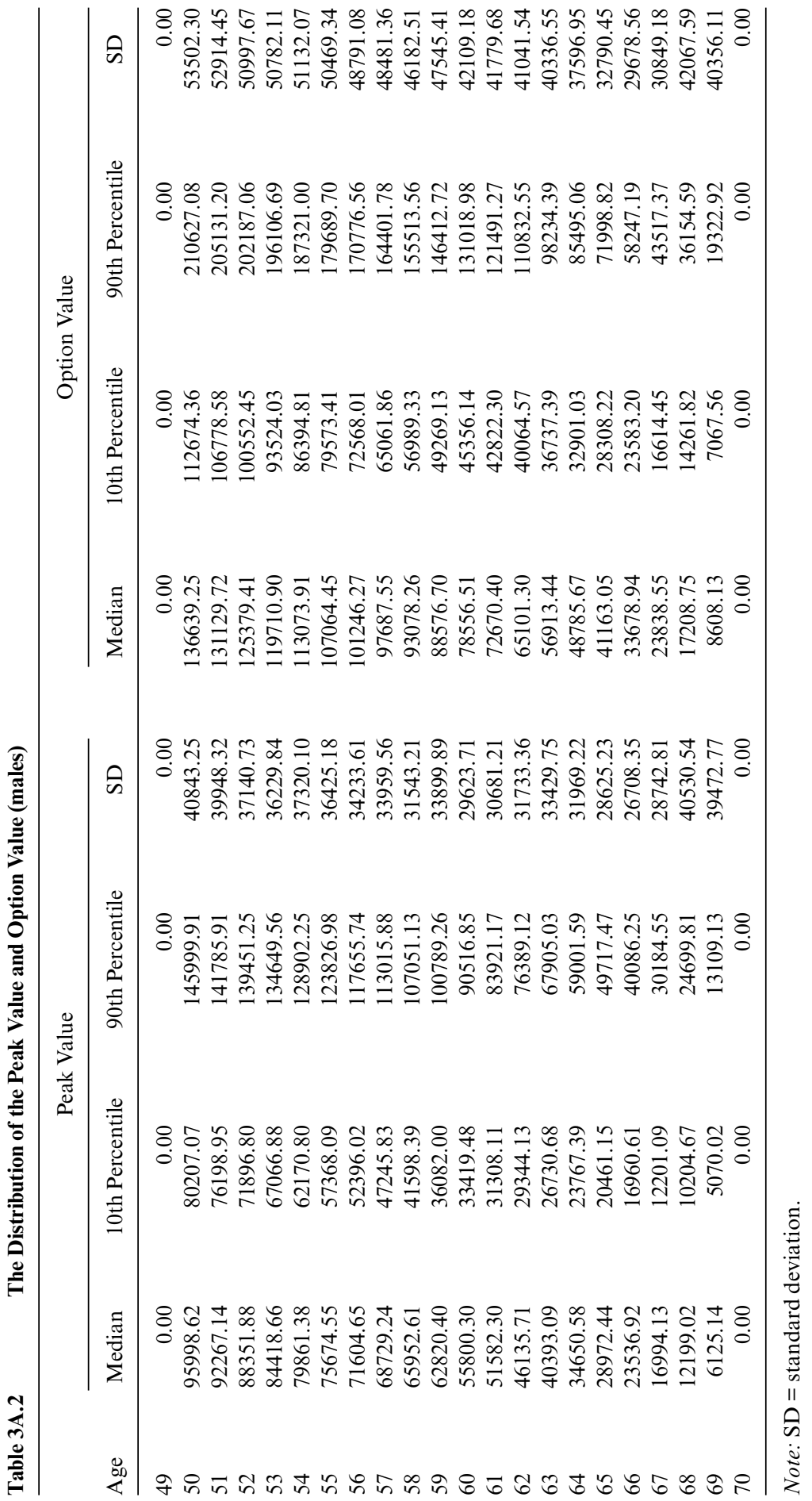




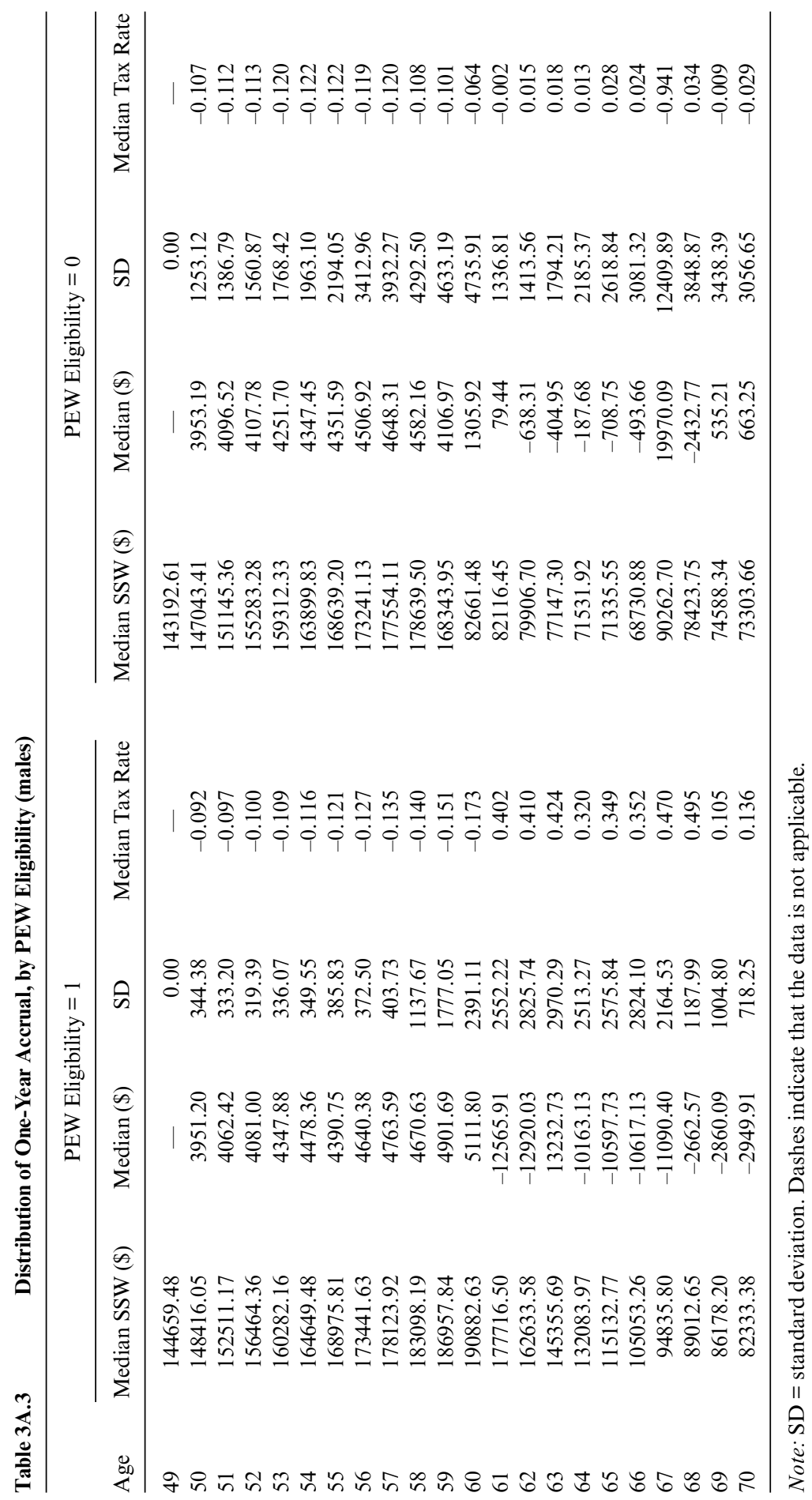




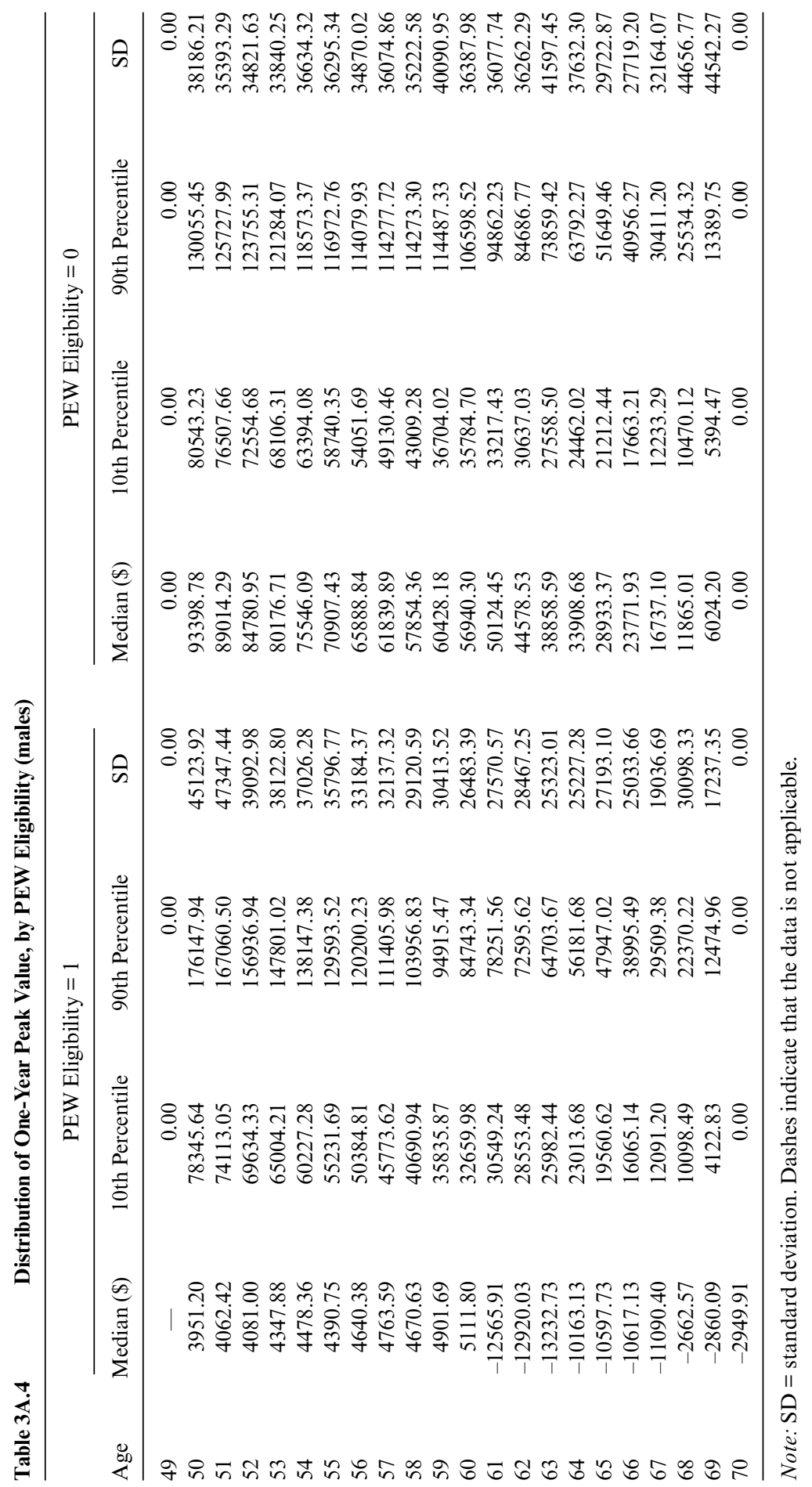




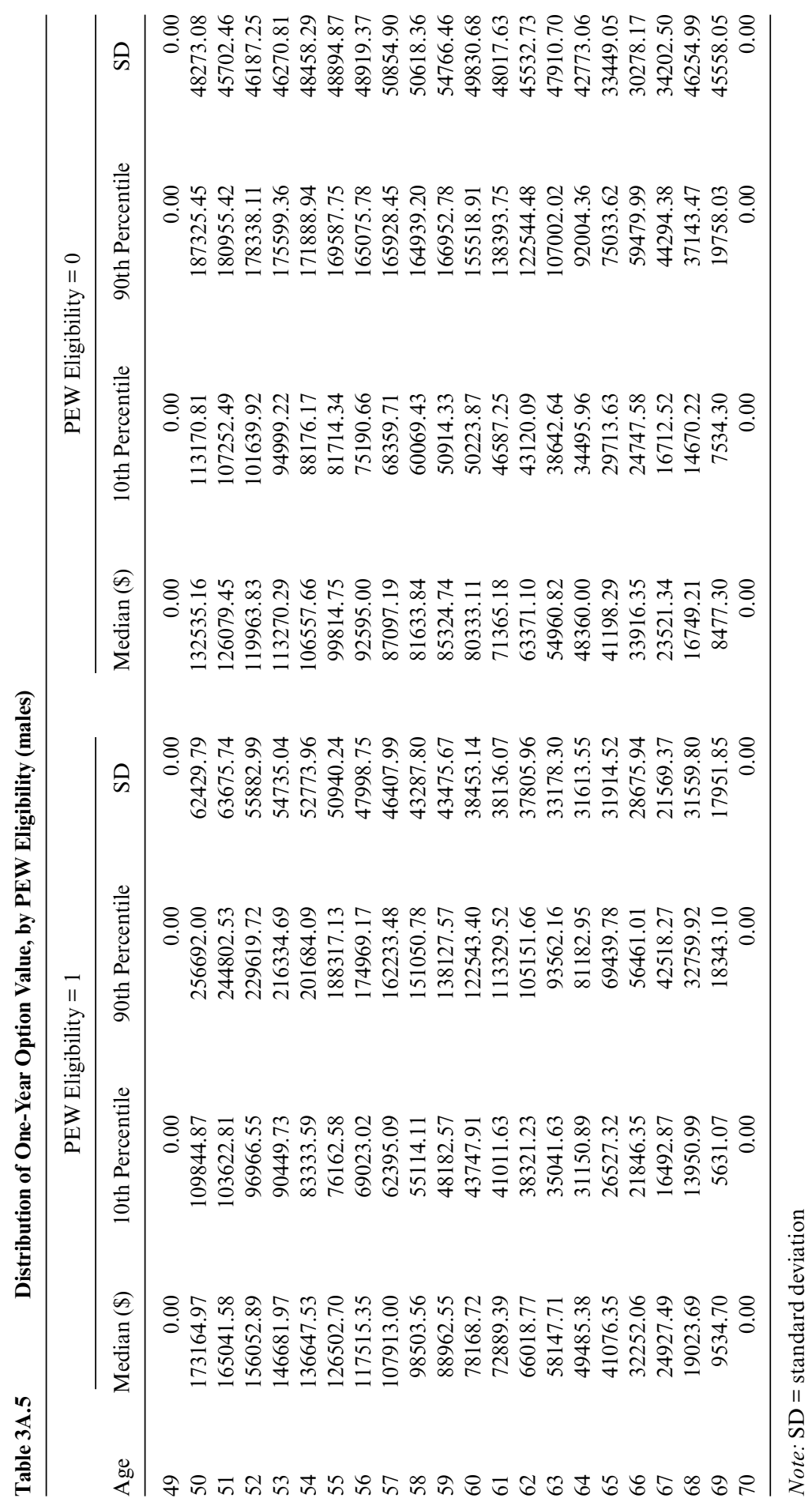


Distribution of One-Year Accrual (females)

\begin{tabular}{|c|c|c|c|c|c|c|}
\hline Age & $\begin{array}{l}\text { Median } \\
\text { SSW } \\
(\$)\end{array}$ & $\begin{array}{l}\text { Median } \\
(\$)\end{array}$ & $\begin{array}{c}10 \text { th } \\
\text { Percentile } \\
(\$)\end{array}$ & $\begin{array}{c}90 \text { th } \\
\text { Percentile } \\
(\$)\end{array}$ & SD & $\begin{array}{l}\text { Median } \\
\text { Tax } \\
\text { Rate }\end{array}$ \\
\hline 49 & 158875.05 & - & - & - & 0.00 & - \\
\hline 50 & 163250.86 & 3778.25 & 2148.21 & 4875.30 & 1037.87 & -0.171 \\
\hline 51 & 167168.27 & 3629.19 & 1824.48 & 4587.98 & 1113.12 & -0.162 \\
\hline 52 & 170994.97 & 3474.39 & 1609.57 & 4594.31 & 1190.89 & -0.156 \\
\hline 53 & 174423.78 & 3494.22 & 1463.80 & 4563.17 & 1287.50 & -0.153 \\
\hline 54 & 177859.48 & 3567.14 & 1282.34 & 4799.66 & 1409.93 & -0.154 \\
\hline 55 & 180839.23 & 3430.91 & 1127.76 & 4745.67 & 1482.65 & -0.157 \\
\hline 56 & 183404.34 & 3137.95 & 597.71 & 4329.91 & 2210.97 & -0.138 \\
\hline 57 & 185599.83 & 2974.00 & 38.72 & 4210.06 & 2362.08 & -0.128 \\
\hline 58 & 187222.30 & 2525.63 & -782.88 & 4010.81 & 2439.66 & -0.117 \\
\hline 59 & 187168.89 & 2036.66 & -1361.98 & 3870.95 & 2464.56 & -0.104 \\
\hline 60 & 186051.48 & 1506.25 & -1685.02 & 3618.73 & 2632.93 & -0.085 \\
\hline 61 & 127766.96 & -3049.71 & -13152.69 & -463.41 & 5261.08 & 0.256 \\
\hline 62 & 121948.33 & -2988.79 & -13205.45 & -354.95 & 4920.24 & 0.262 \\
\hline 63 & 110386.89 & -3318.54 & -13535.91 & -1270.05 & 4588.36 & 0.296 \\
\hline 64 & 102262.80 & -3635.62 & -11325.13 & -1862.73 & 3625.02 & 0.341 \\
\hline 65 & 97501.88 & -4370.25 & -11328.67 & -2338.30 & 3425.55 & 0.401 \\
\hline 66 & 91118.83 & -5056.95 & -9928.78 & -2427.97 & 3139.08 & 0.492 \\
\hline 67 & 101632.31 & 15095.95 & -9779.96 & 21295.80 & 11449.18 & -1.219 \\
\hline 68 & 97780.57 & -759.34 & -3172.29 & 769.04 & 1958.09 & 0.060 \\
\hline 69 & 94683.20 & -226.01 & -3189.26 & 619.16 & 1838.10 & 0.022 \\
\hline 70 & 92215.84 & 525.07 & -3237.77 & 557.57 & 1872.84 & 0.039 \\
\hline
\end{tabular}

Note: $\mathrm{SD}=$ standard deviation. Dashes indicate that the data is not applicable. 


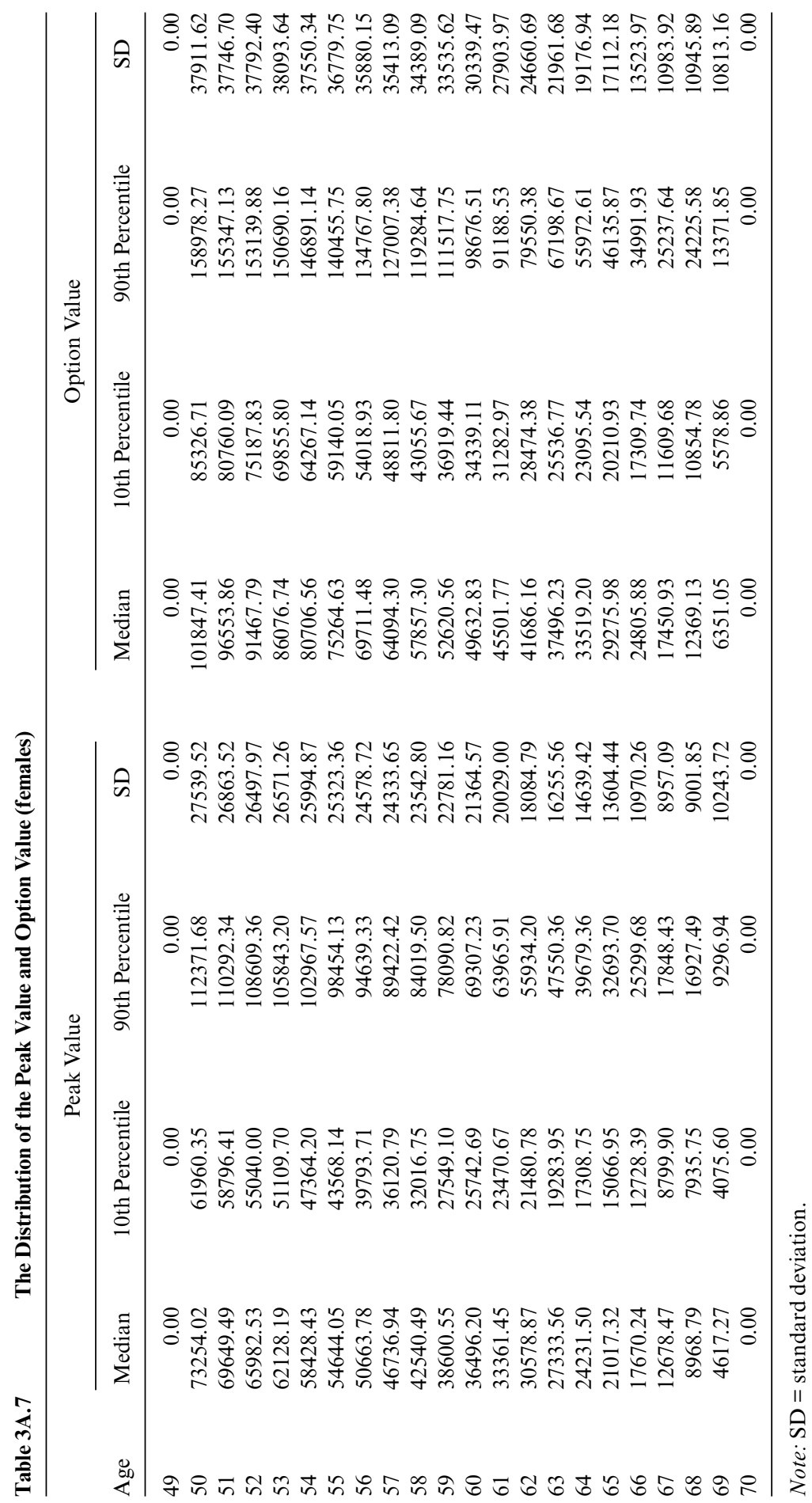




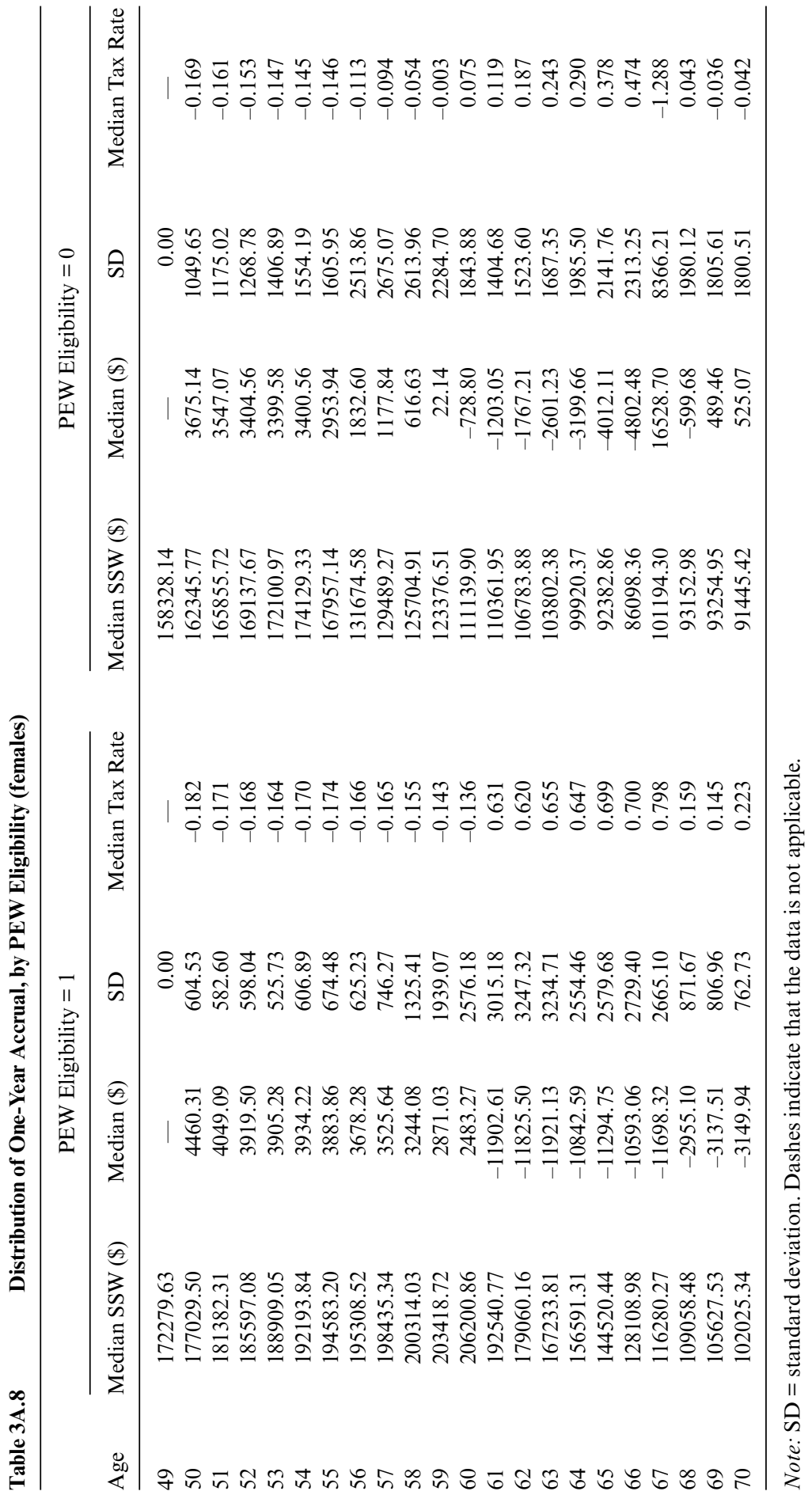




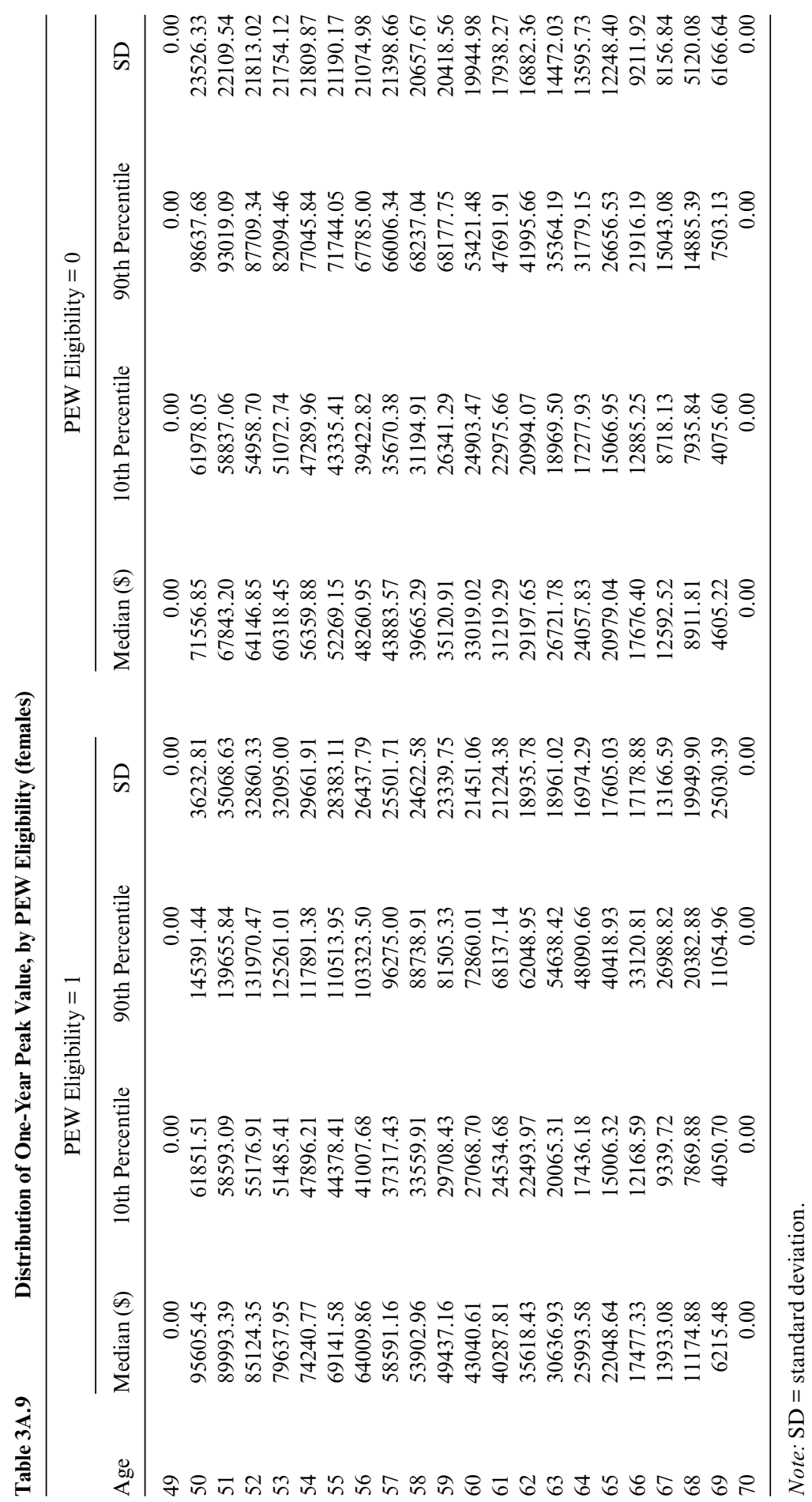




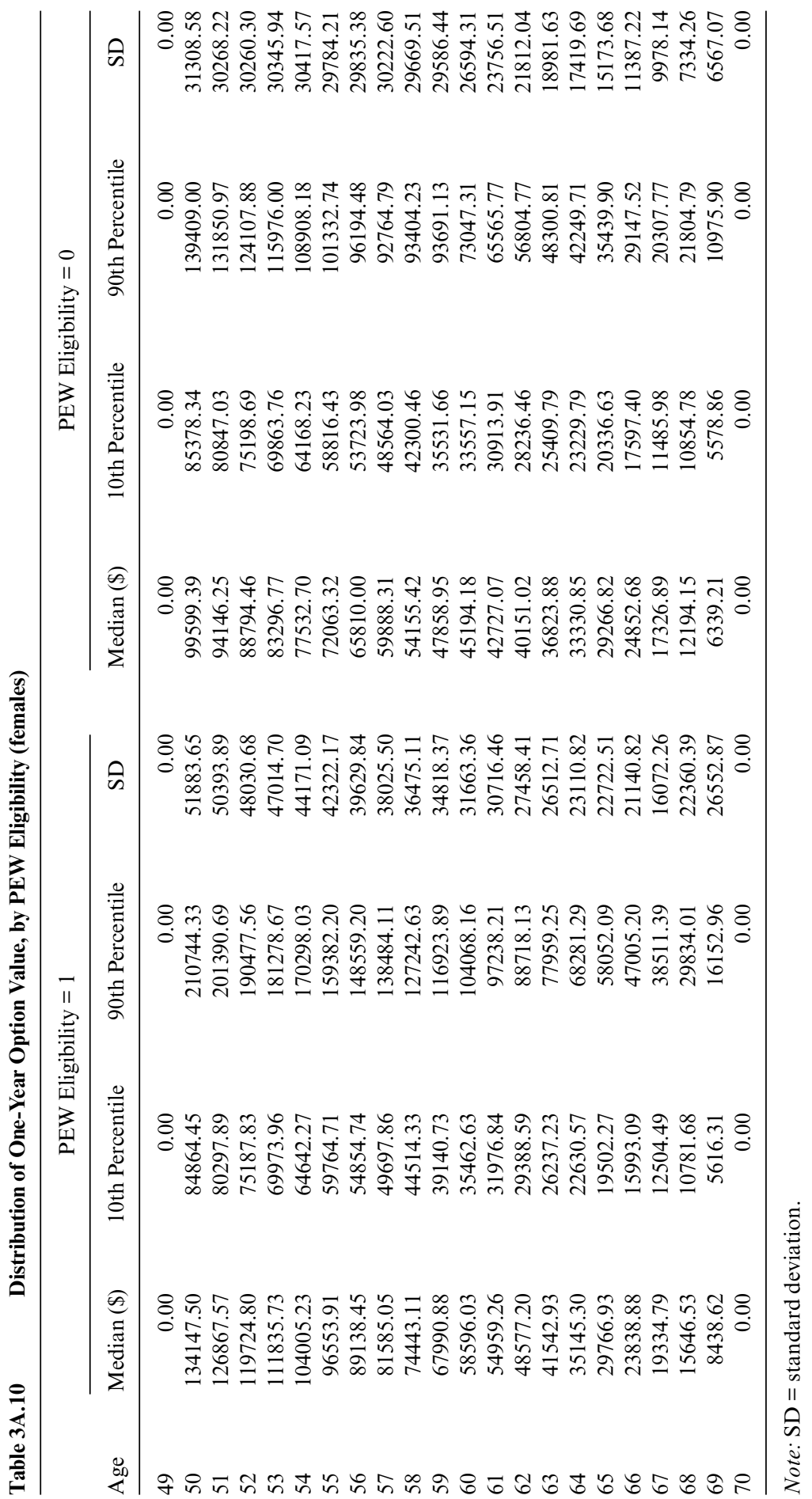




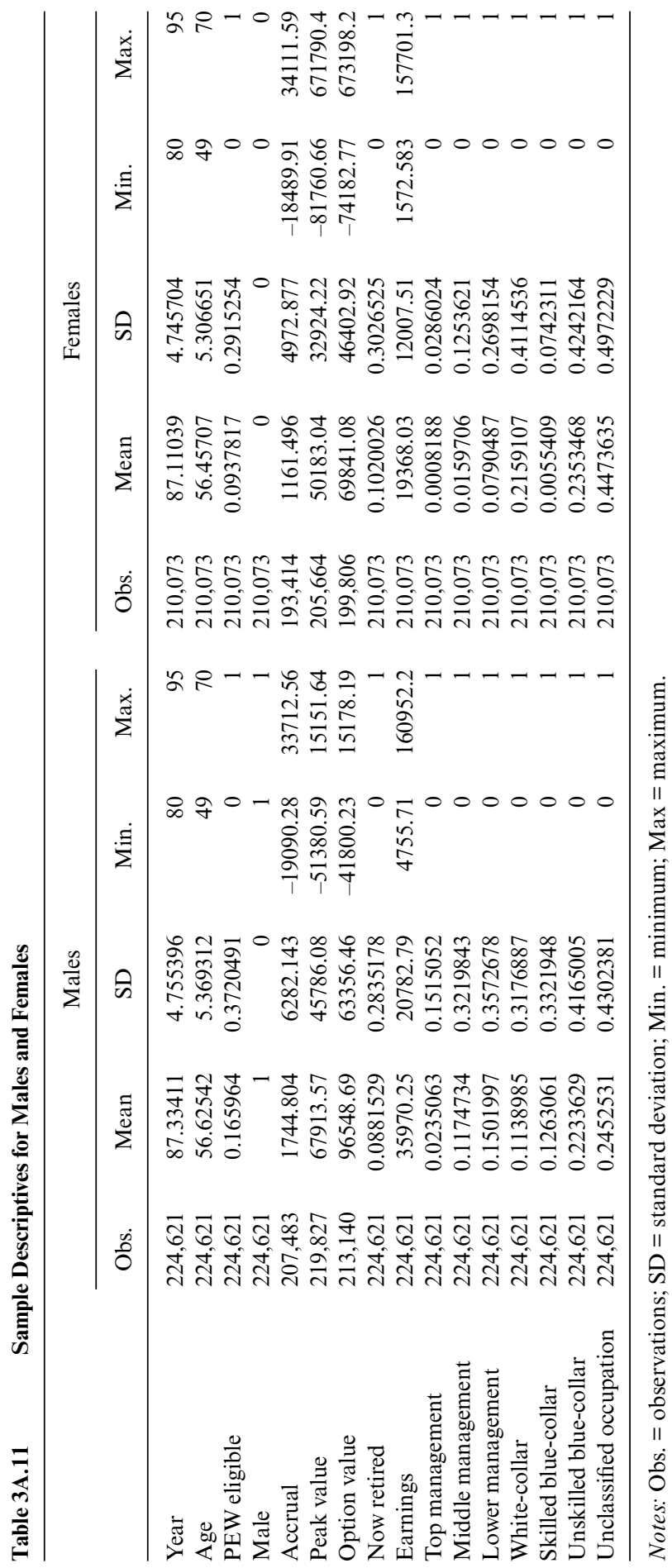




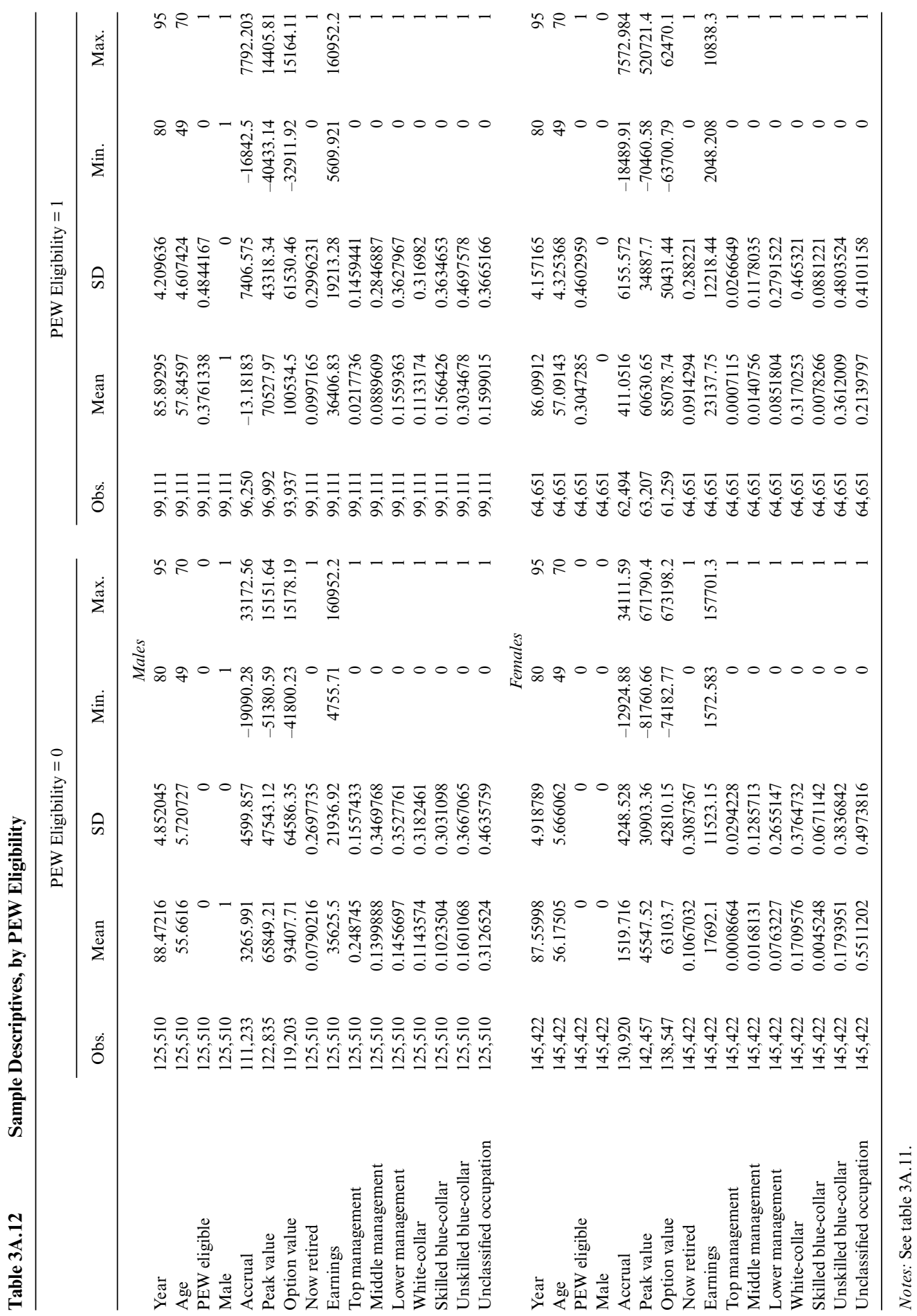




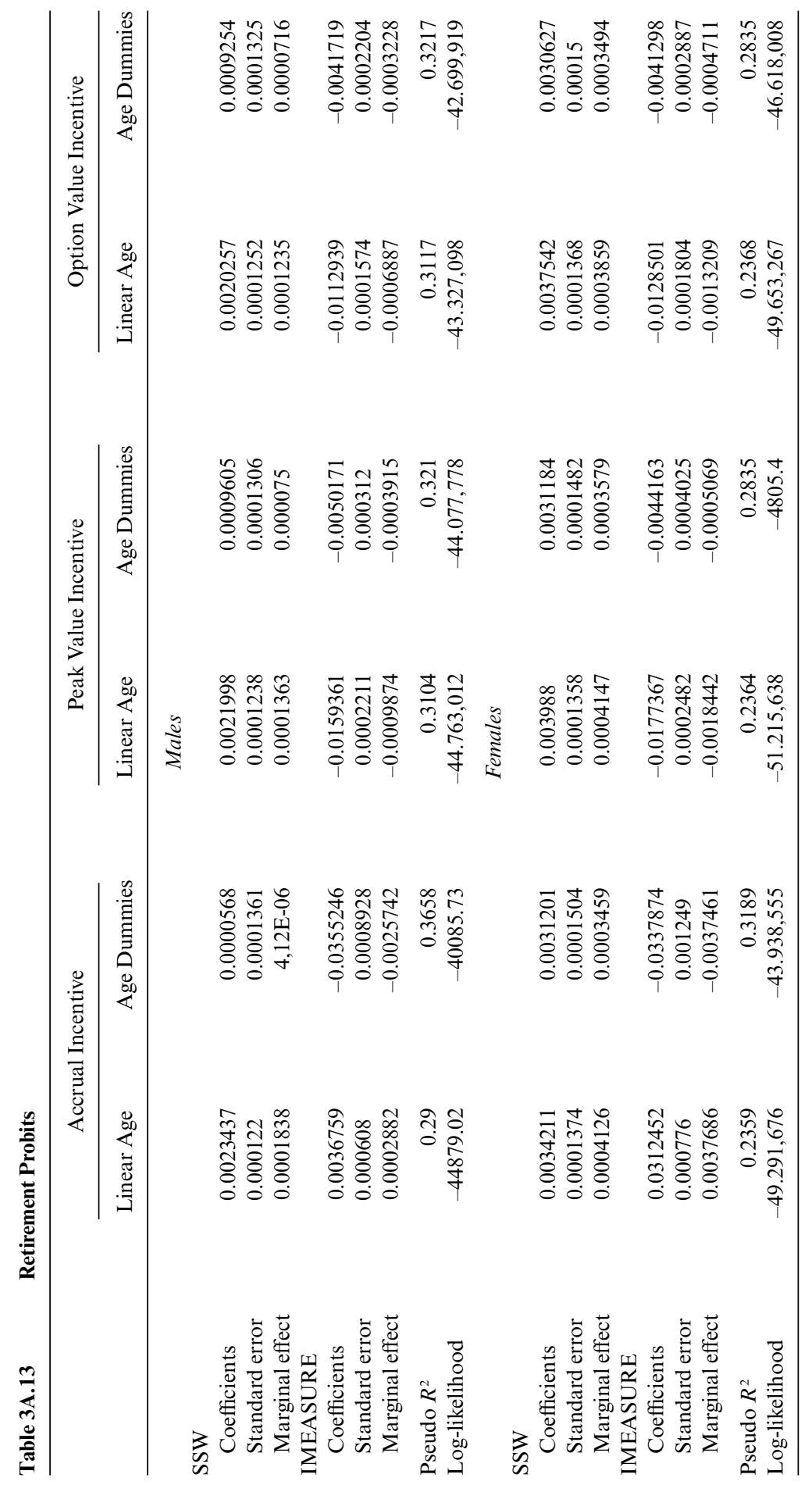




\begin{tabular}{|c|c|c|c|c|c|}
\hline & \multicolumn{5}{|c|}{ Simulated Reform } \\
\hline & Baseline & $\begin{array}{c}\text { Plus Three } \\
\text { Years }\end{array}$ & $\begin{array}{c}\text { Difference } \\
\text { from Baseline }\end{array}$ & $\begin{array}{l}\text { Common } \\
\text { Reform }\end{array}$ & $\begin{array}{c}\text { Difference } \\
\text { from Baseline }\end{array}$ \\
\hline \multicolumn{6}{|c|}{ Males } \\
\hline \multicolumn{6}{|l|}{ Accrual } \\
\hline S1 & 60,44432 & 60,28469 & -0.15963 & 6,38432 & -0.06000 \\
\hline $\mathrm{S} 2$ & 60,27340 & 60,63449 & +0.37009 & 60,95542 & +0.68202 \\
\hline S3 & 60,27340 & 62,28802 & +2.01462 & 59,60625 & -0.66715 \\
\hline \multicolumn{6}{|c|}{ Peak value } \\
\hline $\mathrm{S} 1$ & 60,76490 & 62,12958 & +1.36468 & 61,18836 & +0.42346 \\
\hline $\mathrm{S} 2$ & 60,68337 & 61,23892 & +0.55555 & 61,08496 & +0.40159 \\
\hline S3 & 60,68337 & 62,57302 & +1.88965 & 60,09098 & -0.59239 \\
\hline \multicolumn{6}{|c|}{ Option value } \\
\hline S1 & 60,77458 & 62,16372 & +1.38914 & 61,23221 & +0.45763 \\
\hline $\mathrm{S} 2$ & 60,69852 & 61,32813 & +0.62961 & 61,13278 & +0.43426 \\
\hline S3 & 60,69852 & 62,59626 & +1.89774 & 60,14049 & -0.55803 \\
\hline \multicolumn{6}{|c|}{ Females } \\
\hline \multicolumn{6}{|c|}{ Accrual } \\
\hline $\mathrm{S} 1$ & 60,44432 & 60,28469 & -0.15963 & 60,38432 & -0.06000 \\
\hline $\mathrm{S} 2$ & 60,27340 & 60,64349 & +0.37009 & 60,95542 & +0.68202 \\
\hline S3 & 60,27340 & 62,28802 & +2.01462 & 59,60625 & -0.66715 \\
\hline \multicolumn{6}{|c|}{ Peak value } \\
\hline $\mathrm{S} 1$ & 60,76490 & 62,12958 & +1.36468 & 61,18836 & +0.42346 \\
\hline S2 & 60,68337 & 61,23892 & +0.55555 & 61,08496 & +0.40159 \\
\hline S3 & 60,68337 & 62,57302 & +1.88965 & 60,09098 & -0.59239 \\
\hline \multicolumn{6}{|c|}{ Option value } \\
\hline S1 & 60,77458 & 62,16372 & +1.38914 & 61,23221 & +0.45763 \\
\hline $\mathrm{S} 2$ & 60,69852 & 61,32813 & +0.62961 & 61,13278 & +0.43426 \\
\hline $\mathrm{S} 3$ & 60,69852 & 62,59626 & +1.89774 & 60,14049 & -0.55803 \\
\hline
\end{tabular}




\section{Appendix B}

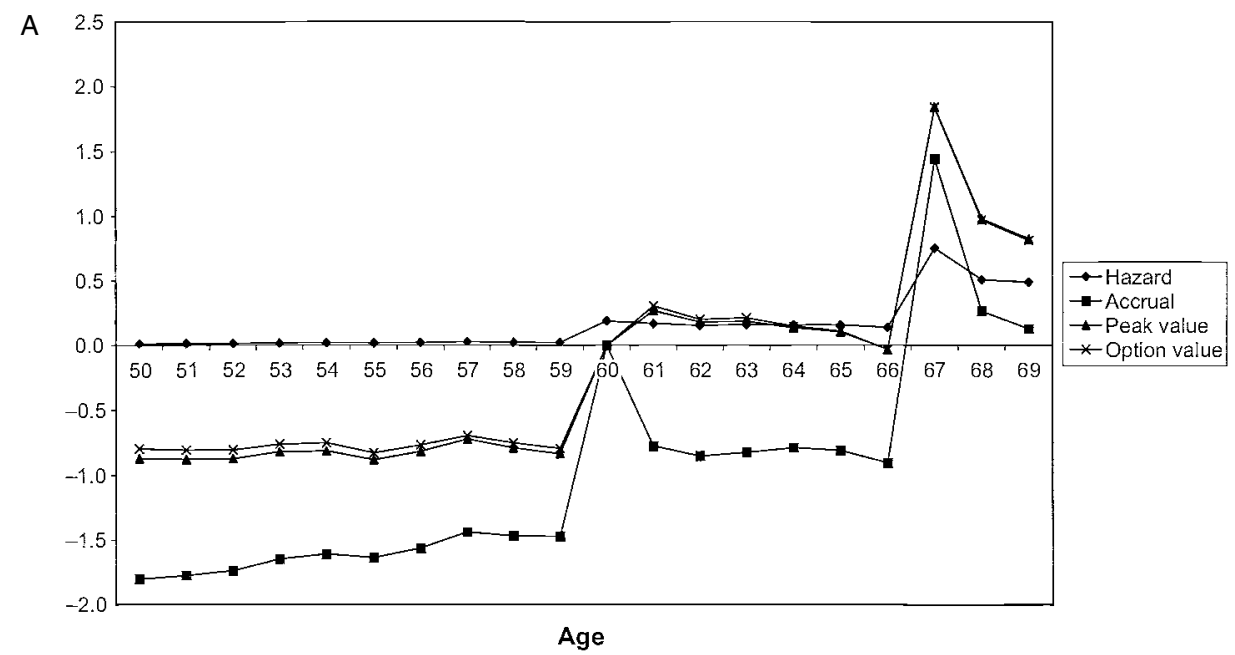

B

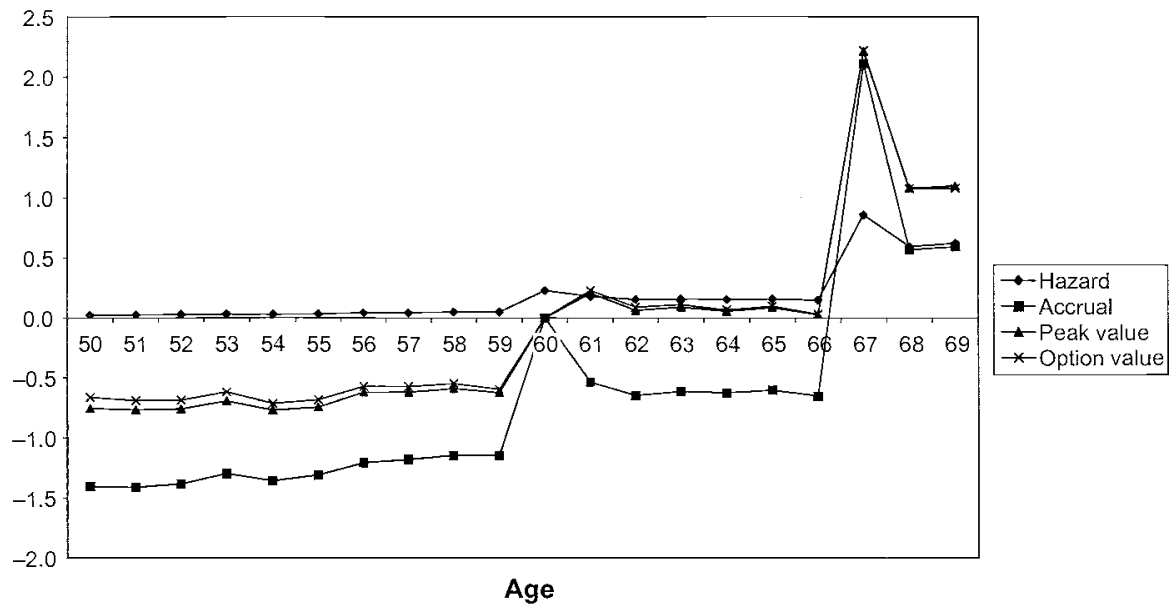

Fig. 3B.1 The retirement hazard and age dummies: $A$, Males; $B$, Females 


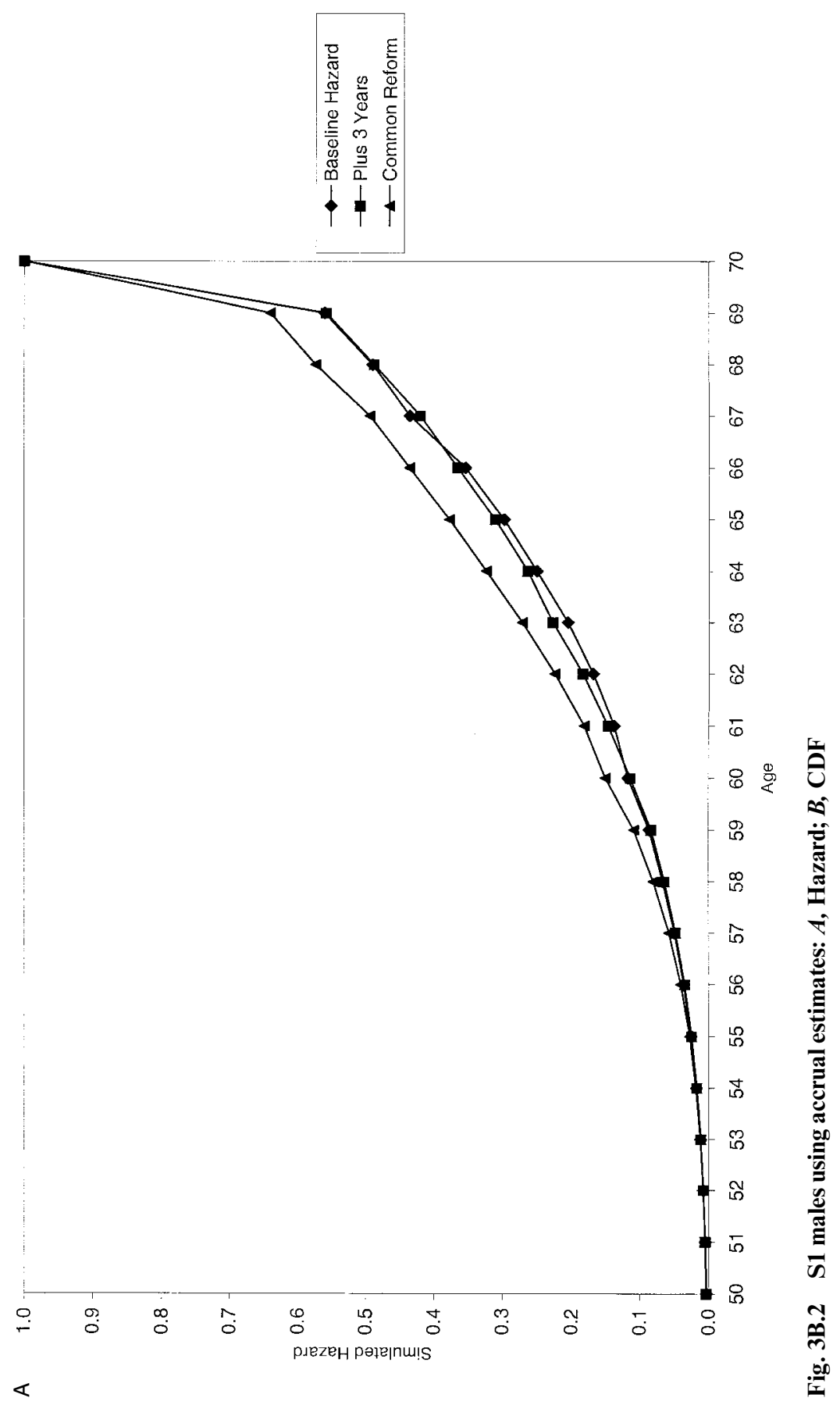




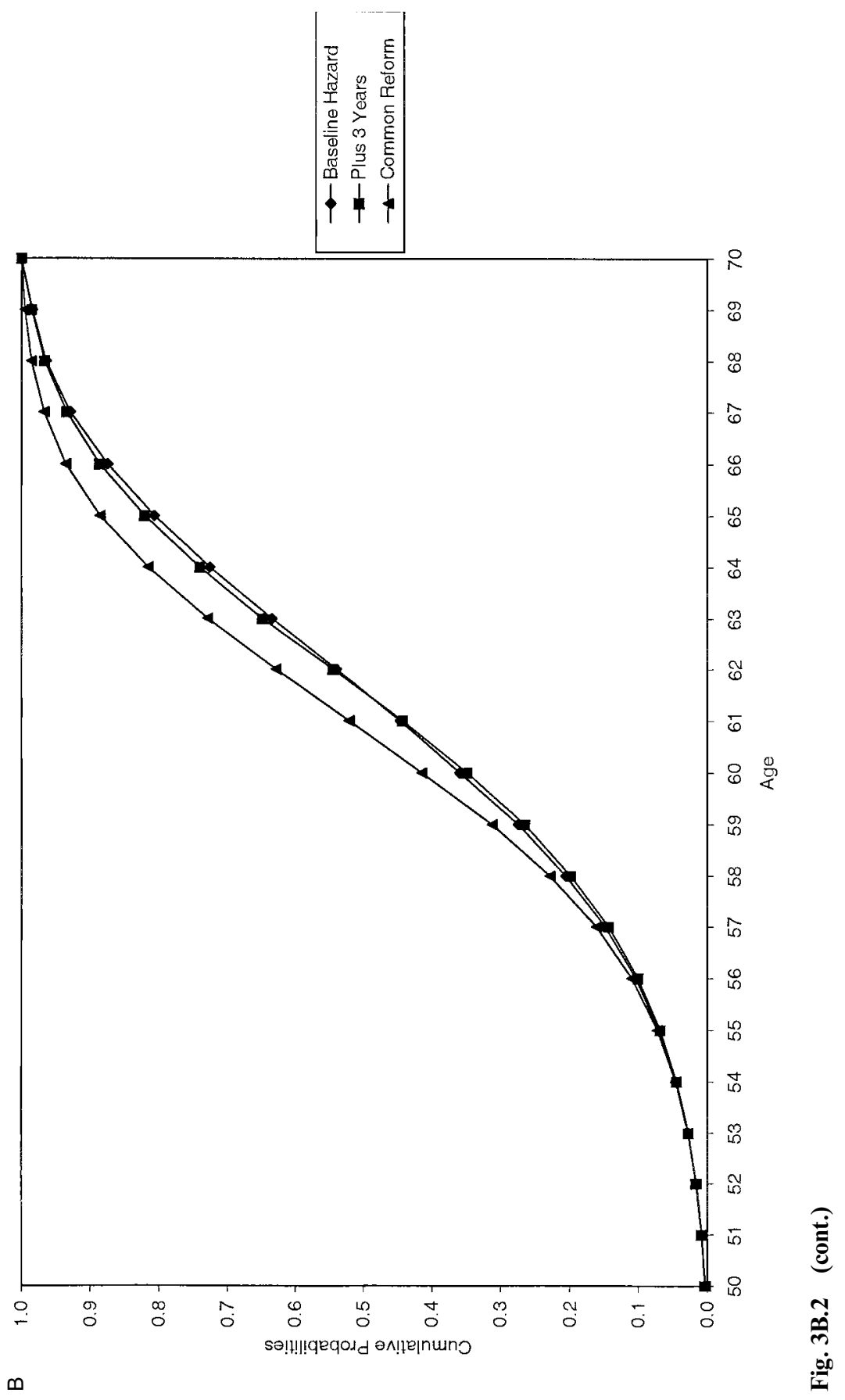




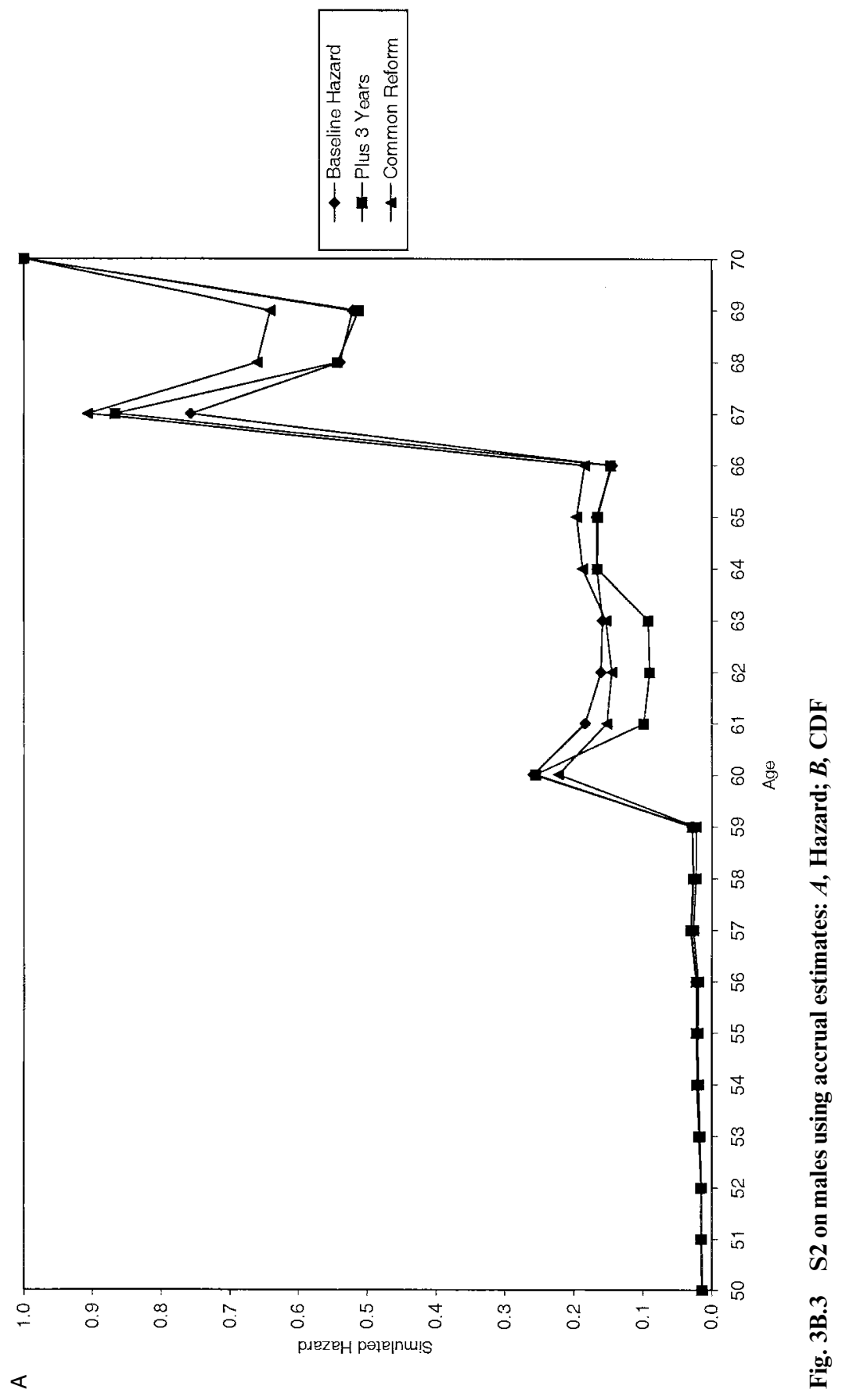




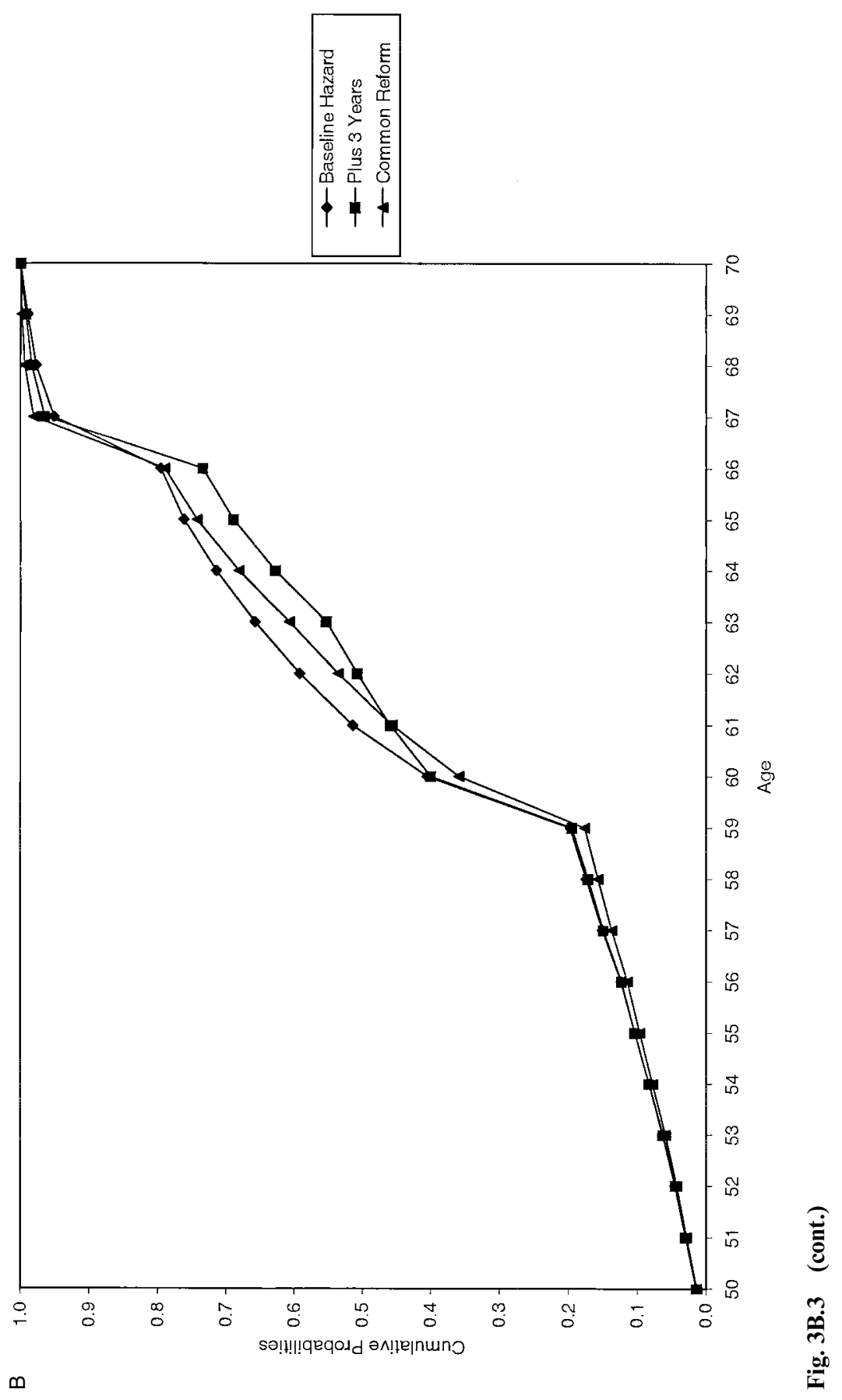




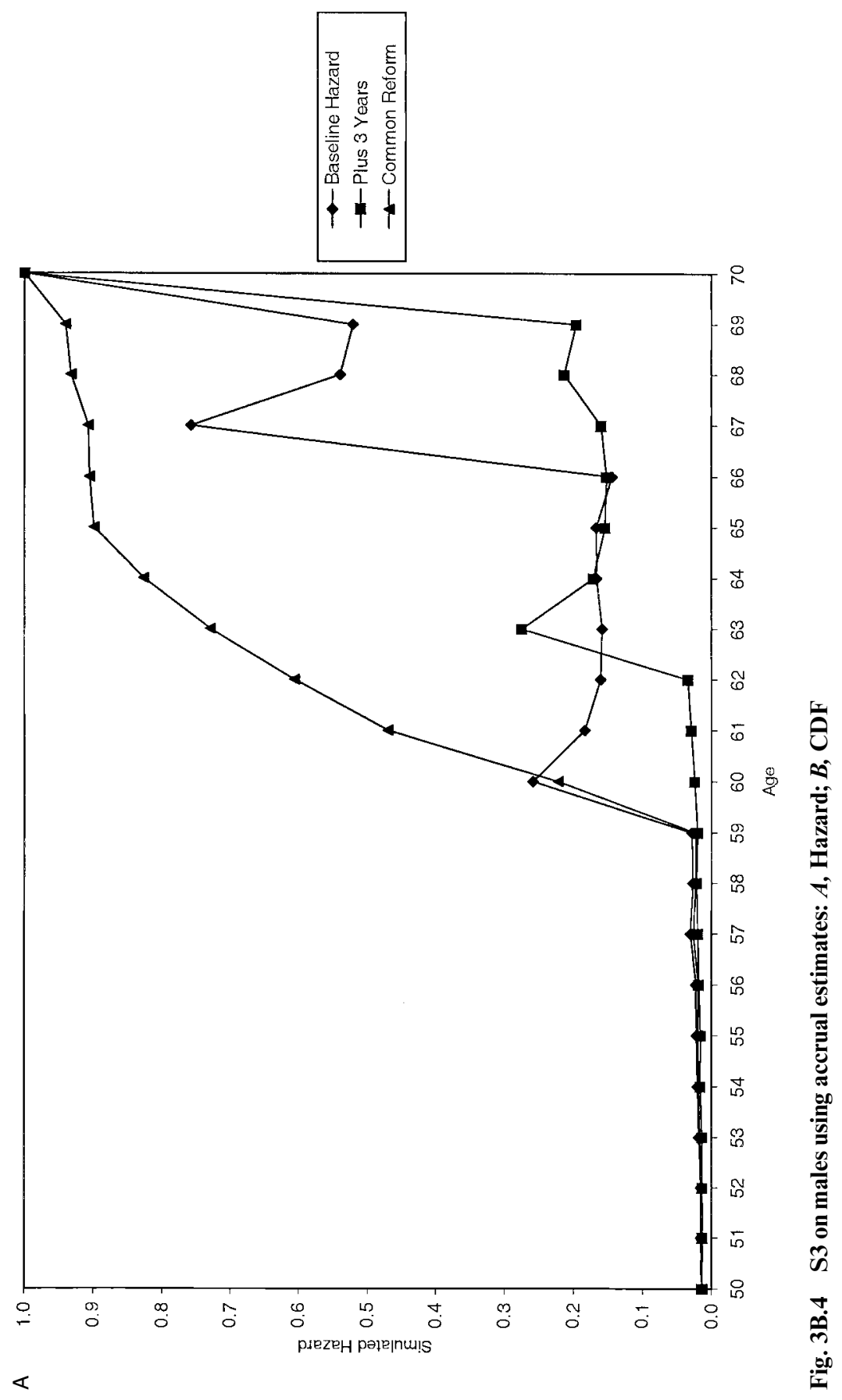




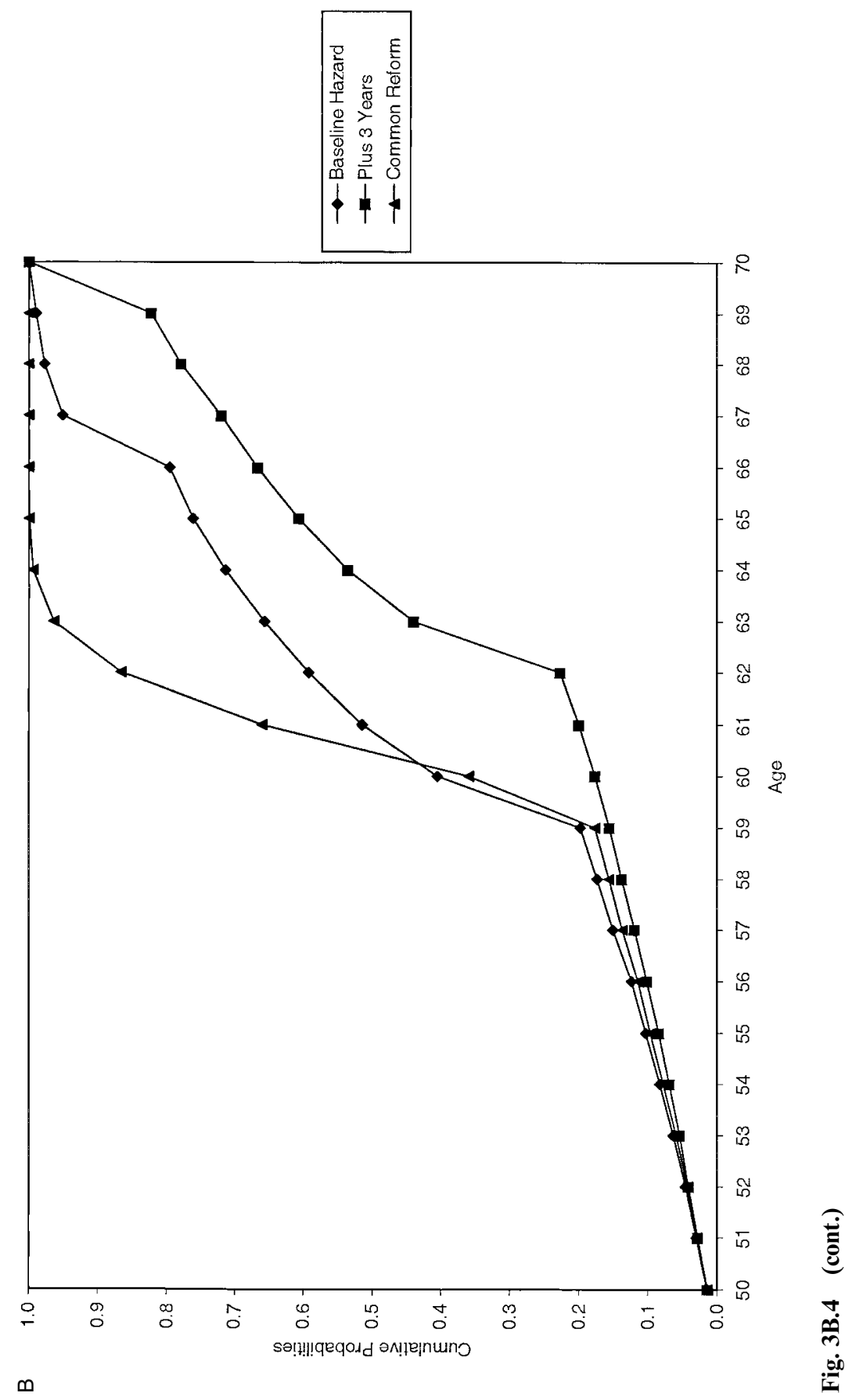




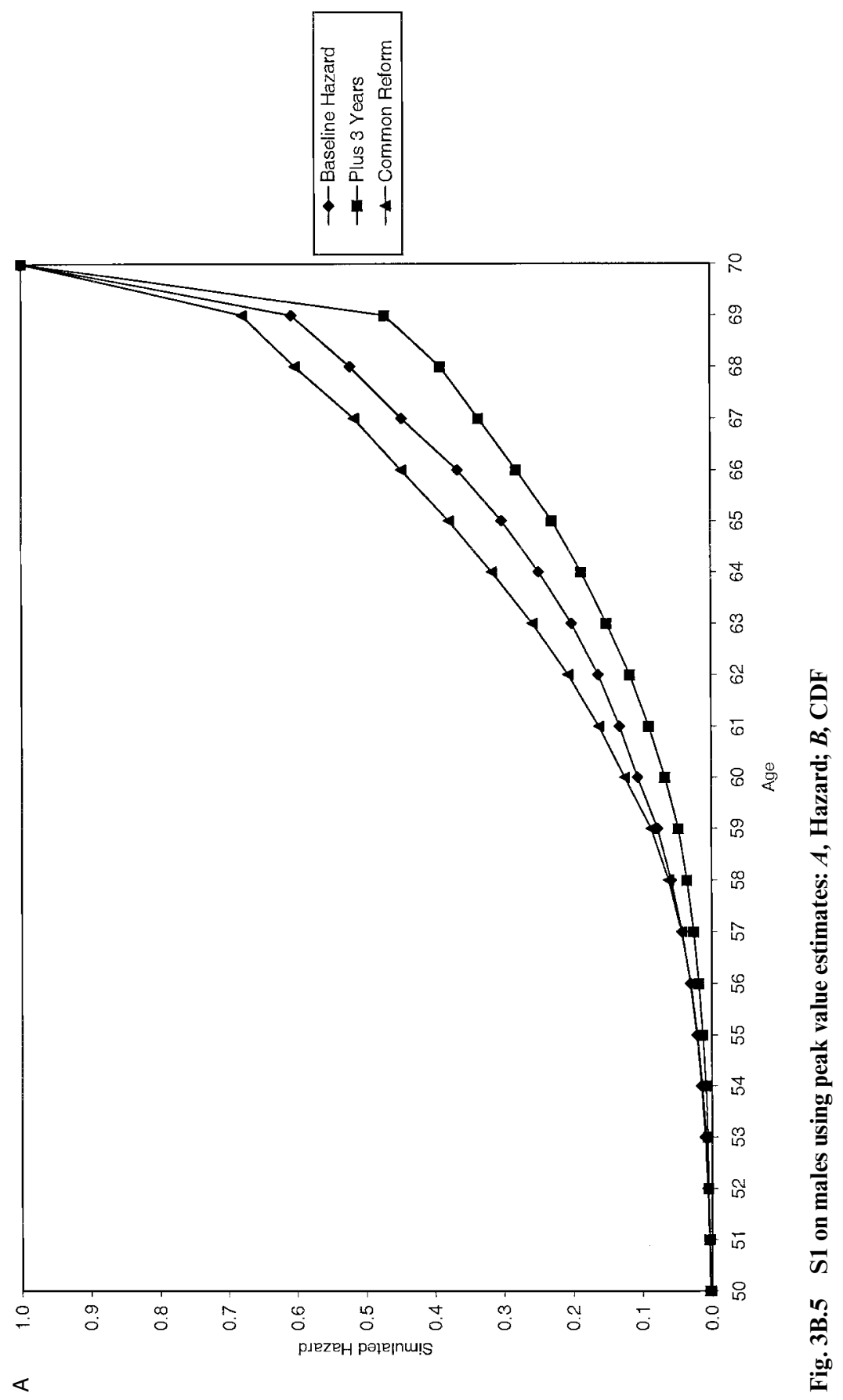




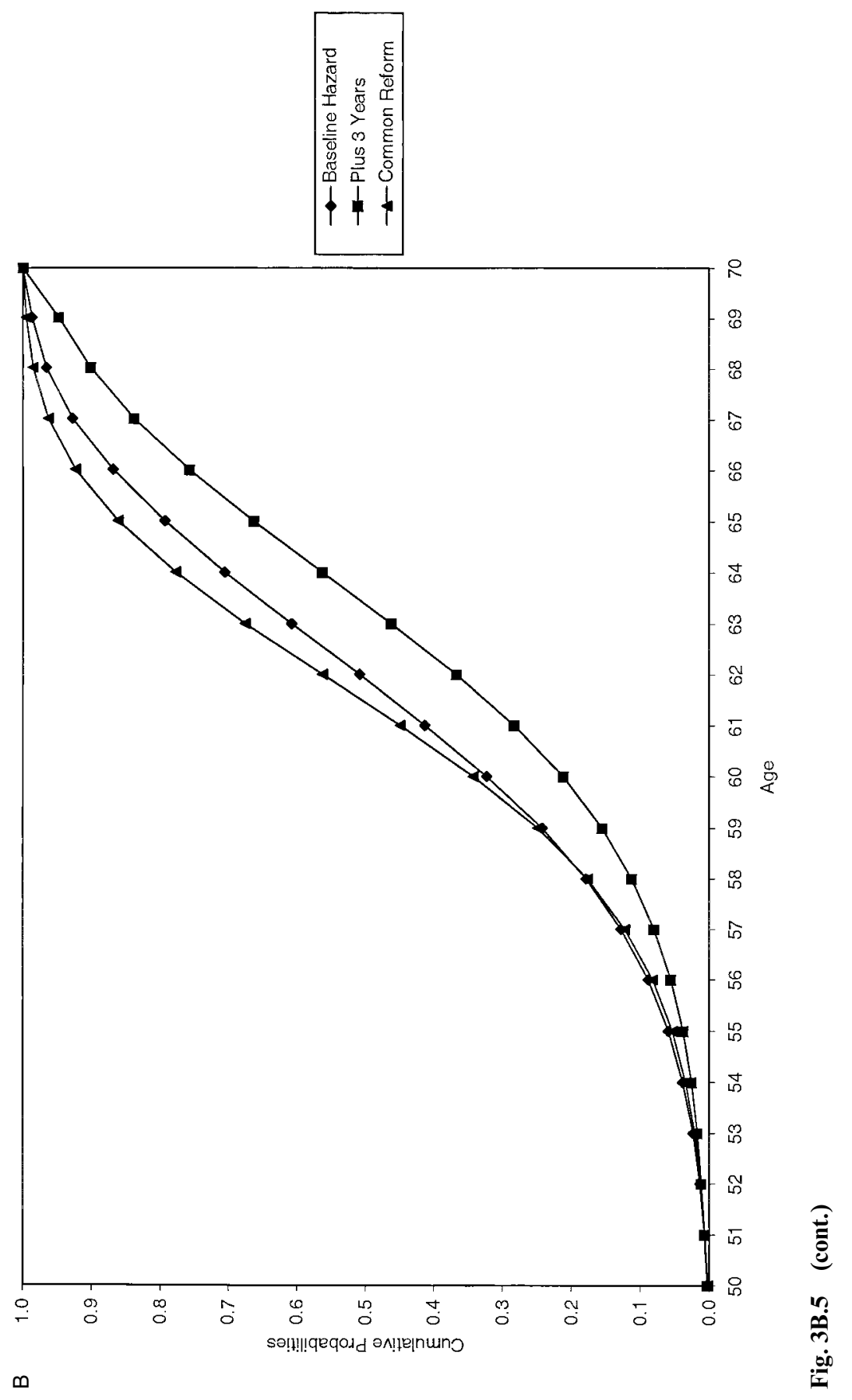




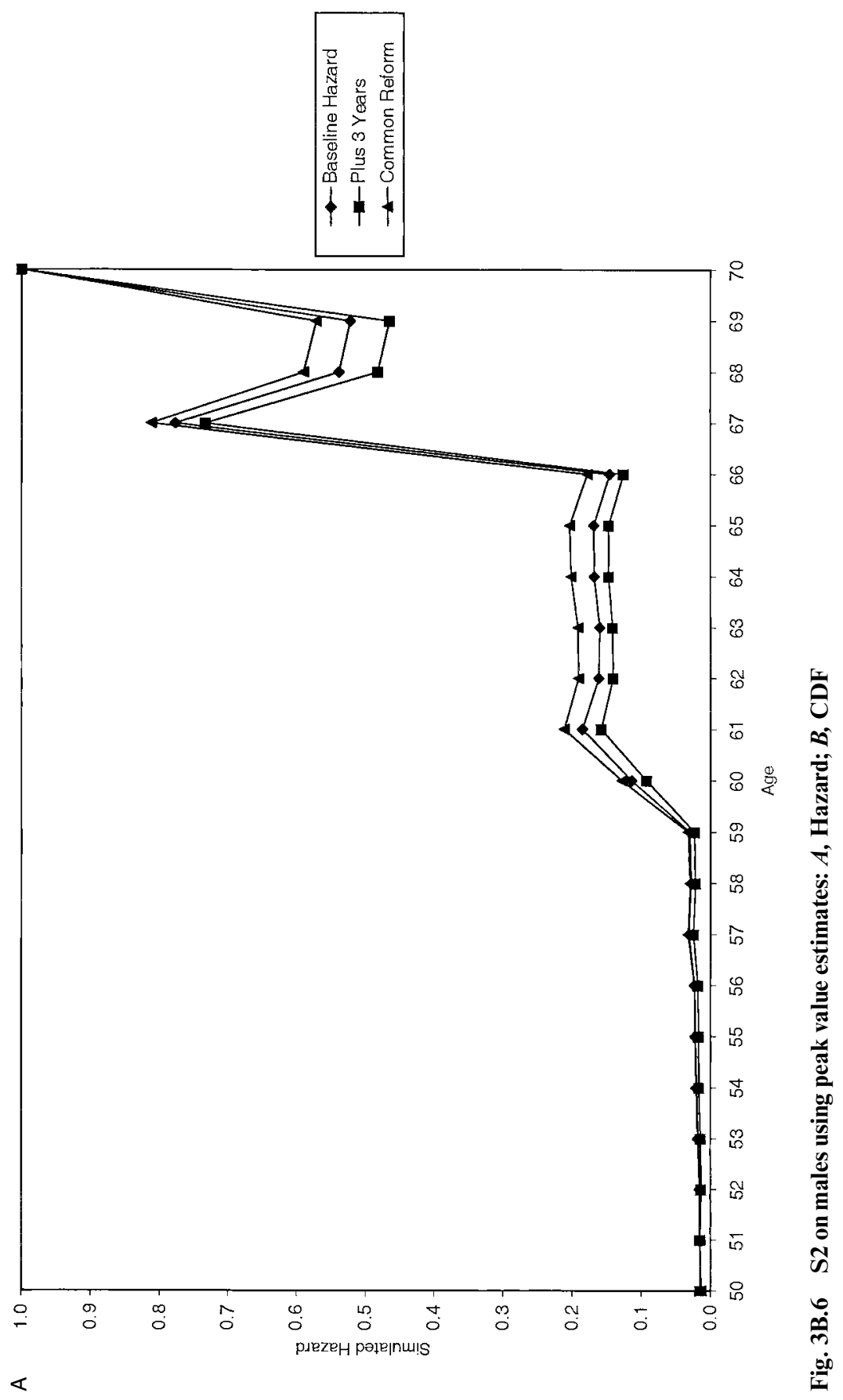




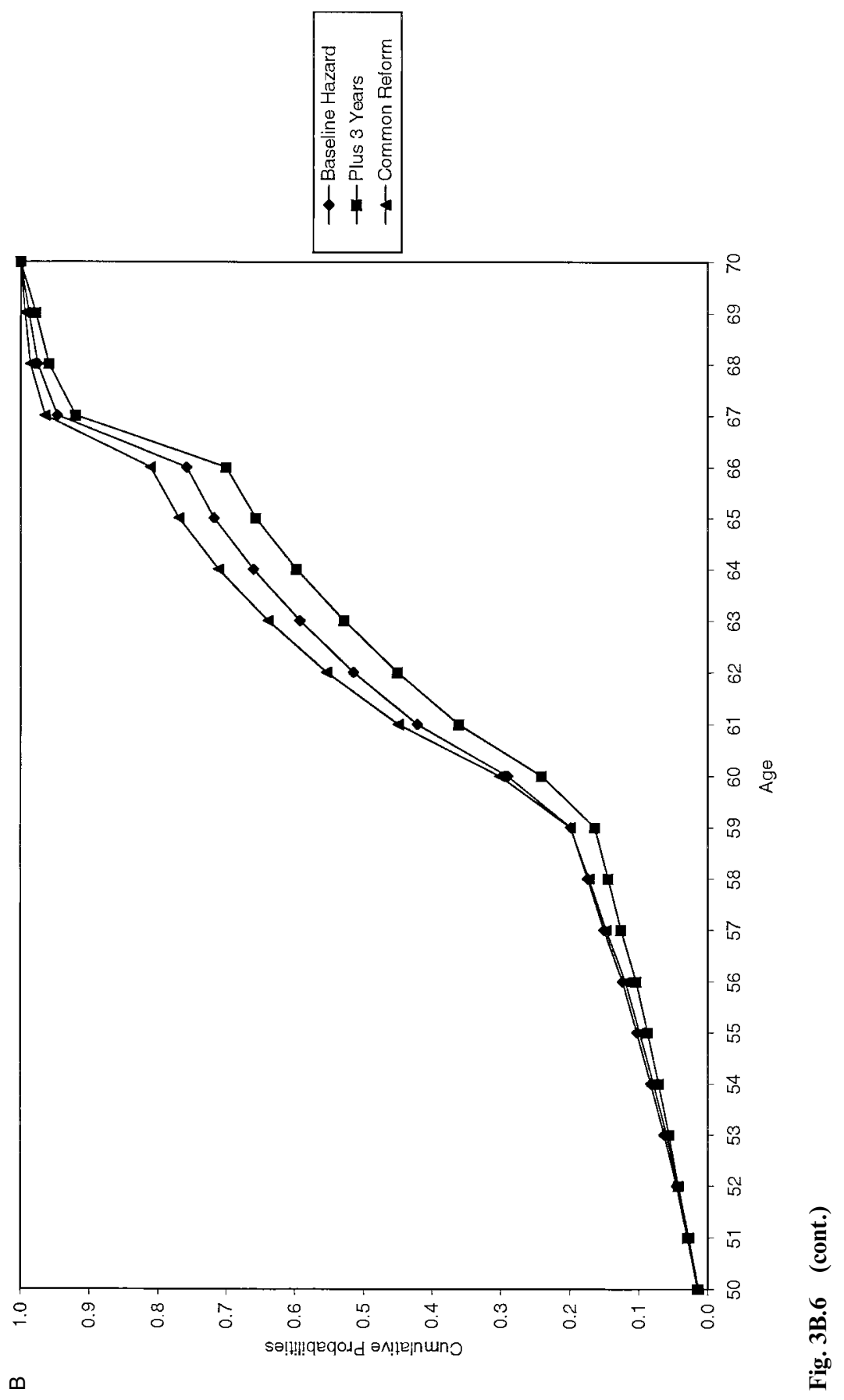




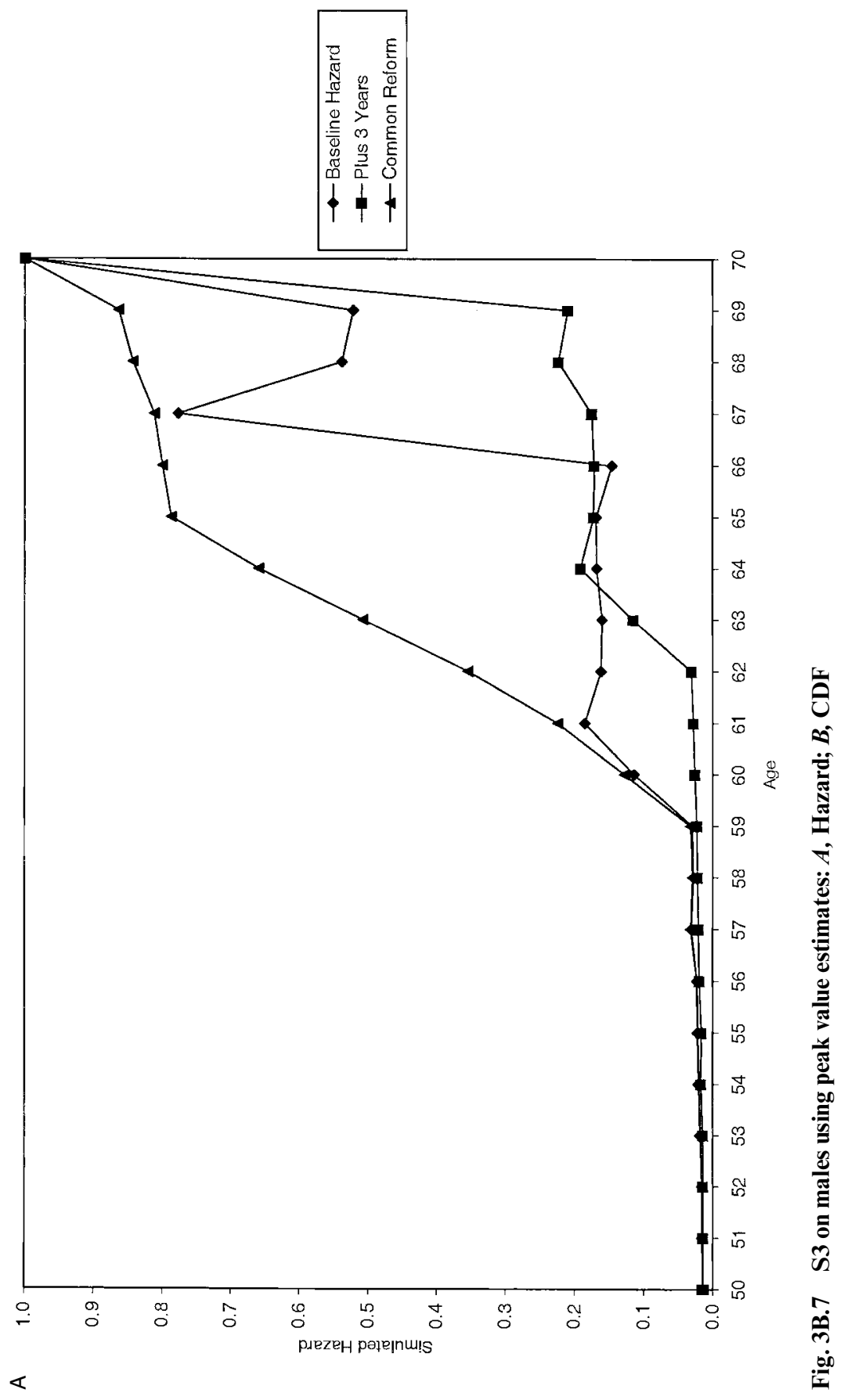




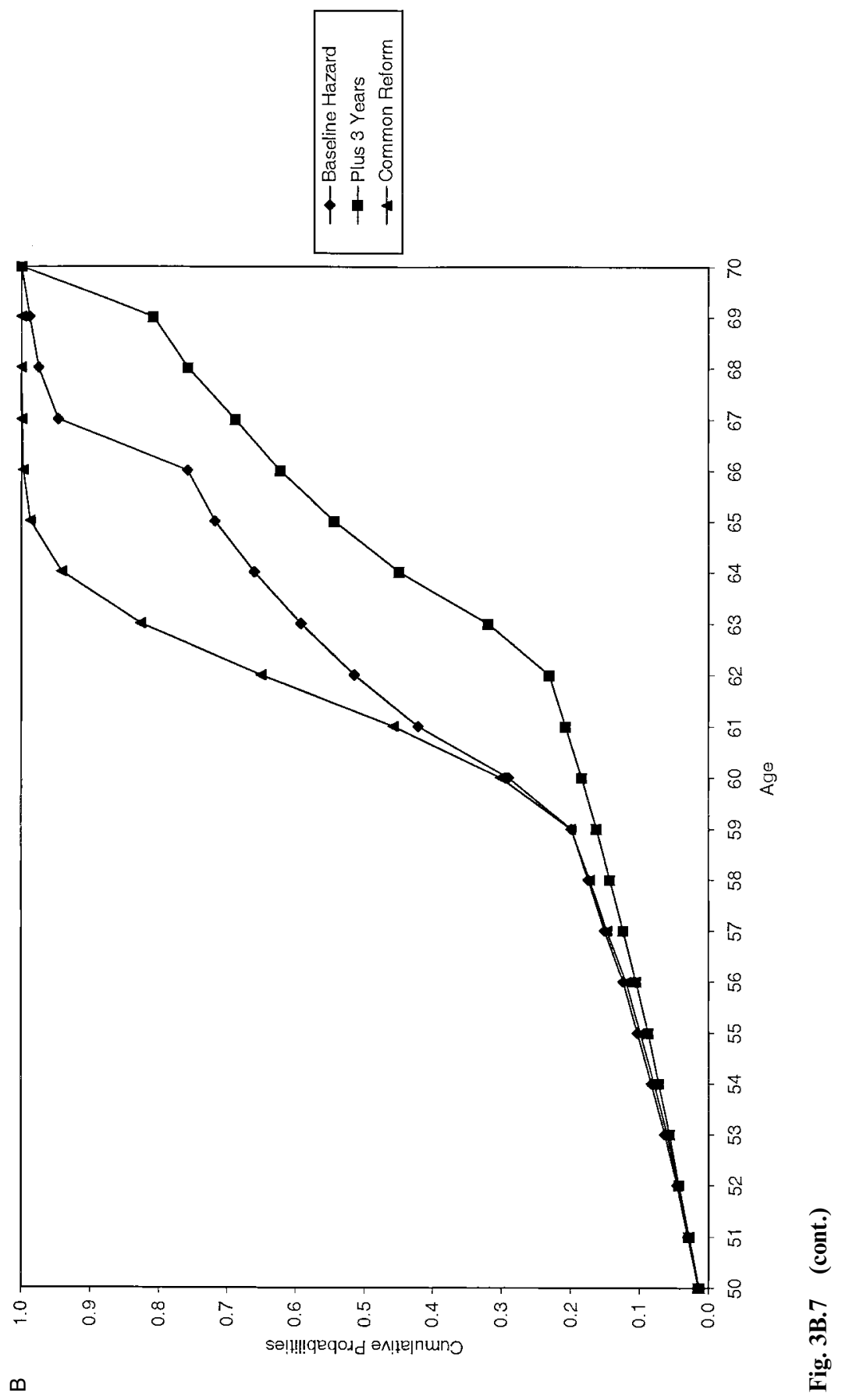




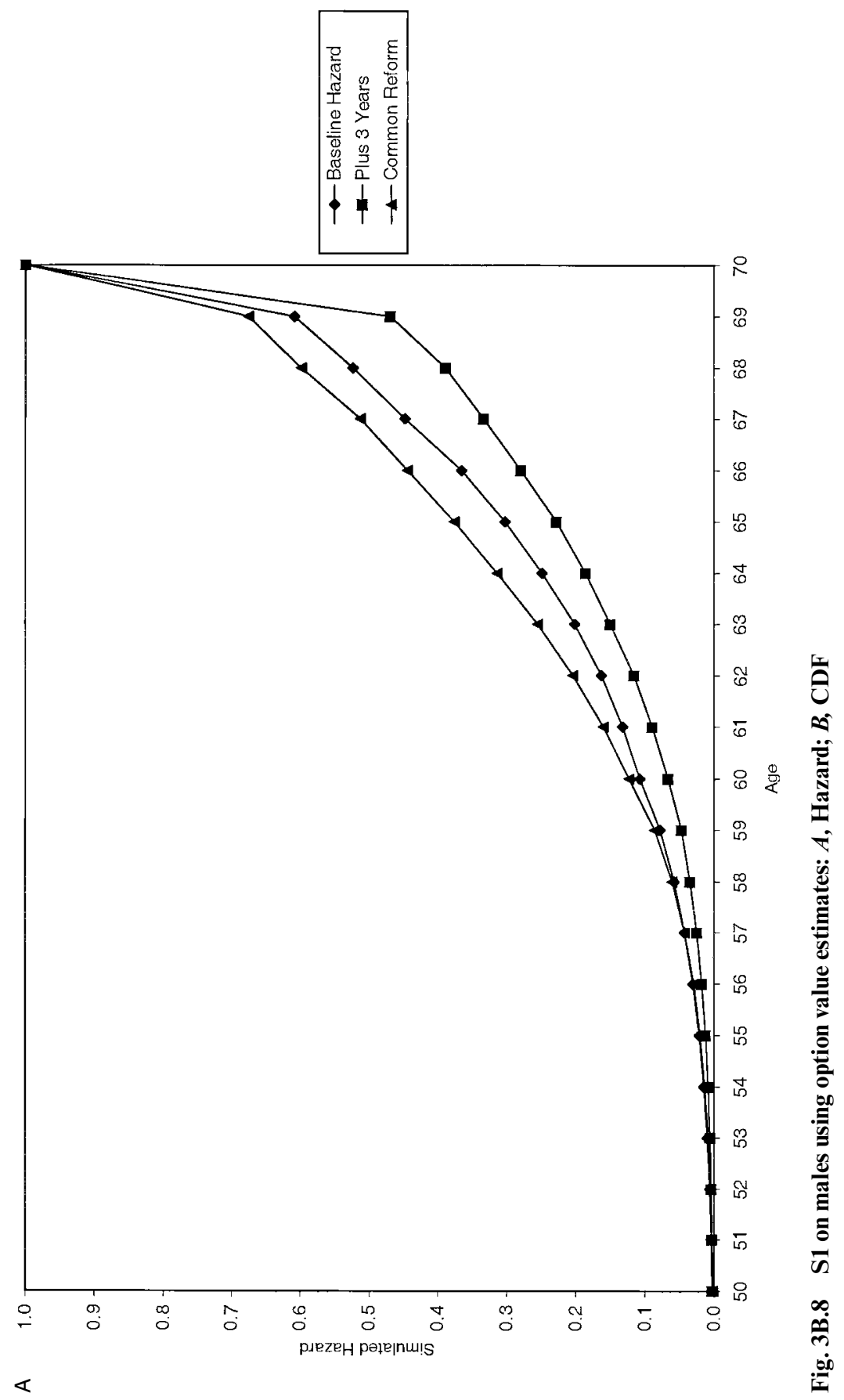




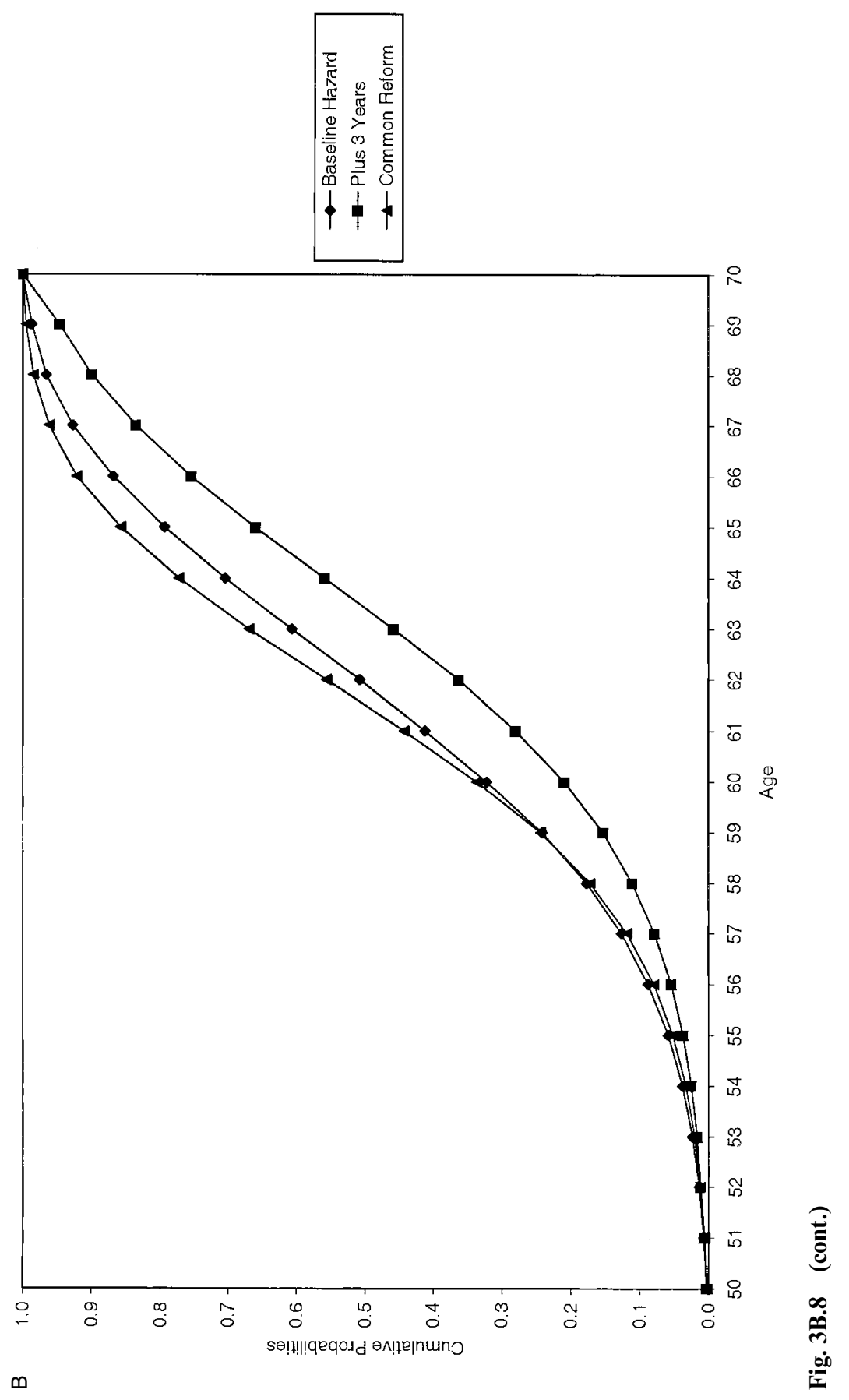




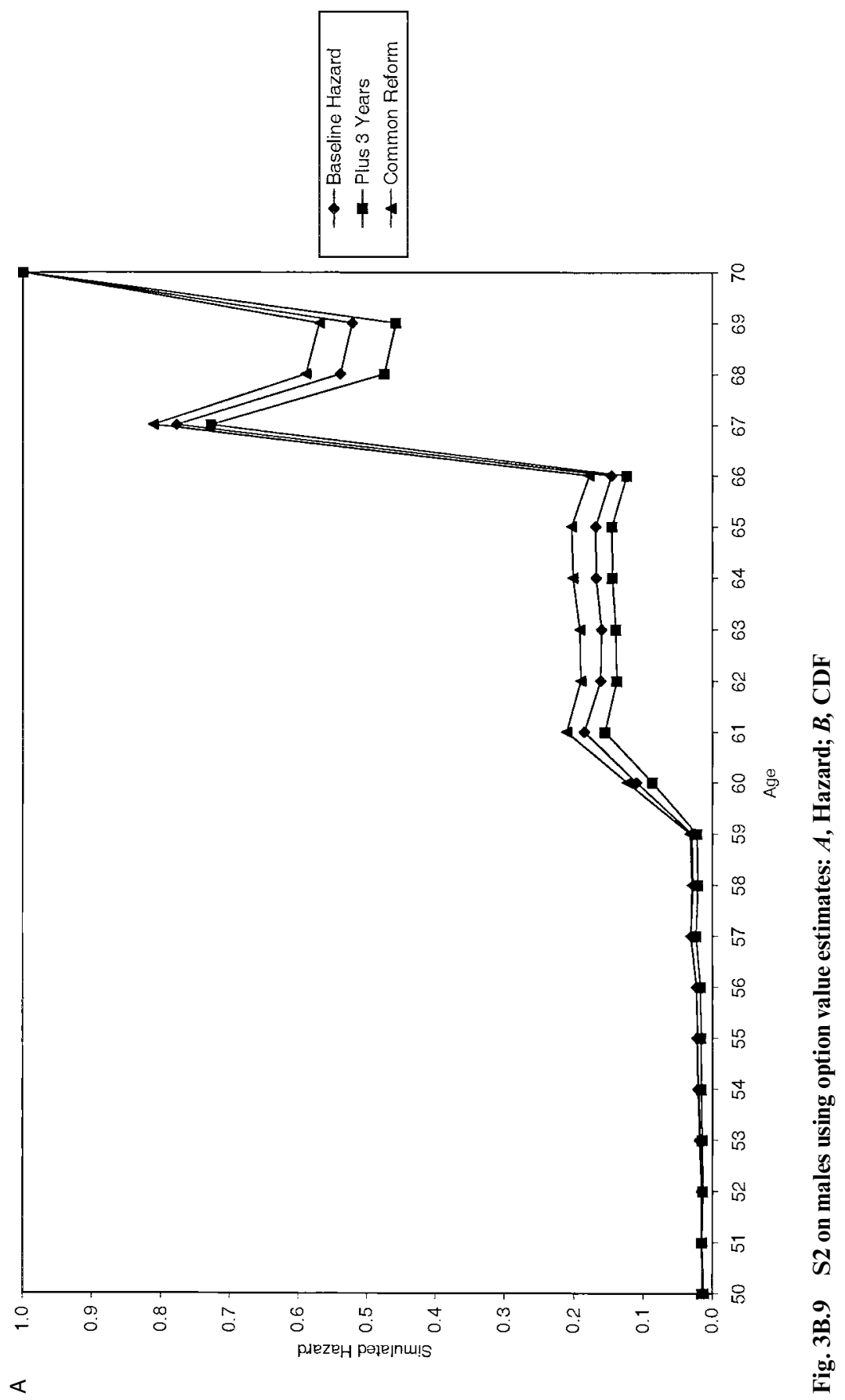




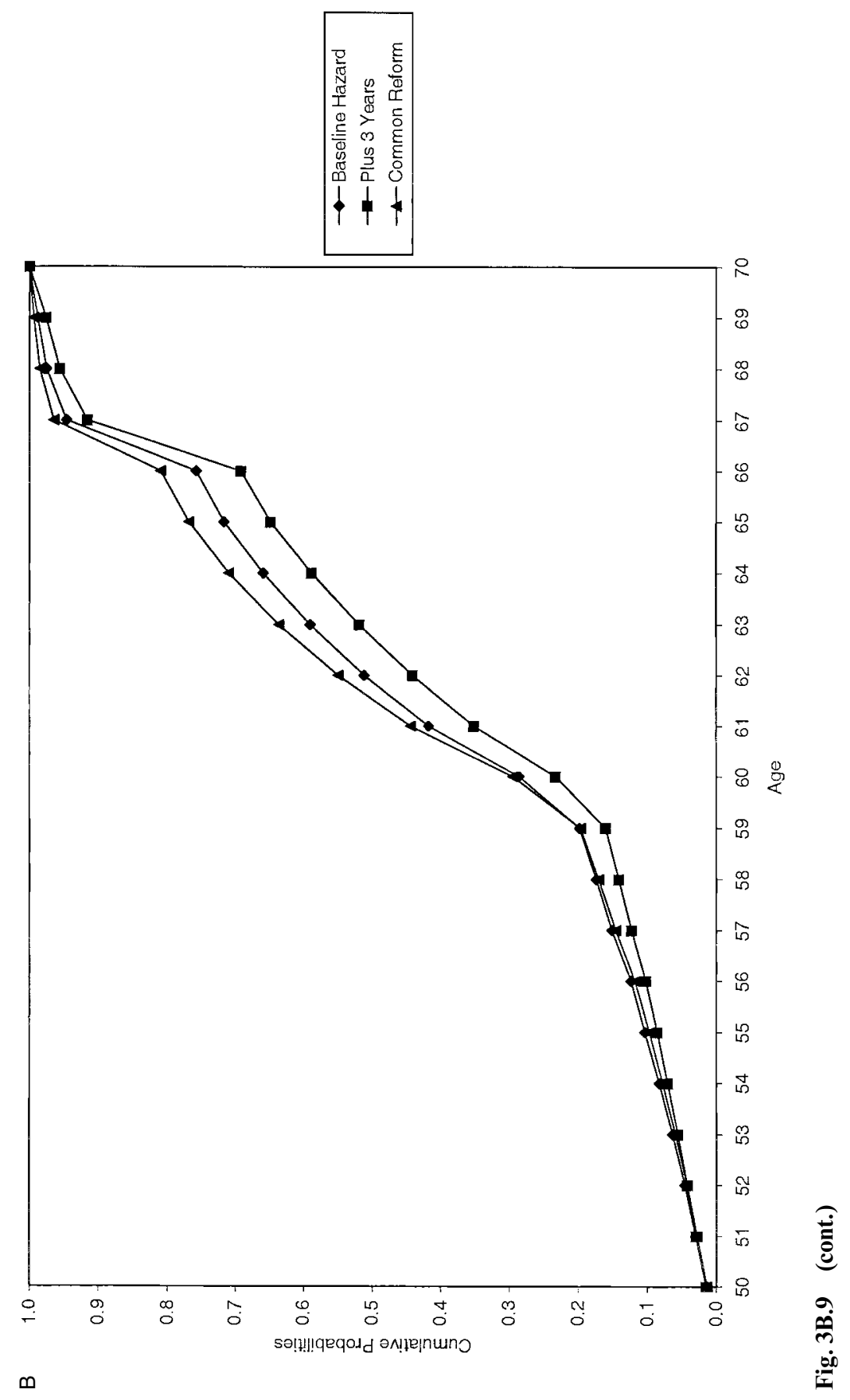




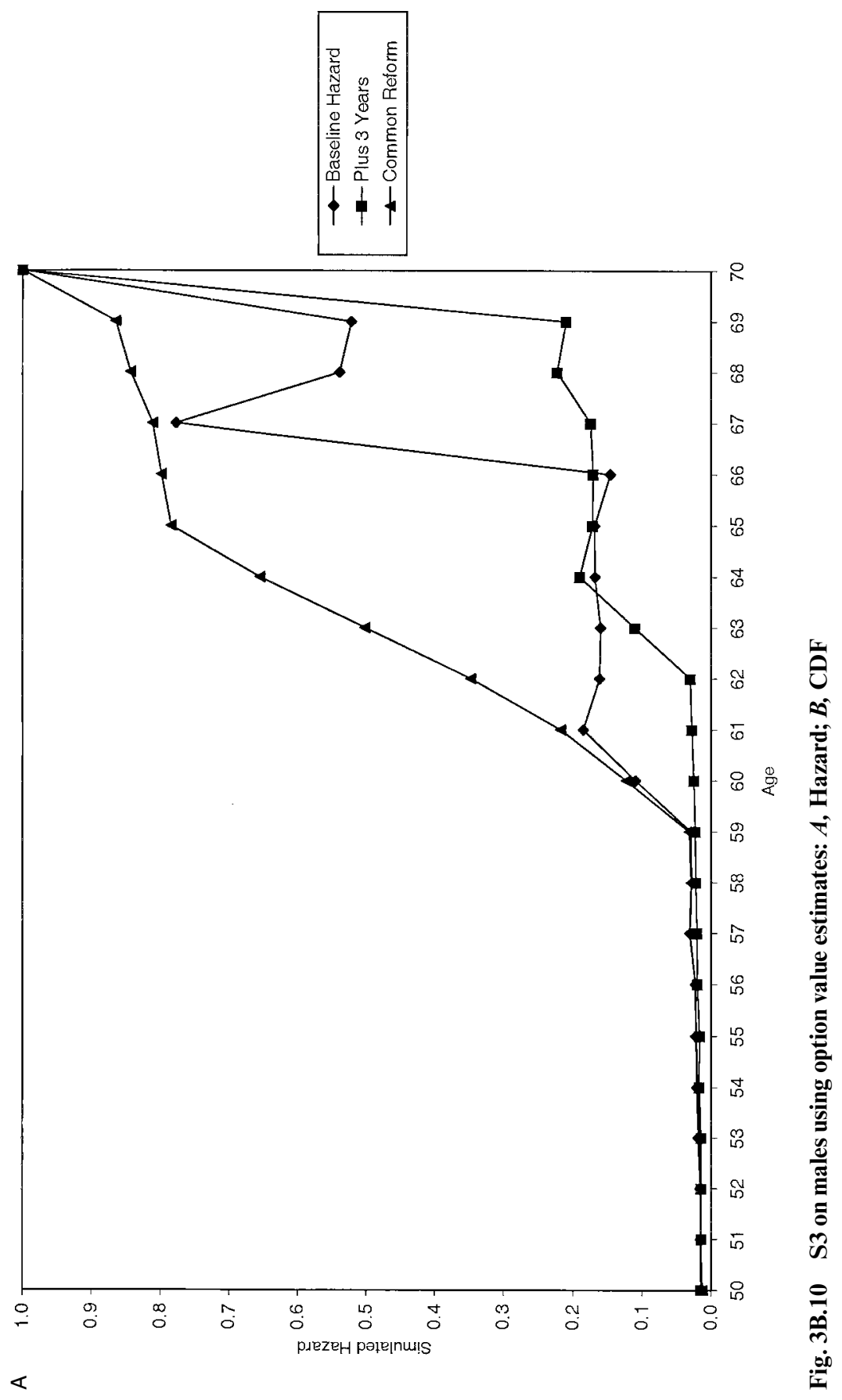



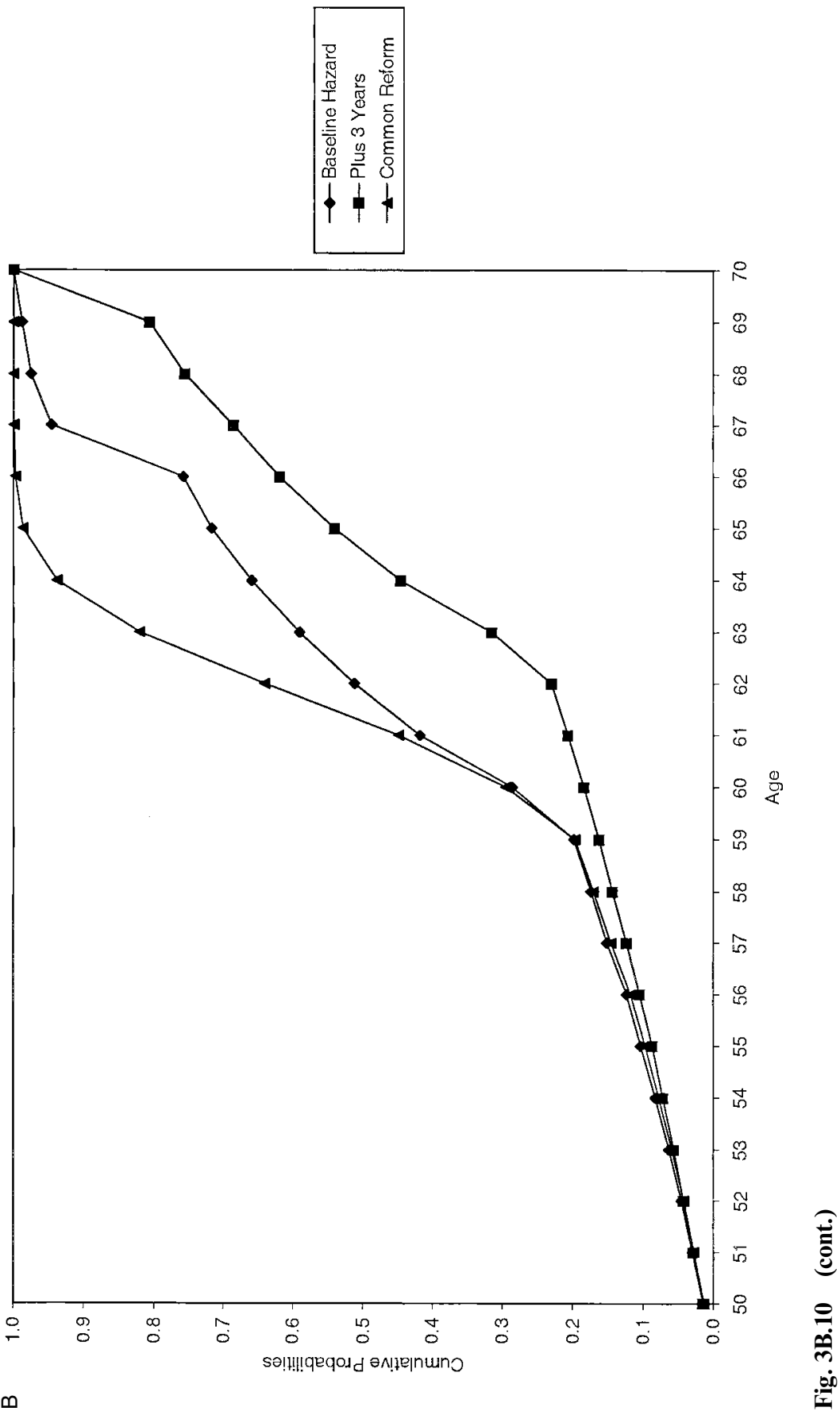


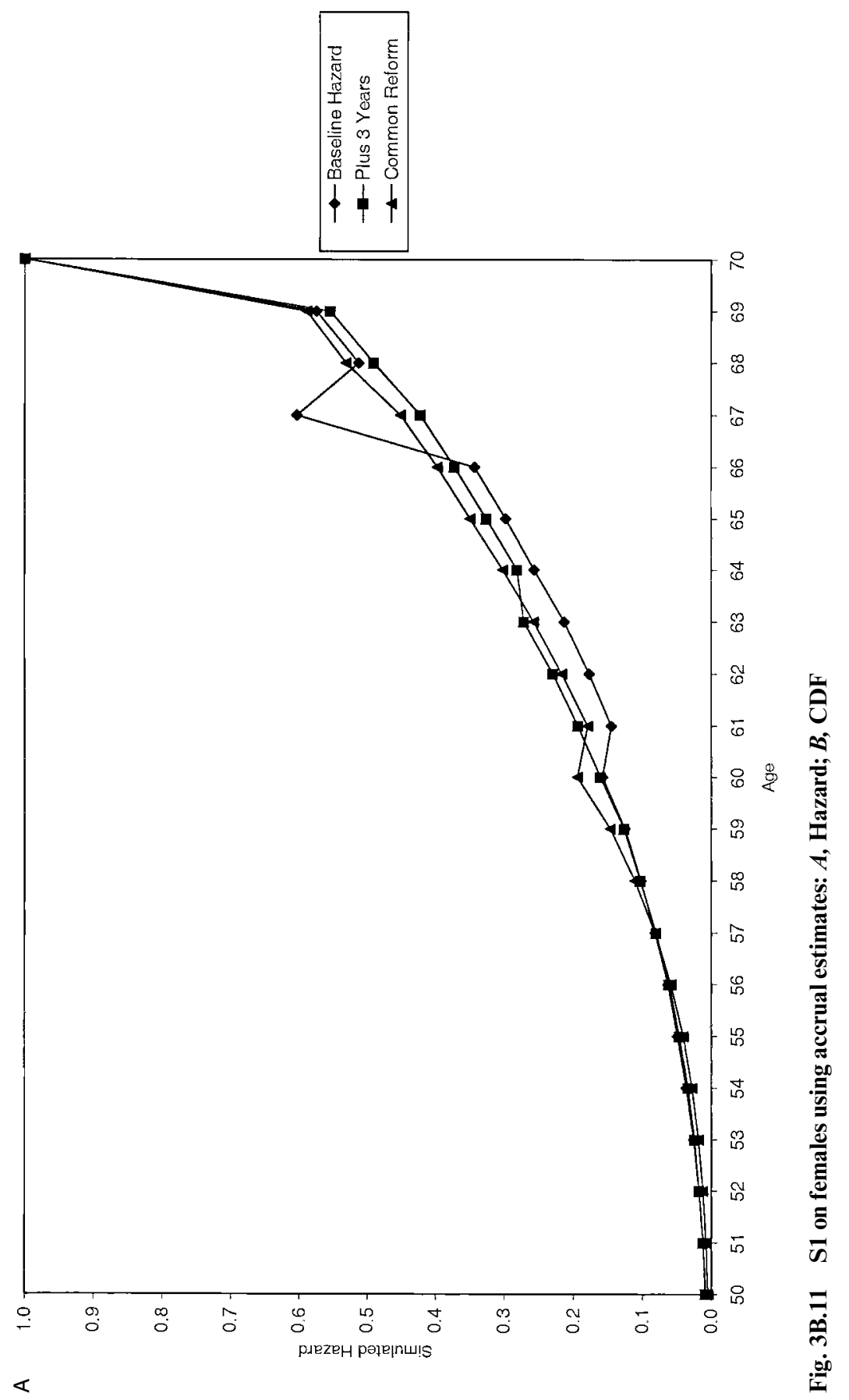




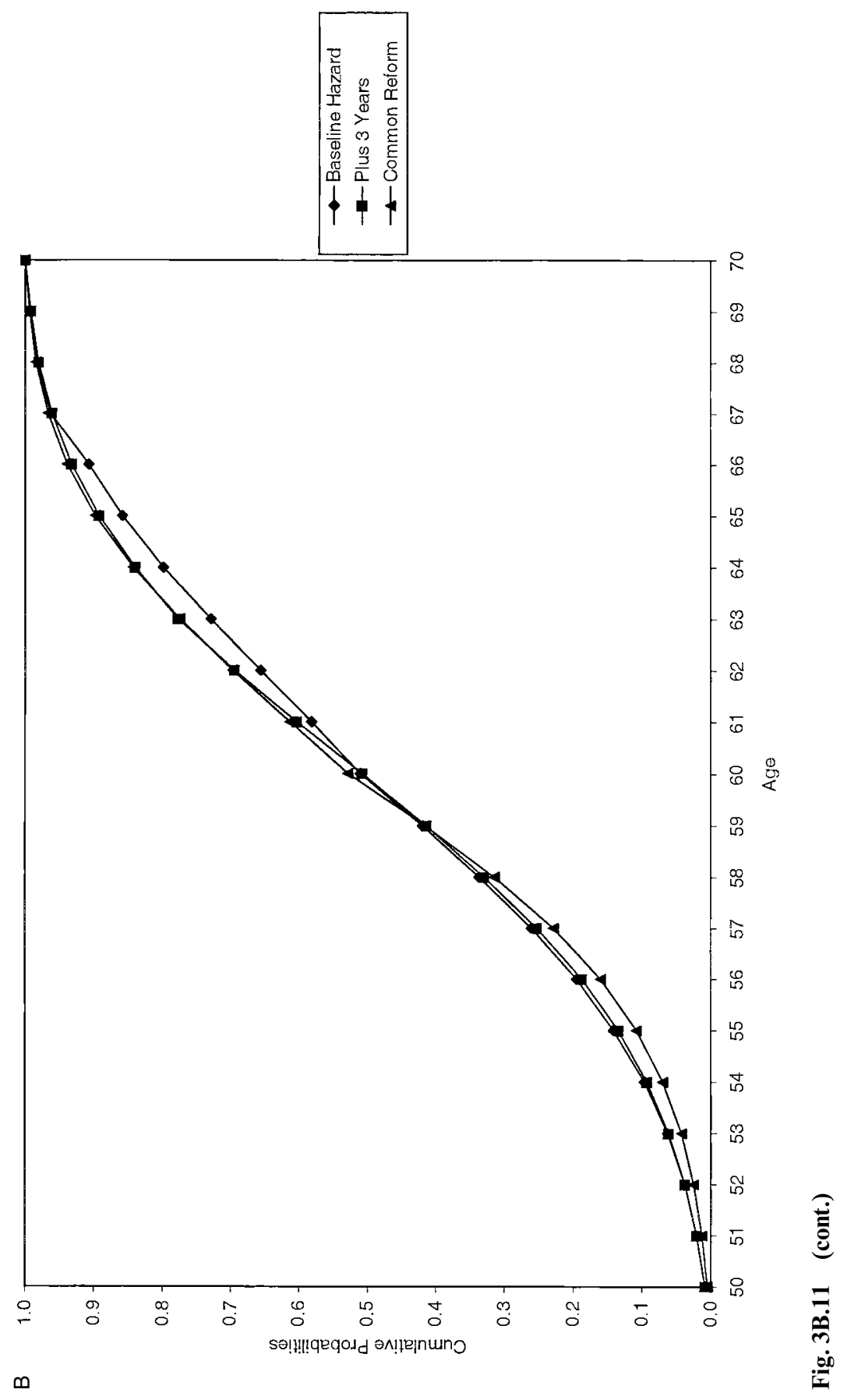




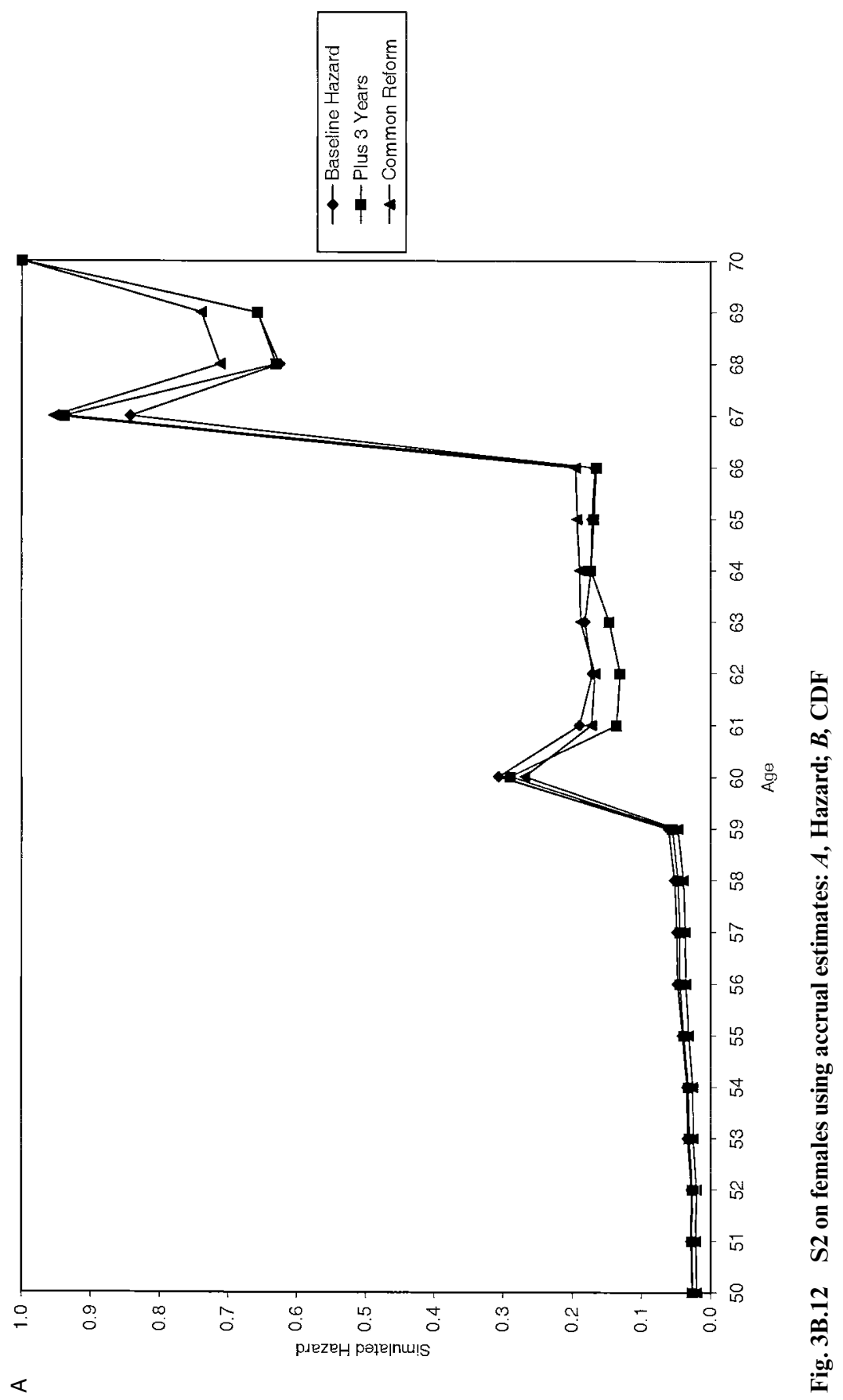




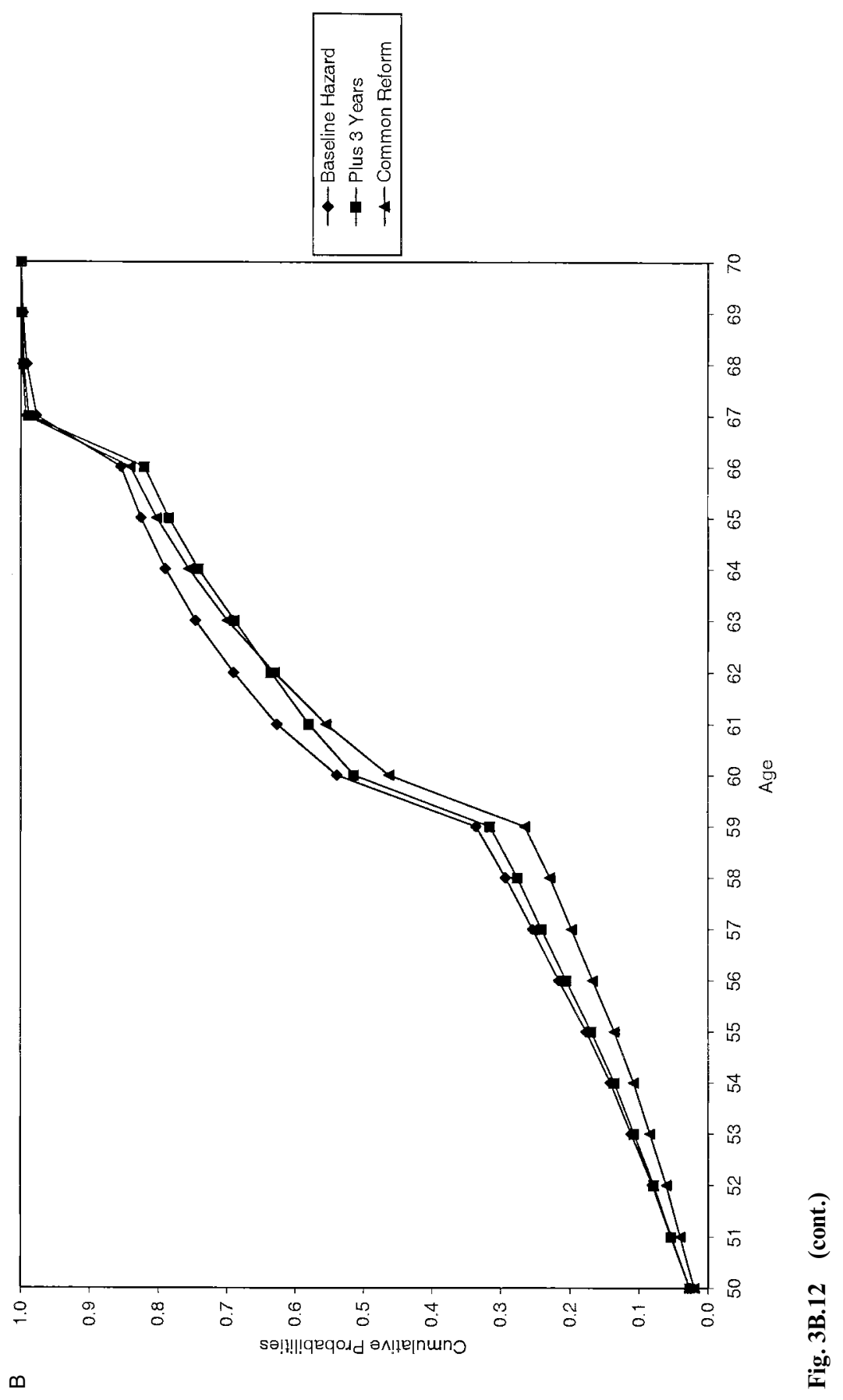




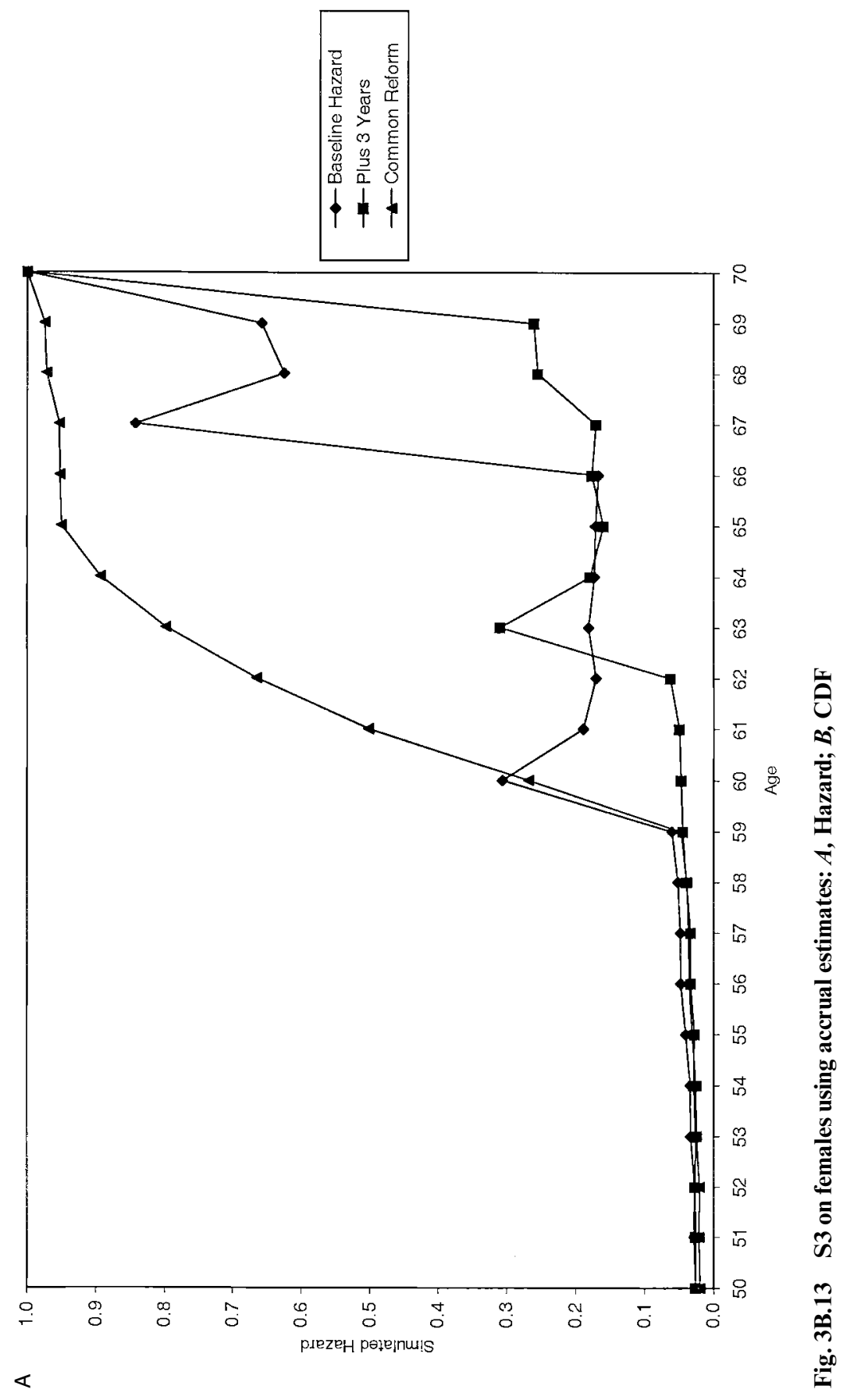




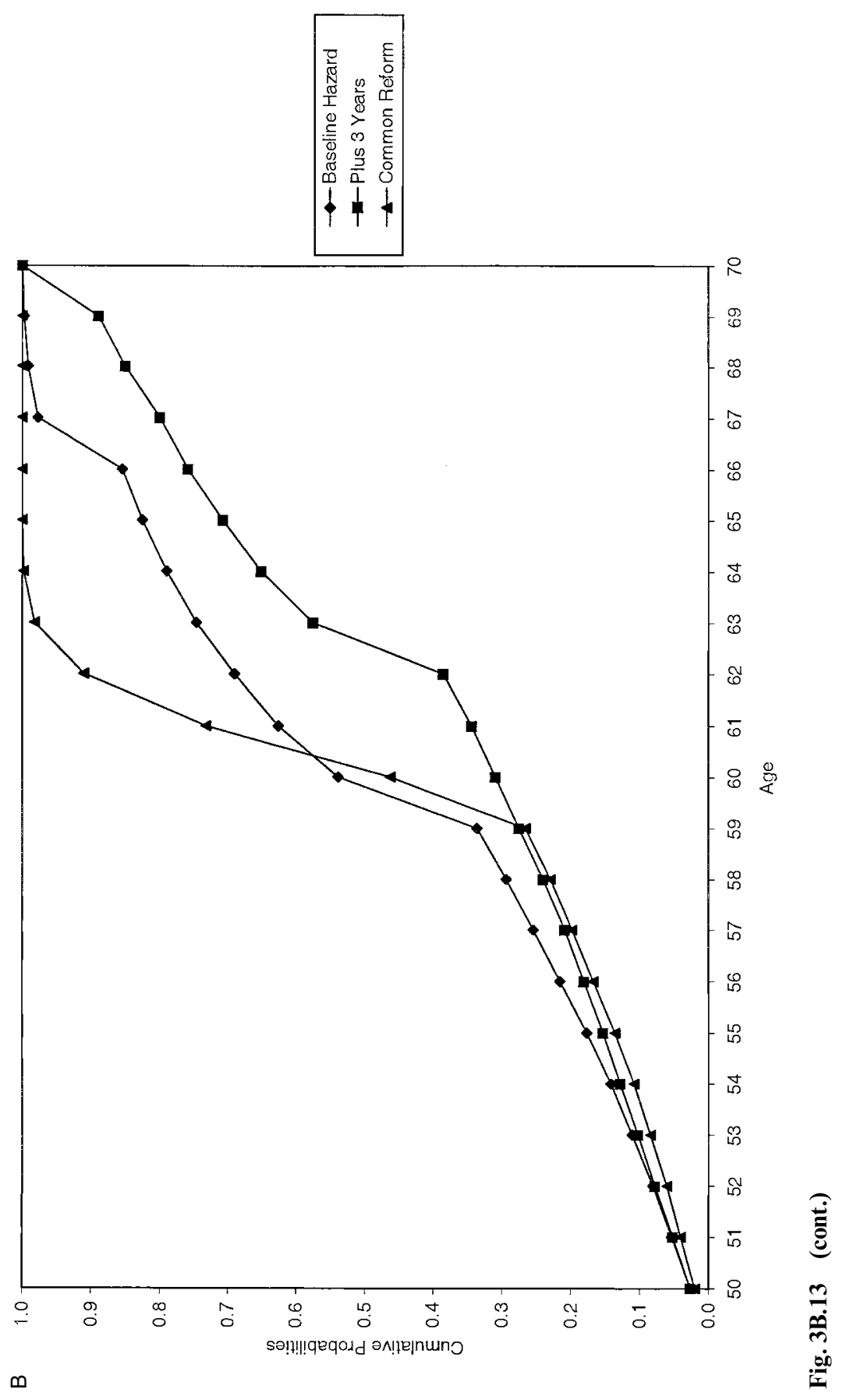




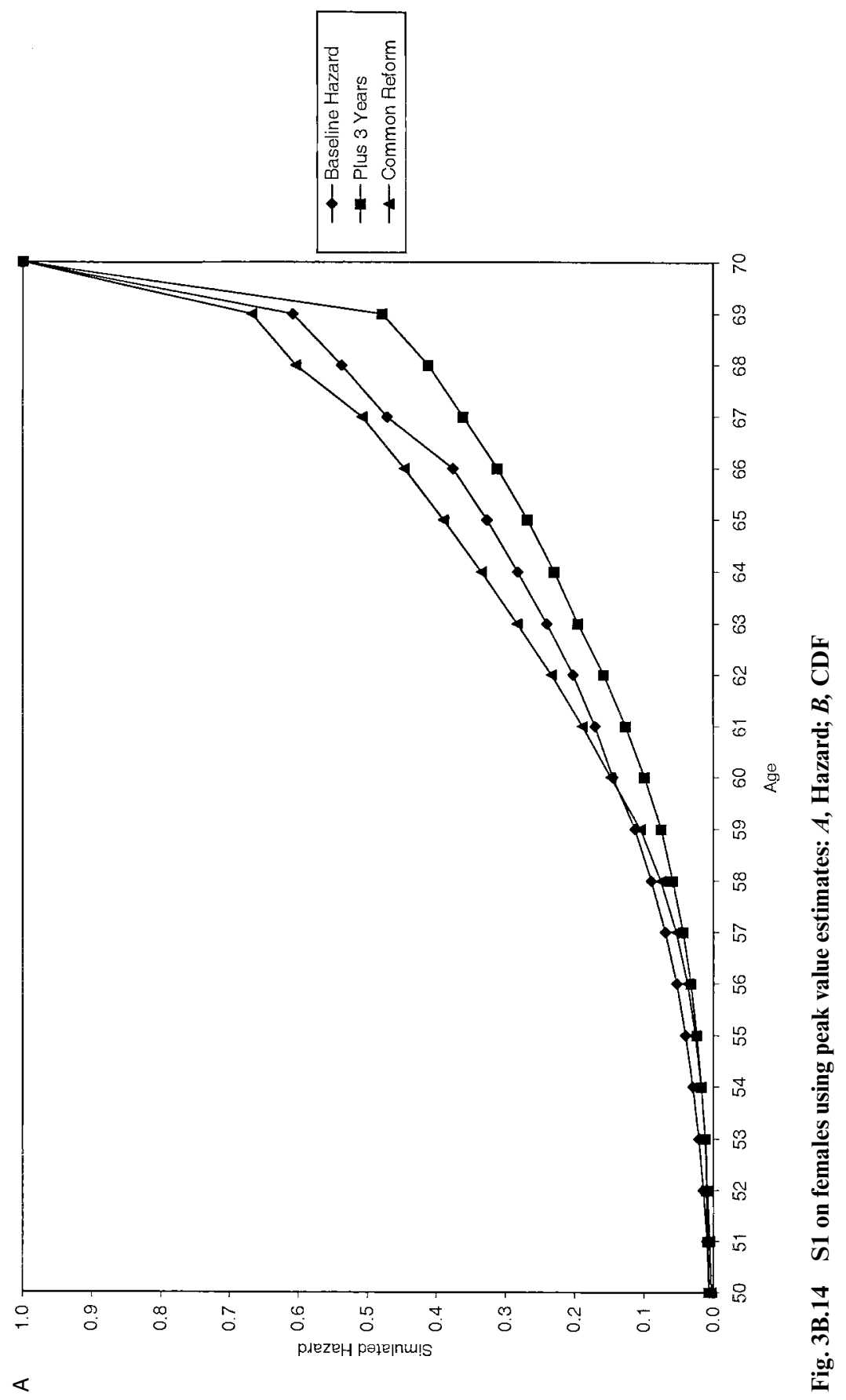




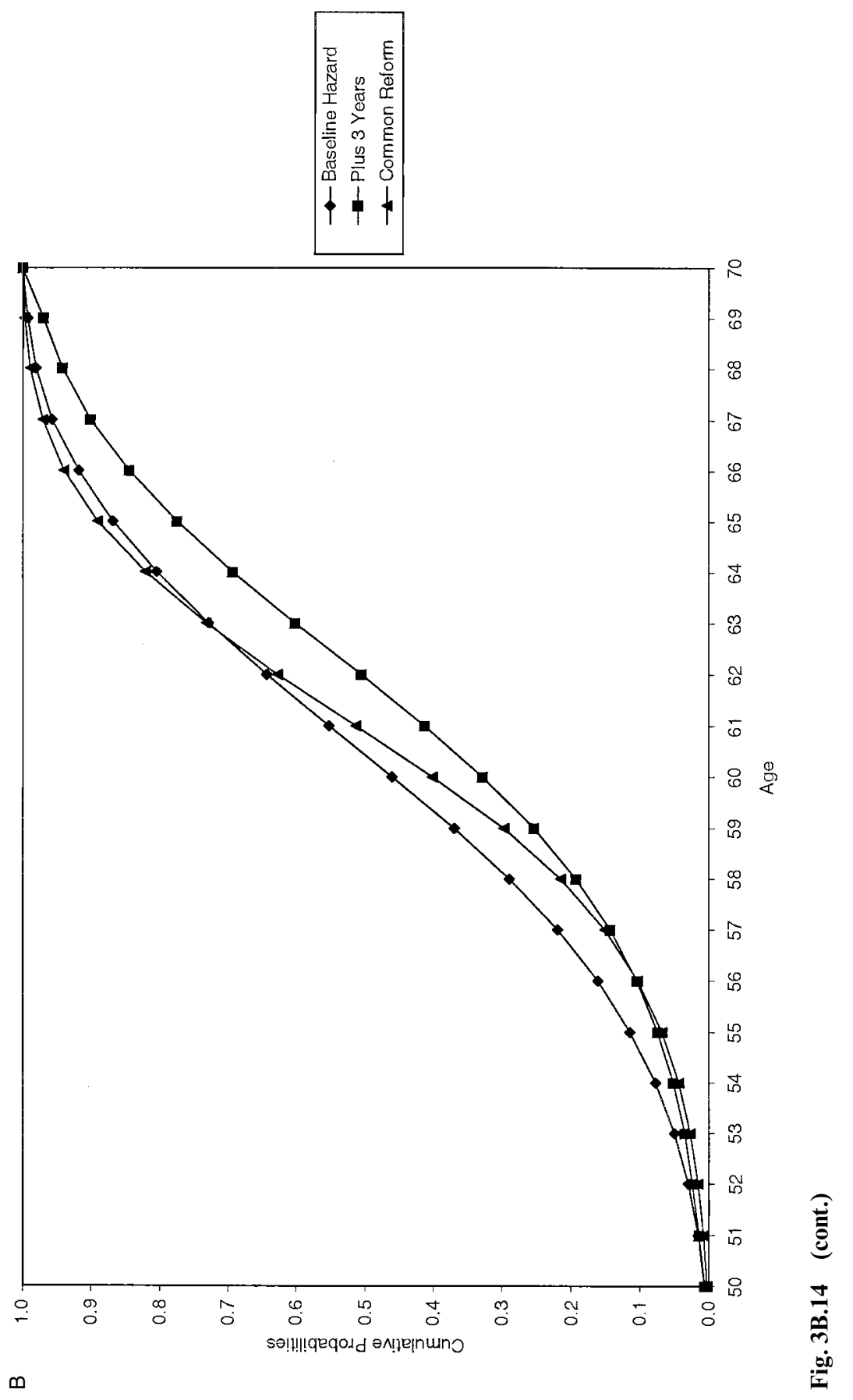




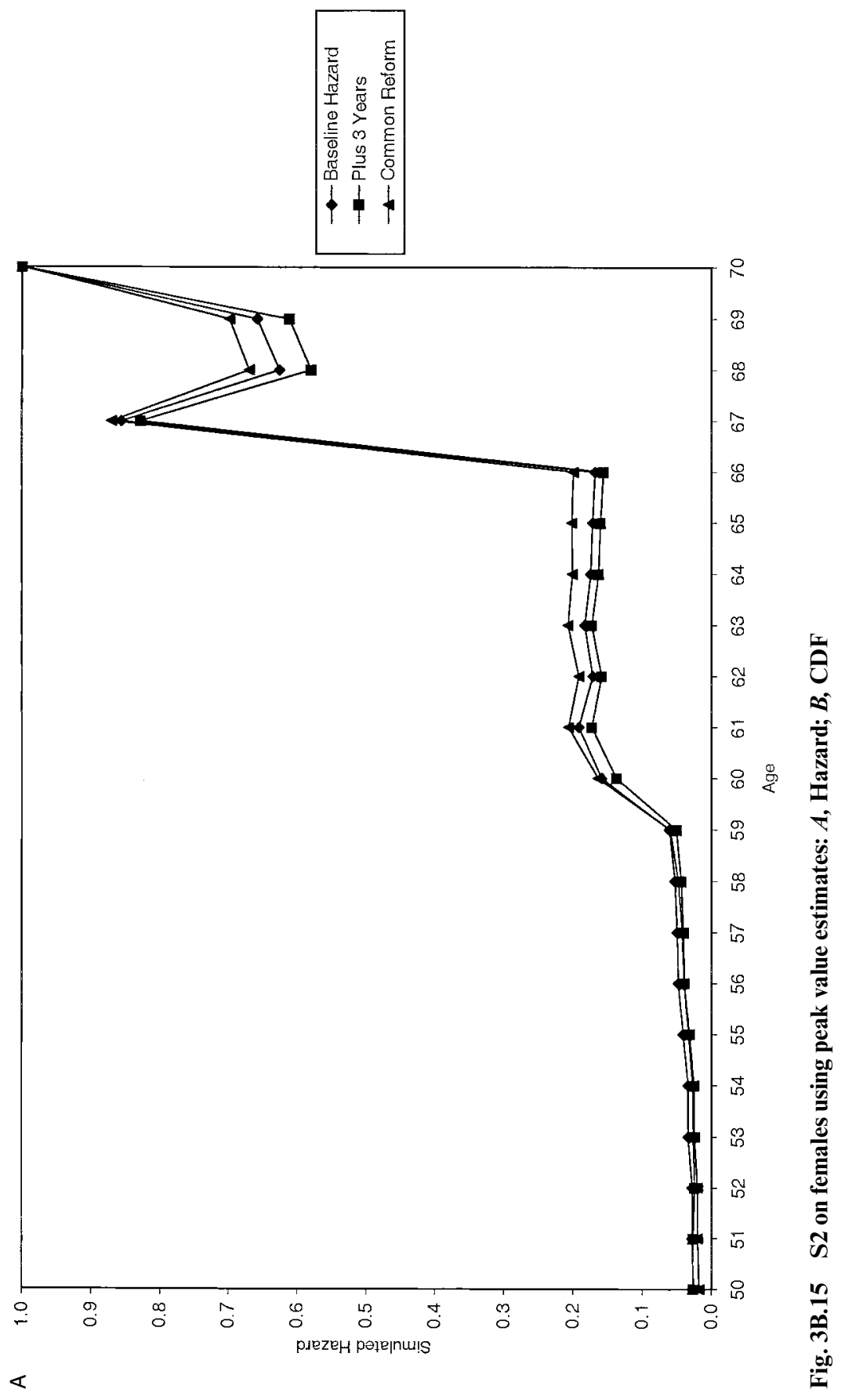




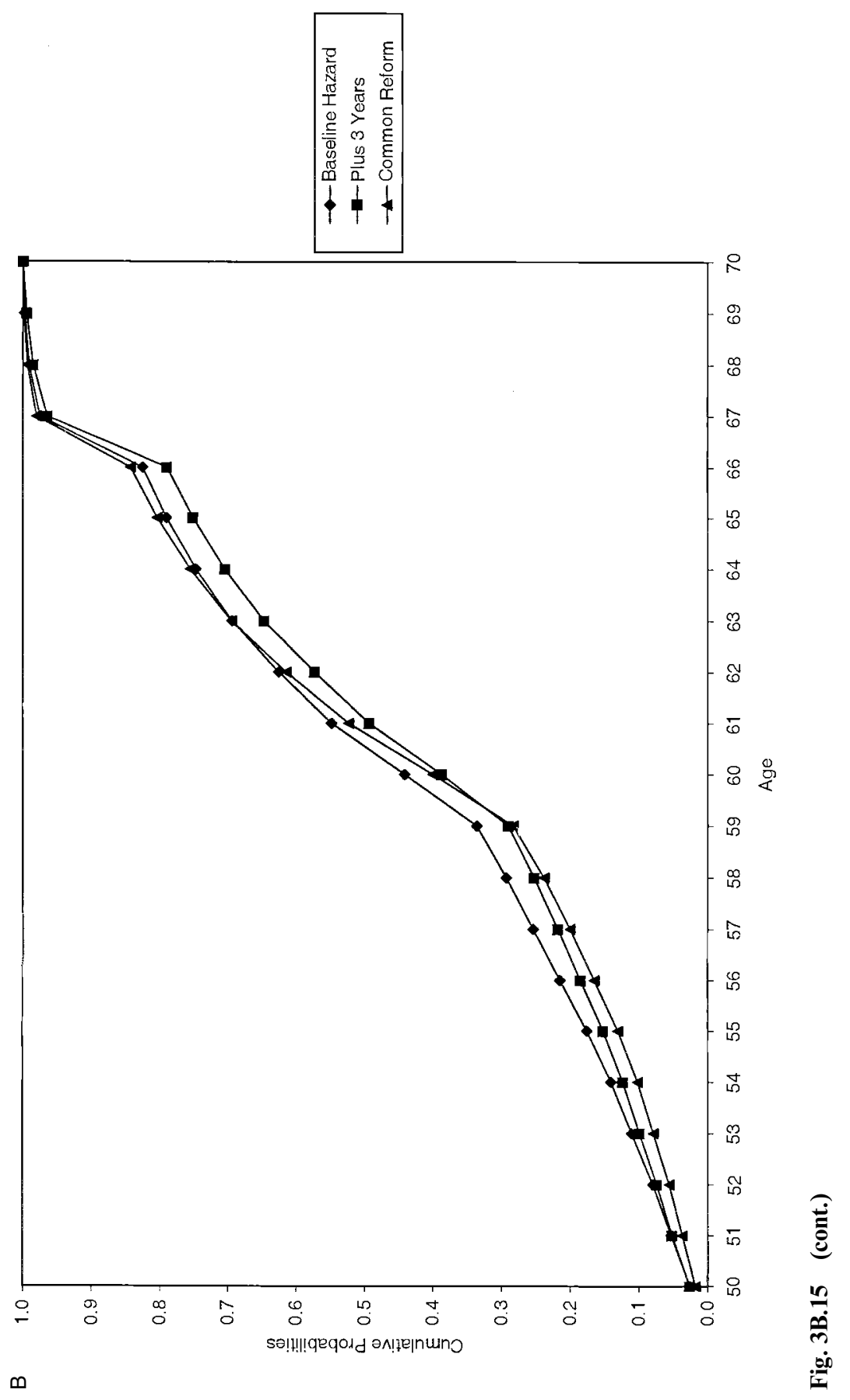




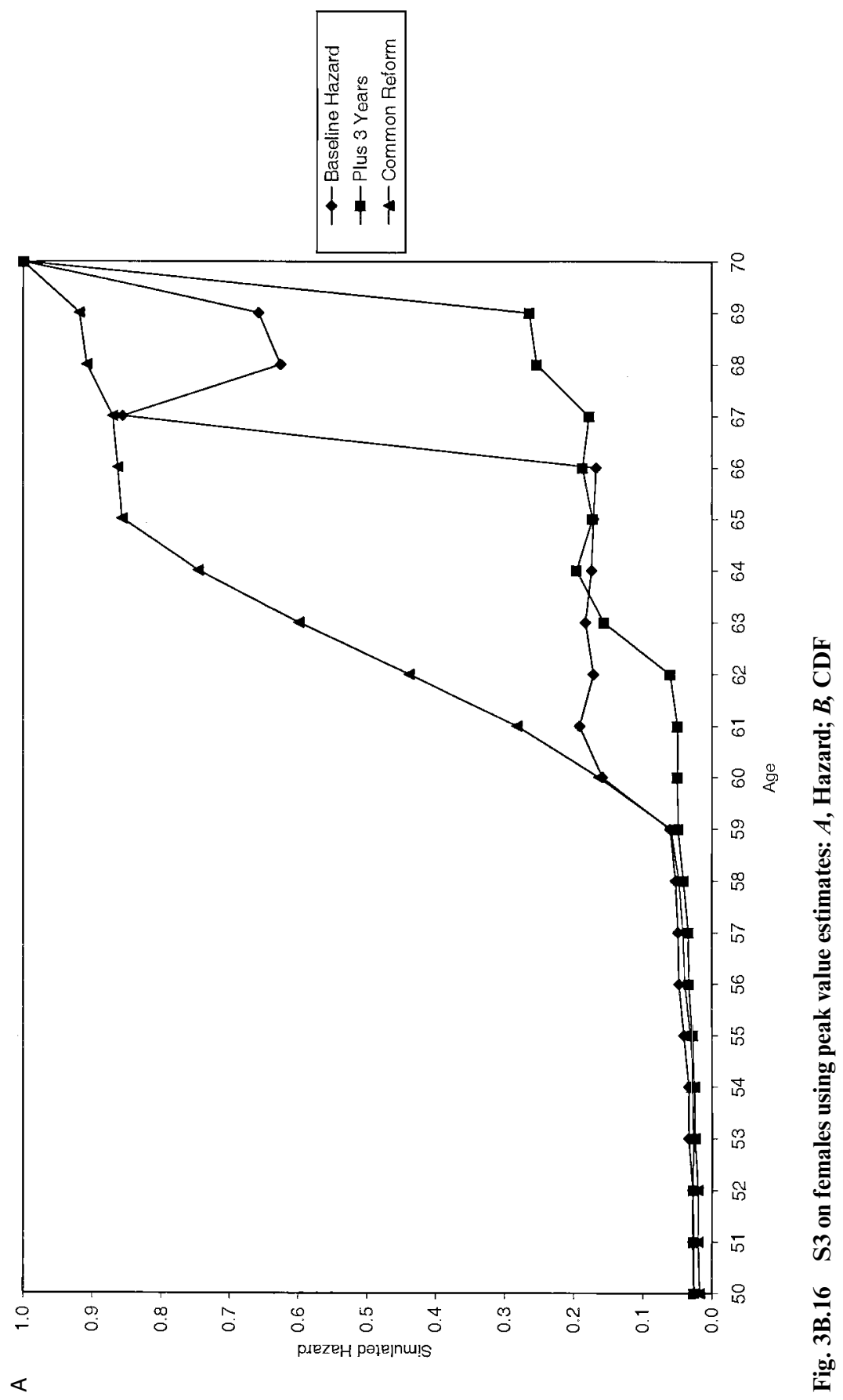




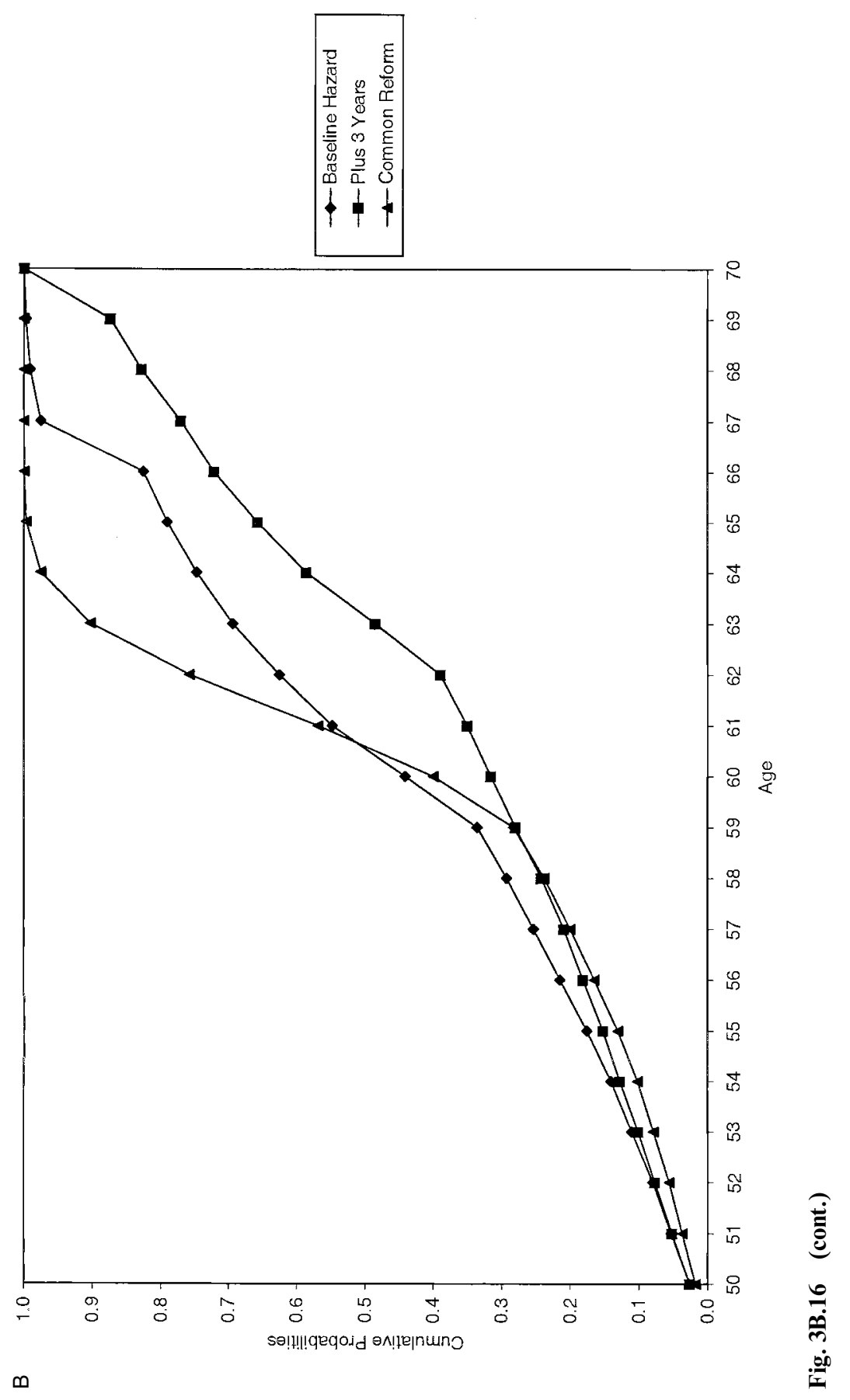




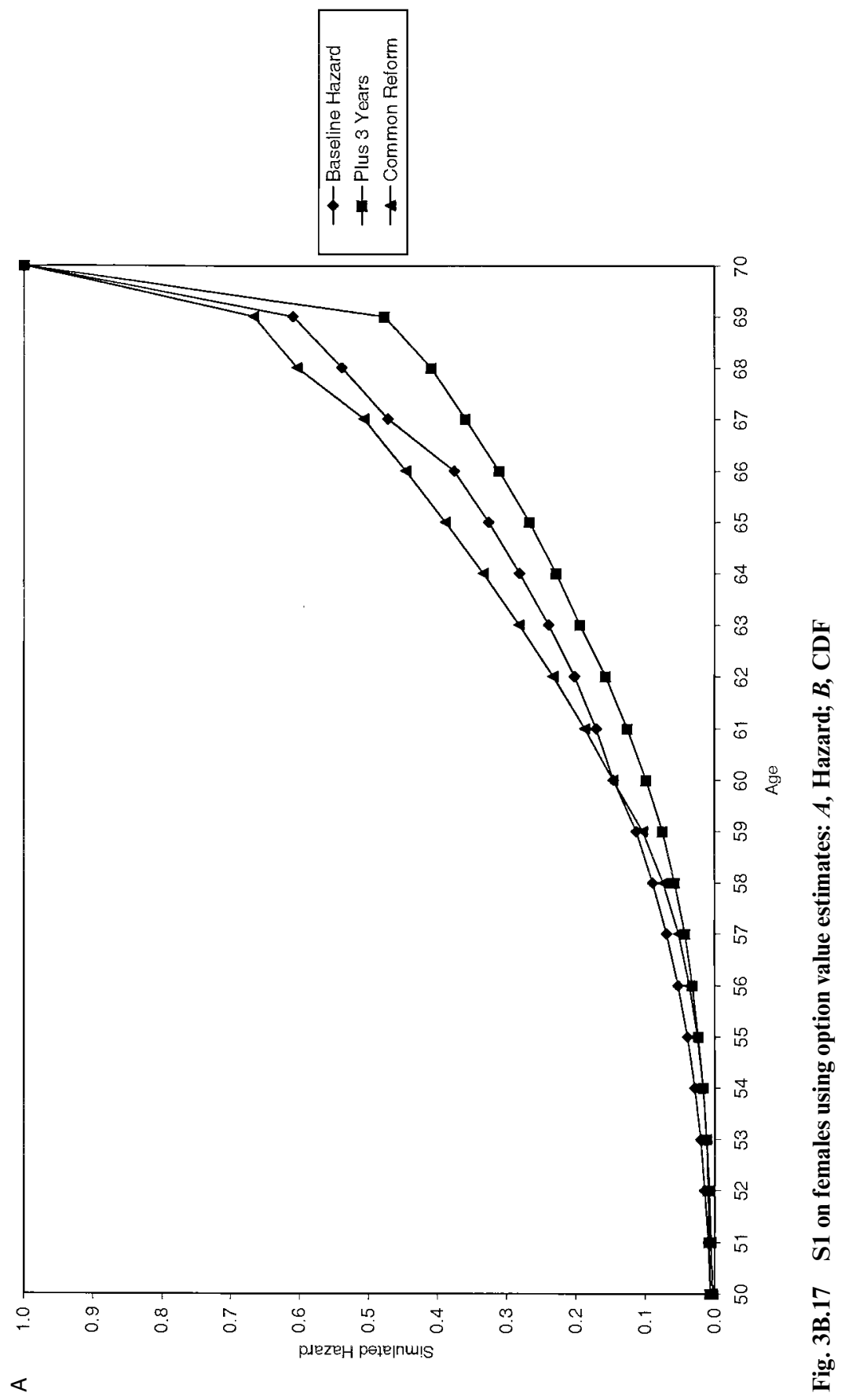




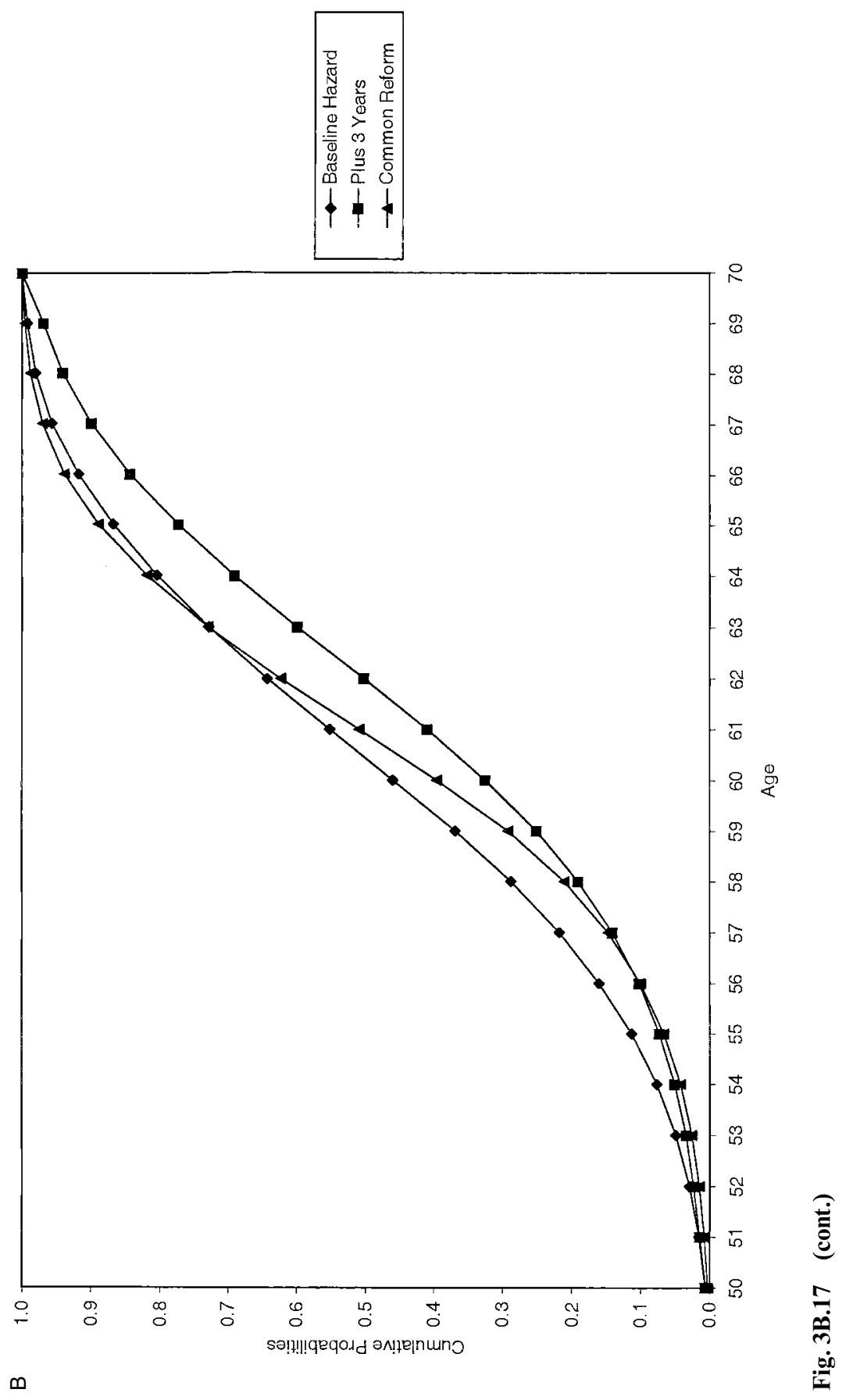




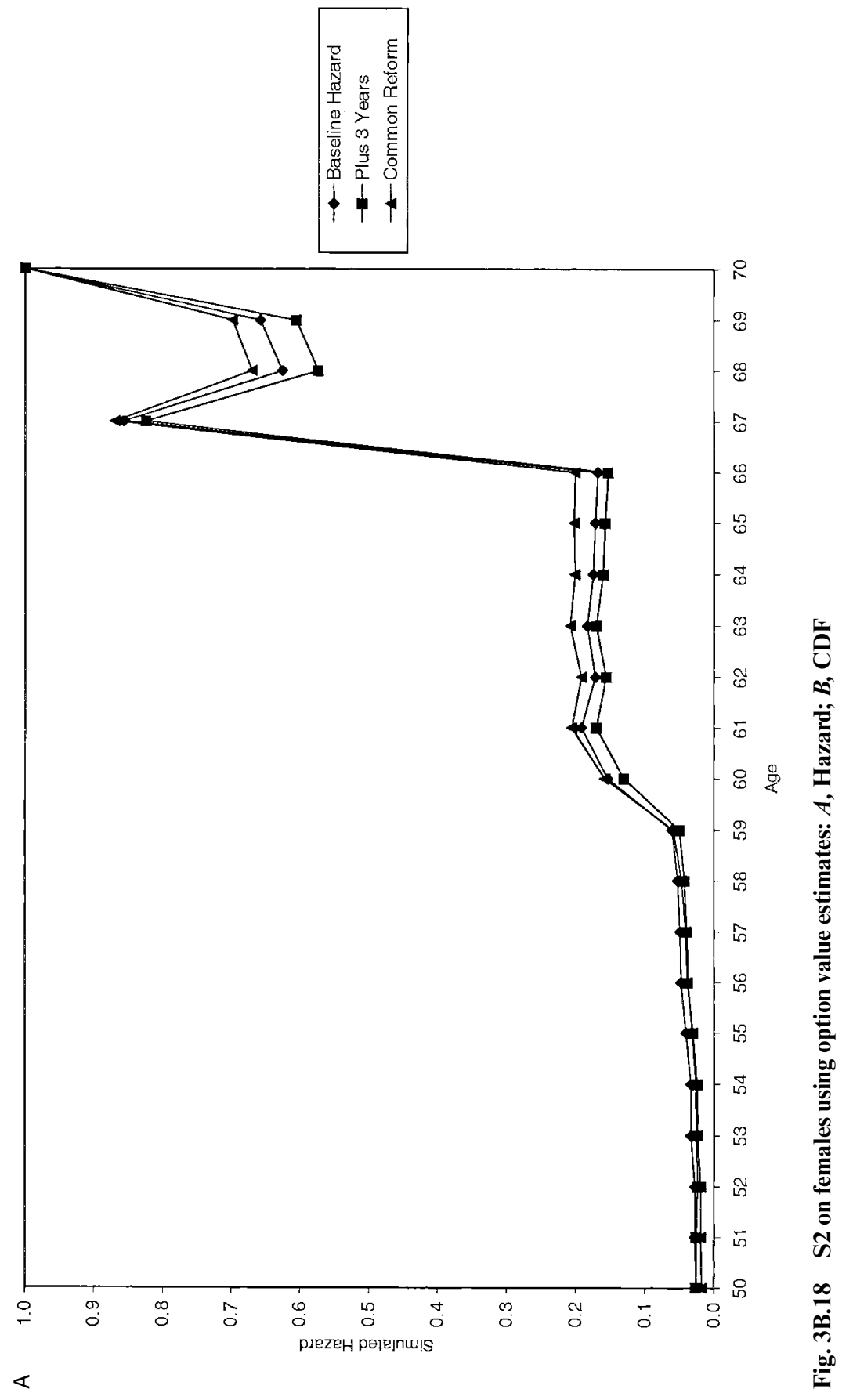




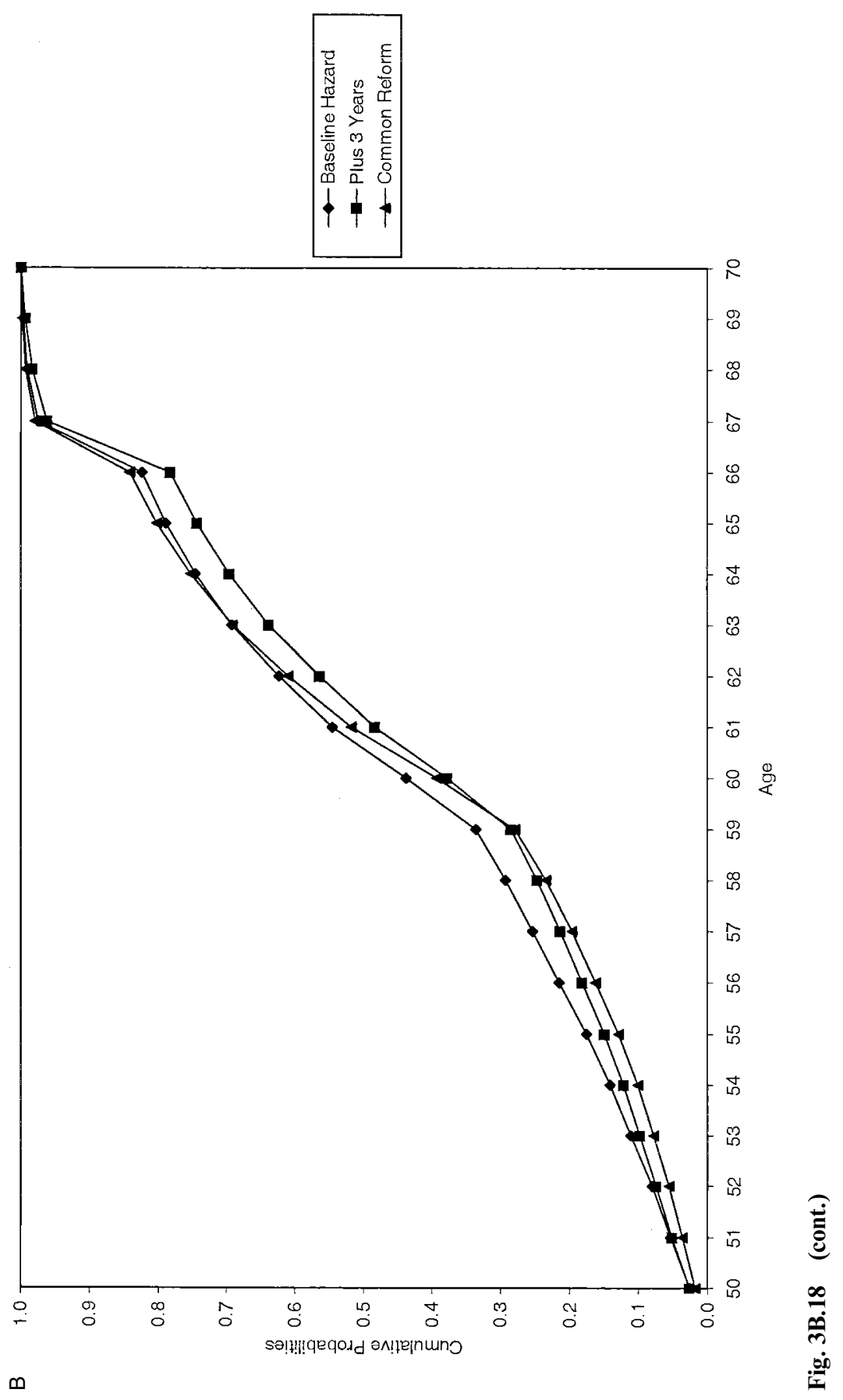




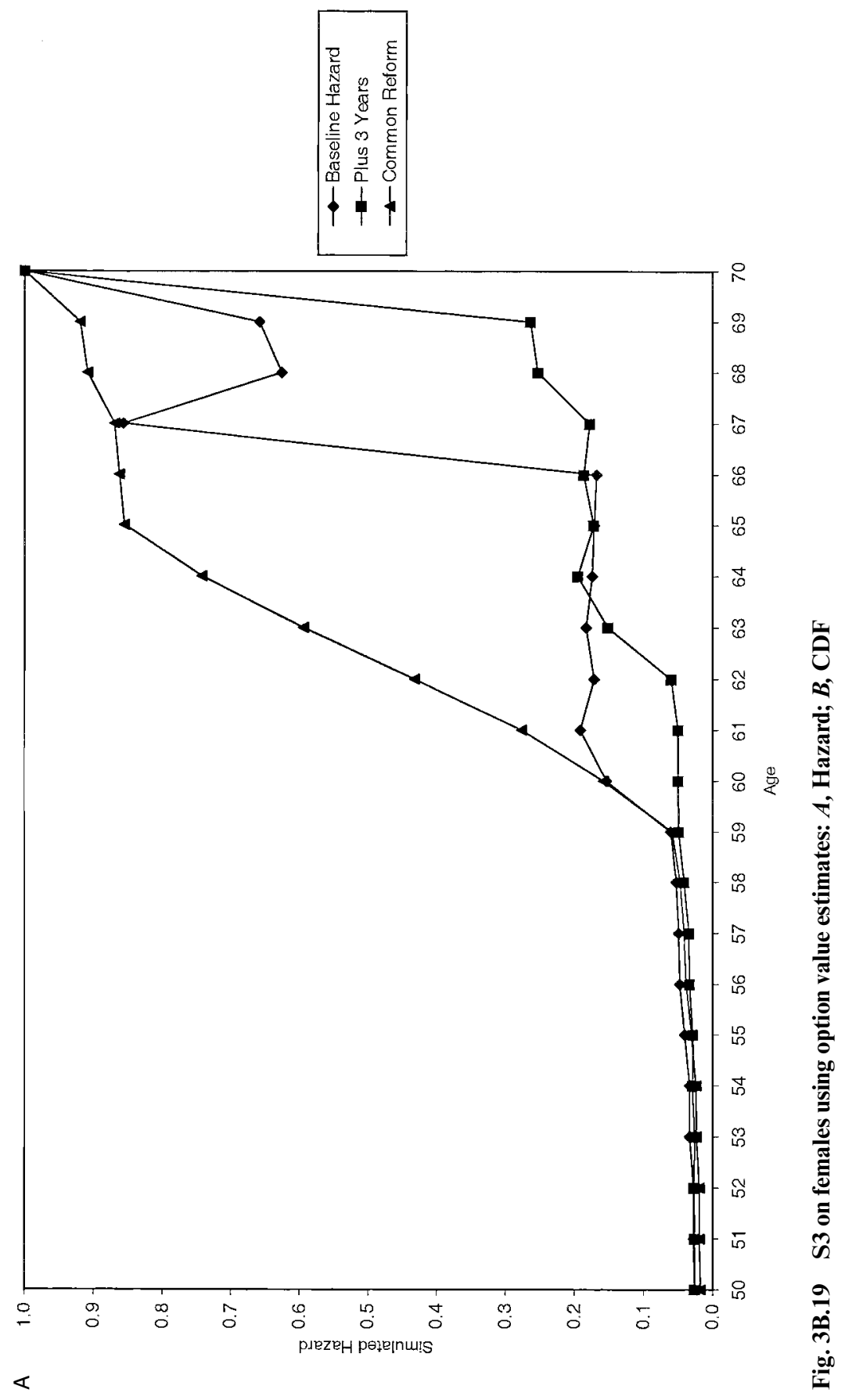




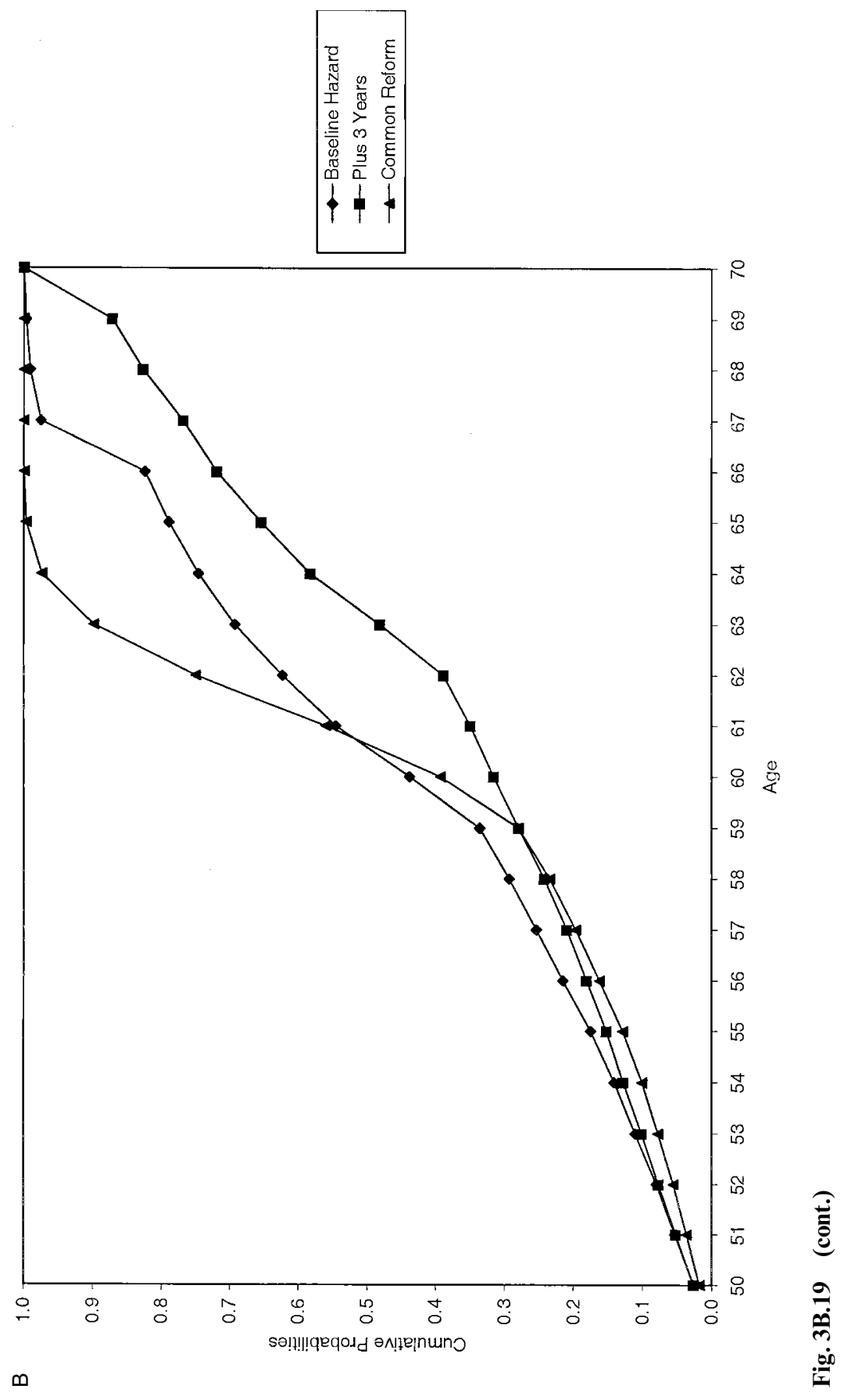




\section{References}

Christensen, B. J., and Datta Gupta, N. 1999. The effects of pension systems reform on retirement and government finances: Predictions using Danish data on married couples. Aarhus School of Business. Working Paper no. 99-01, January. 2000. Effekten af pensionsreform på danske ægtepars udtræden af arbejdsmarkedet (The effect of pension system reform on the retirement behavior of married couples). Nationaløkonomisk Tidsskrift 138 (2): 222-42.

Coile, C., and Gruber, J. 2000. Social security incentives for retirement. NBER Working Paper no. 7651. Cambridge, Mass.: National Bureau of Economic Research, April.

Danø, A. M., M. Ejrnæs, and L. Husted. 2000. Hvordan påvirker efterlønsreformen de ældres tilbagetrækningsalder (How does the reform of PEW influence the retirement age)? Nationaløkonomisk Tidsskrift (138 (2): 205-21.

Economic Council. 1998. The Danish economy, Autumn 1998 (in Danish), Copenhagen: Economic Council.

Finansministeriet (Ministry of Finance). 1996. Finansredegørelse 1996 (Fiscal Report 1996). Copenhagen, Ministry of Finance.

Finansrådet (Financial Council). 1998. Opsparing og fremtidig velfard (Savings and future welfare). Copenhagen: Financial Council.

Gruber, J., and D. A. Wise. Eds. 1999. Social security aknd retirement around the world. Chicago: University of Chicago Press.

Ministry of Economics. 2000. A Stable Pension System (in Danish). Copenhagen: Ministry of Economics.

Pedersen, P. J. 1998. De ældre og arbejdsmarkedet (The elderly and the labor market). In Arbejde, incitamenter og ledighed (Work, incentives and unemployment), ed. N. Smith, 15-78. Aarhus: Aarhus University Press.

Roseveare, D., W. Leibfritz, D. Fore, and E. Wurzel. 1996. Aging populations, pension systems and government budgets: Simulations for 20 OECD countries. Economics Department Working Paper no. 168. Paris: OECD.

Socialkommissionen (Danish Government Social Commission). 1993. De ældreEn belysning af ældregenerationens forsørgelse, rapport nr. 5 (An analysis of the provision for the elderly). Copenhagen: Social Commission.

Statistics Denmark. 1999. Statistical reports. Labour market series no. 37. Copenhagen: Statistics Denmark.

\section{Denmark.}

Stock, J. H., and D. A. Wise. 1990. Pensions, the option value of work, and retirement. Econometrica 58 (5): 1151-80. 